$$
\begin{aligned}
& +\mathrm{QK} \\
& 313 \\
& . \mathrm{L} 59 \\
& \text { Suppl. }
\end{aligned}
$$




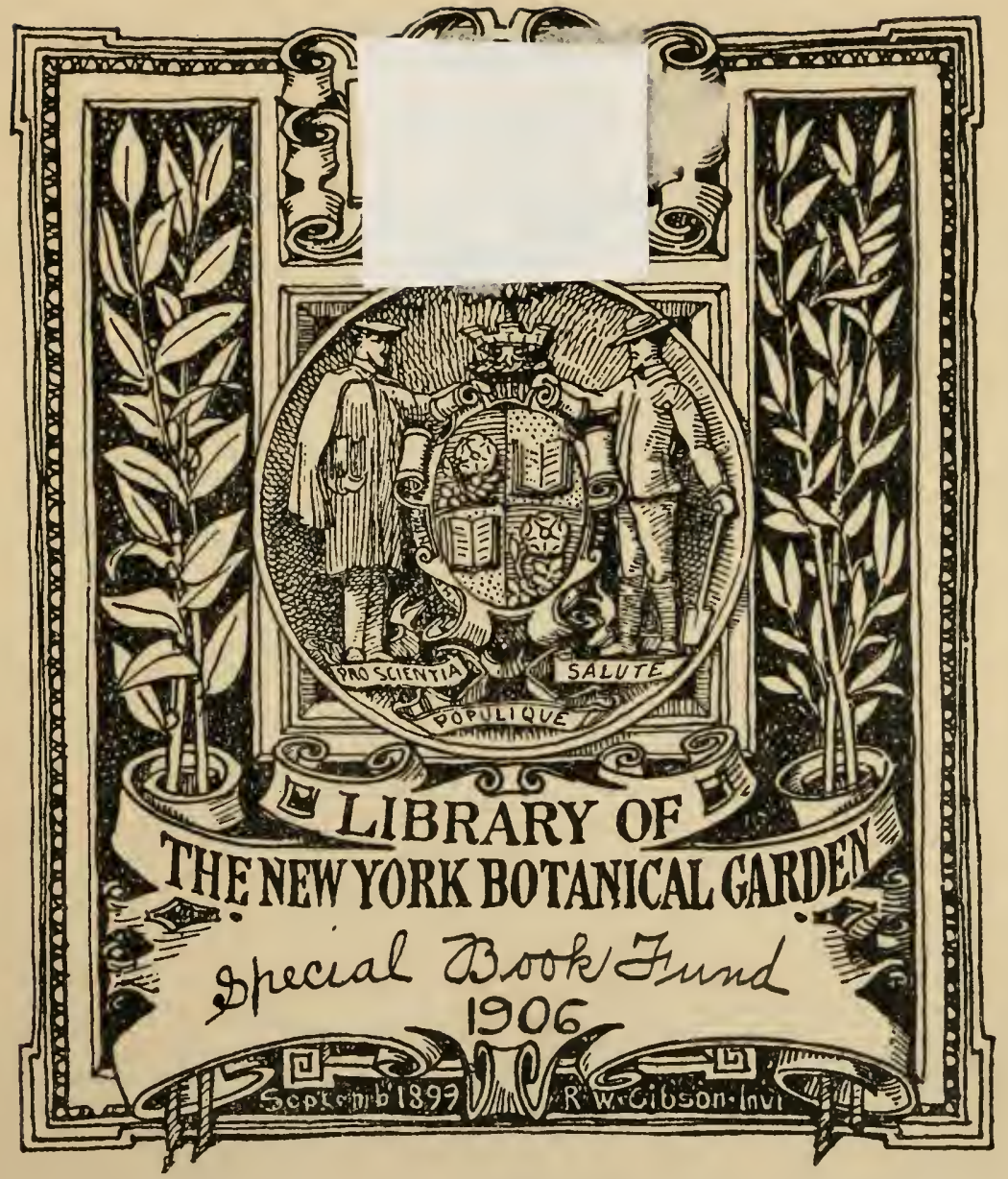








\section{SUR LES PLANTES}

A AJOUTER

A LA FLORE DE FRANCE (FLORA GALLICA);

Avec quelques Corrections et Observations;

$$
\text { P A } \dot{R}
$$

\section{J. L. A. LOISELEUR DESLONGCHAMPS,}

Docteur en Médecine, de la Faculté de Paris.

\section{A PARIS,}

Chez $\left\{\begin{array}{l}\text { LiAuteur, rue de Jouy, n. } .^{\circ} 8 . \\ \text { Migneret, rue du Sépulce, no } 20 . \\ \text { Gabon, place de l'Ecole de Médecine. }\end{array}\right.$

IMPRIMERIE DEJ. B. SAJOU, RUE DE LA HARPE, ${ }^{\circ}$ II, 


\section{Explication des Figures.}

Pl. 1. Fig. I. Agrostis elegans, de grandeur natu. relle; a fleur vue à la loupe.

Fig. 2. Myosotis pusilla, de grandeur naturelle; $a$ calice, $b$ corolle, $a$ corolle ouverte avec les étamines, $d$ graine, $\boldsymbol{e}$ leuilles: le tout vu à la loupe.

Pl.2. Galium verticillatum avec un fruit et un verticille grossis.

Pl. 3. Fig. I. Primula Allionii. Fig. 2. Valerianella eriocarpa; a $b$ c fruit très-grossi et vu sur toutes les faces.

Pl. 4. Pimpinella canescers; a fiuit rù la loupe. Pl. 5. Fig. I. Euphorbia rotundifolia; a corolle avec l'ovaire vus à la loupe, $b$ c graine grossie. Fig. 2. Euphorbia ambigua; a fleur vue à la loupe.

Pl. 6. Fig. 1. Dianthus subacaulis. Fig. 2 Ulev Provincialis; $a$ calice, $b$ corolle, $c$ légume, grossis. Hig. 3. Chrysanthemumb perpusilluin; $a$ fleur, $b$ calice, $c$ graine, grossis.

\section{E R R A T A.}

Pag. 7, lig. I9, Anthoxandium, lisez Antmosanthum. P. 28, lig. 20, racide, lisez radice.

P. 42. Iasione, lisez Jasione; et dans tout l'article substituez le J à l'I.

P. I47, lig. dernière, iconc. lisez icone.

Pl. 3, Valerianelra eriosperma, lisez ValeriaNELla eriocarpa. 


\section{N O T I C E}

Sur les Plantes à ajouter à la Flore de France (Flora Gallica);

Avec quelques Corrections et Obseryations.

\section{DIANDRIE.}

CIRCAA LUTETIANA. Lin, - Lois., Fl. Gall. 6.

D'après l'observation de MM. Poiteau et Turpin (Flor. Paris., pag. 12 ), la Cïrcea intermedia, placée dans ma Flore comme variété de la Circaea alpina, n'appartient point à cette espèce, mais elle doit être rapportée à la Circrea lutetiana, dont elle n'est qu'une légère variété, puisque c'est la même plante venue au soleil, au lieu d'avoir poussé à l'ombre.

\section{VERoniCa PARMULARia. Poit. et Turp., Fl. Paris., pag. 19, t. 14.}

Cette płante n'est qu'une simple variété de la Veronica scutellata; c'est la var. $\beta$ indiquée dans ma Flore, pag. 7 . 
VERONICA SATUREIAfOLIA. Poit. et Turp., Fl. Paris., pas. 22.

T. spicis lateralibus caulem prostratam superantibus, foliis infimis oblongis, supernè serratis, intermediis subdenticulatis, aliis linearibus integerrimis. Poit., L. C.

Cette Véronique, comme l'a déja observé M. Desvaux (Journ. Bot., vol. 2, pag. 52), ne paroìt être qu'une variété de la Veronica prostrata, qui elle-même a les plus grands rapports avec la Veronica teucrium. MM. Poiteau et Turpin indiquent leur plante à Rony, dans les environs de Mantes; je l'ai trouvée à Fontainebleau, et il est probable qu'on la rencontrera dans beaucoup d'autres lieux, quand on la distinguera de l'espèce principale, avec laquelle les Botanistes la confondent sans doute.

\section{VERONICA TENELLA. All. - Lois., Fl. Gall. ro.}

Cette plante ne doit pas former une espèce particulière; elle n'est pas mème une variété distincte de la Veronica serpyllifolia, à laquelle elle doit être réunie.

\section{VERoniCa BELlardi.' All. - Willd. - Lois., Fl. Gall. 12.}

MI. Decandolle a fait de celle plante une 


\section{(3)}

variété de la Veronica verna; je l'avois adoptée comme espèce d'après la figure d'Allioni; mais il paroît qu'elle doit être entièrement exclue de la Flore, car selon M. le professeur Balbis, non-seulement on ne la trouve pas en Piémont, mais elle n'existe pas même dans l'herbier d'Allioni, ainsi que plusieurs autres espèces mentionnées dans la Flore de cet auteur. Voici ce que M. Balbis m'écrit à ce sujet : «Plnsieurs espèces décrites par Allioni « sont très-donteuses à présent. Je possède « tout son herbier, et je puis prononcer sur « cela en toute assurance. Plusieurs même " de ces plantes n'existent pas dans son " herbier; il les a décrites sur la bonne foi " de quelques botanistes, ou sur un simple " et quelquefois mauvais échantillon. Ainsi « je ne puis vous procurer la Veronica bel" lardi, ni les $V$. succulenta, romana, pu" mila, toutes espèces que je crois qu'il n'a « pas assez vues ni examinées, et que l'on "ne trouve point dans son herbier.»

VERONICA FILIFOR MIS. Smith, Soc., Lin., Lond. I, pag. I 95. Pers., Syu. I, pag. I3.

'V. floribus solitariis, foliis subcordatis crenatis pedunculo filuformi longissimo brevioribus, calycinis laciniis lanceolatis capsulá majoribus, caule ramoso procumbente. 


\section{(4)}

Celte plante doit être placée immédiatemen! après la Veronica agrestis, avec laquelle elle a de si grands rapports qu'on pourroil croire qu'elle n'en est qu'une variété. Elle croît dans les champs et les lieux cultivés aux environs de Toulon, où elle a été trouvée par M. G. Robert; elle croît aussi en Piémont et en Toscane, d'où elle m'a été envoyée par MM. Perset et Savi : elle fleurit en avril et mai; ses fleurs sont d'un bleu clair. ( $\odot$.

VERoNiCA CYMbalaria. Bertol., Pl, Gen., pag. 3.

$V$. floribus solitaris, foliis petiolatis subcordatis subseptemlobis pedunculo brevioribus, calycinis foliolis ovatis obtusis, caule ramoso prostrato. $V$. hedercefolia $\beta$. Lin., sp. זg. V. cymbalaricefolia. Viv., Fl. Ital., frag., pag. I4, tab. I6, f. I. $V$. Chic cymbalariae folio verna, flore albo, umbilico virescente. Buxb., cent. I, pag. 25, tab. 39 , f. 2 .

Quoique cette plante soit très-voisine de la Teronica hedercefalia, elle paroît mériter d'être distinguée comme espèce, d'après des caractères constans, comme l'a tres-bien observé M. Bertoloni. Elle se trouve dans les lieux cultivés du pays de Gènes et de la Toscane, d'où MM. Bertoloni et Savi me l'ont envoyée; 


\section{( 5 )}

M. G. Robert l'a aussi recueillie aux environs de Toulon : ses fleurs sont blanches, elkes paroissent dans les mois de février et de marș. $(\odot)$.

PINGUICULA FLAVESCENS. Schrad., Fl. Germ. 1, pag. 53.

P. calcare conico curvo corollâ multò breviore, lab̉io superiori emarginato, labii inferioris laciniâ mediâ retusâ, lateralibus obtusis. P. Alpina auctorum.

Cette espèce doit remplacer dans la Flore la Pinguicula alpina, qui ne se trouve pas en France, mais qui y avoit été indiquée parce que tous les auteurs, avant M. Schrader, avoient confonda et pris lá Pinguicula flavescens pour la Pinguicula alpina; mais cette dernière ne croît qu'en Laponie. La première se trouve daus les terrains humides des Alpes de la Haute-Provence et de la Savoie; je l'ai reçue de MM. Clarion et Castan : elle fleurit en juin et juillet; sa corolle est blanchâtre avec la gorge jaune. 4 .

\section{PINGUICULA LUSITANICA. Lin. - Lois., Fl. Gall. I4.}

Cutte espèce que le premier j’ai indiqué en France, paroît y être assez commune; M. Guersent l'a trouvée aux environs de 


\section{(6)}

Rouen, et M. de S. Hilaire l'a recueillie dans les marais de la Sologne, aux environs d'Orléans.

SALVIA OFFICINALIS. Lin. - Lois., Fl, Gall. 16.

La Salvia agrestis. Vill. rapportée comme variété à cette espèce, appartient au contraire à l'espèce qui va suivre.

SALVIA PRACOX. Savi., Fl. Pis. I,

$$
\text { pag. } 22 .
$$

'S. foliis ovato-oblongis subcordatis duplicatodentatis (non rarò profundè sinuatis), corollâ calyce dịplò longiori, labio superiori subfalcato glandulis destituto. S. agrestis. Vill. Datuph. 2, pag. 402 (exclus. plerisque synon. ). S. clandestina. Thore, Chlor. Land. 17 (non Lin.).

Quoiqu'il soit assez difficile de bien caractériser cette Sauge, elle me paroît cependant différer assez de la Salvia pratensis, pour constituer une espèce distincte. Elle âiffère principalement de celle-ci, parce qu'elle s'èlève beaucoup moins, et qu'elle est plus petite dans tontes ses parties; sa corolle est plus plane, moins courbée en faux, une fois seulement plus longue que le calice, et dépour- 


\section{( 7 )}

vue de glandes en sa lèvre supérieure. Cette lèvre dans la Sauge des prés est beaucoup plus recourbée en faucille, couverte de glandes qui lá rendent visqueuse, et la corolle entière est trois à quatre fois plus longue que le calice. La Sauge précoce croît sur le bord des champs, dans les prés secs et montueux du Dauphiné, de la Provence; on la trouve aux environs de Bordeaux, de Dax, de Nice: ses fleurs bleues et quelquefois blanches paroissent dès le mois de mars, même dès celui de févirier dans les pays chauds, comme en Toscane, et la plante continue à fleurir dans le printemps. Je dois à $\mathbf{M}$. Artaud la distinction de celte espèce qui est très-commune dans la Crau, aux environs d'Arles; c'est M. G. Robert qui m’a envoyé de Toulon, des échantillons à fleurs blauches. 4 .

\section{ANTHOXANDHUM ODORATUM $\beta$.}

A. glumis calycinis pubescentibus.

M. Requien a trouvé cette variété à Avignon, M. Rohde dans les champs à Nice; je l'ai reçue de l'Auvergne, et je l'ai recueillie moi-même dans les bois aux environs de Dreux. 


\section{( 8 )}

\section{TRIA NDRIE.}

VALERIANA SUPINA. Lin. - Lois., Fl. Gall. 22.

M. Requien m'a communiqué des échantillons de cette plante, recueillis au mont Ventoux, dont les feuilles caulinaires sont pinnatifides. Cette espère se rapproche alors beaucoup de celle que j'ai nommée V aleriana heterophylla. Fl. Gal. 22 , et les deux plantes pourroient bien n'être que des variétés l'une de l'autre.

LOEFLINGIA. Calyx 5-partitus, laciniis basi 2-dentatis. Petala 5 minima conniventia. Capsula supera I-locularis 3-valvis polysperma.

LOEFLINGIA HISPANICA. Lin., sp. 50. Loefl., It. I I3, tab. I, f. 2. Cavan., Ic. I, n. ro3, tab. 94.

Z. caule ramoso prostrato pubescente vis. cido, foliis oppositis subulatis mucronatis, floribus axillaribus sessilibus.

Cette plante se trouve dans la petite île Sainte - Lucie, près de Narbonne; je l'ai vue dans l'herbier de M. Rohde, à qui elle avoit été communiquée par M. Pech. $(\odot)$. 


\section{( 9 )}

IRIS FLORENTINA. Lin., sp. 55, Red. Lil. I, tab. 23.

1. barbata, foliis ensiformibus glabris brevioribus scapo subbifloro. Thunb., Diss., n. 5. I. alba florentina. Moris., hist. 2, pag. 35r, s. 4 , tab. 5 , f. 5 . Iris de Florence. Regnault, Bot. ic.

Cette plante ressemble beancoup à l'Iris d'Allemagne, mais elle en diffère par sa fleur constamment blanche, et par sa racine odorante; je l'ai reçue de M. G. Robert, qui l'a trouvée dans les champs aux envirous de Toulon; elle fleurit à la fin d'avril, et au commencement de mai. 4 .

\section{IRIS SIBIRICA. Lin. - Lois., Fl. Gall. 27.}

Cette plante, indiquée seulement en Alsace et en Dauphiné, se trouve encore en Piémont; MM. Balbis et Perret m'en ont communiqué des échantillons recueillis dans les bois aux environs de Turin.

IRIS TUBEROSA. Lin. - Lois., Fl. Gall., pag. $7 \mathrm{I} 7$.

Cette plante que j’ai indiquée aux environs de Toulon, a été retrouvée aux environs d'Agen, par M. S. Amans, et dans le Poitou , par M. Desvaux. 
GYPERUS PANNONICUS. Lin., suppl. Io3, Jacq, Fl. Aust. app., pag. 29, tab. 6.

C. culmo obsoletè triqüetro, spicis subquaternis sessilibus, glumis lateralibus spliacelatis.

M. Lamouroux m'a communiqué un échantillon de cette plante, qu'il m'a dit avoir trouvé dans les Hautes-Pyrénées. 24?

SCIRPUS PUBESCENS. Desf., Fl. Atl. r, pag. 52 , tab. 10.

S. culmo triquetro folioso supernè pubescente, spiculis ovatis glomeratis subsessilibus terminalibus, glumis pubescentibus mucronatis. Carex pubescens. Poir. Ilin. 2, pag. 254 .

Gette plante a été trouvée par M. G. Robert, dans les lieux humides, aux environs d'A jaccio, dans l'île de Corse. 4.

SCIRPUS LITTORALIS. Schrad., Fl. Germ. 1, pag. 142 , tab. 5 , f. 7 .

S. culmo triquetro nudo, basi vaginis foliiferis munito, cymầ laterali decompositâ, spiculis oblongis, stigmatibus duobus.

Celte plante a le port du Scirpus lacustris, 


\section{( II )}

mais elle en diffère par sa tige triangulairs; elle fleurit en juin et juillet : on la trouve dans les marais du bord de la mer, à Hières près de Toulon, où elle a été recueillie par MM. LéonDufour, Rohde et G. Robert. 2 .

PANICUM REPENS. Lin., sp. 87. Willd., sp. I , pag. 347 . Desf., Fl. Atl. I, pag. 60. Cavan., Ic. 2, n. I I9, tab. I Iо.

$P$. radice repente, culmis adscenclentibus virgatis, foliis inferioribus vaginâ pubescentibus, superioribus glabriusculis, floribus paniculce remotiusculis, valvulâ caIycinâ exteriori obtusâ.

Cette plante a été trouvée an bord de la mer, du côté d'Hières, dans la ci-devant Provence, par M. G. Robert; elle fleurit en septembre et octobre. 2 .

\section{SYNTHERISMA. Walt. Schrad.}

Calyx uniflorus trivalvis, valvulis corollce appressis incequalibus, tertiâ minimâ. Corollce valvula exterior connexa, interiorem planiusculam amplectens. Semen corollá corticatum. Flores subsessiles secundi, in spicas lineares subdigitatas dispositi.

SYNTHERISMA GILIARE. Schrad., FI. Germ. I, pag. 160, tab. 3, f. 7 .

S. foliis vaginisque pilosis, spicis subdigi- 


\section{( 12 )}

- tatis, flosculis oblongis ciliatis, culmis basi procumbentibus supernè erectis. Panicum ciliare. Willd., sp. i, pag. 344. $P a-$ nicum ciliatum. Ro:h. Germ. 2, P. 2, pag. 564. Digitaria ciliaris. Koel. Gram. $27 \cdot$

M. Schleicher a tronvé cette plante dans le Valais, sur les confins de la Savoie; elle fleurit en juin et juillet. $(\odot$ )

SYNTHERISMA VULGARE. Schrad., Fl. Germ. I, pas. $16 \mathrm{r}$.

S. culmis basi procumbentilus supernè erectis, foliis vaginisque pilosis, spicis digicatis, valvulis calycinis oblongis incequaZibus. Panicum sanguinale. Lin., sp. 84. Schreb. Gram. I, pag. I 9, tab. 16. Engl. Eōt., t. 849. Lois., Fl. Gall. 40. Digitaria sanguinalis. Scop. Carn., n. 72. Dactylon sanguinale. Vill. Dauph. 2, pag. 59. Paspalum sanguinale. Dec., Fl. Fr., n. 1504.

Cette plante est commune en France, dans les champs sablonneux et les lieux cultivés : je l'avois déja mentionnée dans ma Flore, et je ne la rapporte de nouveau, que parce que jai ajouté deux autres espèces pour lesquelles jai adopté une nouvelle dénomination générique. 


\section{( $\mathrm{x} 3$ )}

SYNTHERISMA GLABRUM. Schrad., Fl. Germ. I, pag. 163, tab. 3, f. 6.

S. culmis basi procumbentibus, supernè erectis, foliis vaginisque glabris, spicis subdigitatis, walvulis calycinis ovatis sequalibus. Digitaria filifurmis. Koel. Gram. 25. Paspalum ambiguum. Decand., Fl. Fr. 1505.

Cette graminée flemrit en août et septembre; elle se trouve, selon M. Decandolle, dans jés jardins, les champs et les vignes: M. Requien l'a recueillie aux environs d'Avignon. ( $)$.

AGROSTIS MLLIACEA. Lin. - Lois., F!. Gall. 42.

Cette plante se trouve en Provence, d'où M. Gérard en a envoyé des graines à M. Cels. M. Rohde l'a recueillie à Toulon et à Arles, et M. Requien à Avignon; elle fleurit en mai et juin.

AGROSTIS SETACEA. Curt. Lond. Fasc. 6, t. 12. Smith. El. Brit. 79 .

A. Foliis radicalibus crespilosis setaceis glatcescentibus, paniculá erectiâ, calycibus lanceolatis, corollâ basi aristatâ, aristấ, gericulatâ.

Celte plante lleurit au printemps; elle est 


\section{( 14 )}

commune dans les landes de Bordeaux et dans celles de Bretagne: je l'ai recue des environs de Dax par M. Thore, et de Quimper par M. Bonnemaison. 4 .

AGROSTIS VULGARIS. With. Brit. ed. 3 , p. 132. Smith. Fl. Brit. 79. Schrad. Fl. Germ. I, p. 206 , t. 2 , f. 3.

1. Culmis erectis, foliis scabriusculis, ligulà brevissimâ truncatâ, panicula ramulis laeviusculis capillaribus divaricatis, valvulis calycinis a qualibus, glumâ corollinâ interiori duplò breviori retusâ.

Le port de cette plante, qui est très-commune dans les prés, les bois et sur le bord des champs, est extraordinairement variable, selon le terrain où elle a pris naissance, et il est très-difficile de bien séparer ses différentes variétés dont plusieurs anteurs ont fait des espèces. Après avoir examiné avec beaucoup d'attention tous les échantillons que j'avois dans mon herbier sous les noms d'Agrostis stolonifera, A. hispida, A. varians, $A$. violacea et $A$. verticillata, je n'ai $\mathrm{pu}$ trouver aucun caractère solide pour les séparer; ce qui m'engage à réunir en une scule toutes ces espèces mentionnées dans ma Flore, pag. 43,44 . 


\section{( $x 5)$}

\section{AGROSTIS ELEGANS. T. I, f. $x$.}

A. Culmo erecto filiformi, foliis involuits subulatis, ligunulá truncatí erosá, paniculce ramulis laxis, valuulis calycinis cequilibus patentibus, corollis ovatis muticis calyce paulò brevioribus. A. elegans. Thore, ined.

Chaumes très-menus, légèrement coudés à chaque noeud, sélevant de trois à six pouces de hauteur, solitaires ou par petites touffes de deux à six tiges redressées. Feuilles subulées, dont les bords se replient en dedians; leur gaine est munie d'une languette membraneuse, tronquée et laciniée au sommet. Panicule sortant de la gaine de la feuille supérieure, d'abord resserrée sur elle-même avant l'épanouissement des fleurs, ayant ensuite ses rameaux capillaires très-ètalés. Valves du calice ovales, glabres, comprimées lateralement, très-ouvertes, d'une demi-ligne de long tout au plus. Corolle membraneuse, luisnte, un peu plus courte que le calice, paroissant en. velopper la graine après la floraison.

Cette jolie graminée m’a été communiquée par M. Thore, qui l'a découverte dans les landes anx environs de Dax; elle m'a aussi été envoyée du mème pays par M. Grateloup; elle fleurit au printemps. ( $)$. 


\section{( 16 )}

AGROSTIS PUNGENS. Willd, - Lois. Fl. Gall. 44.

Cette plante fleurit au mois d'août; elle n'étoit indiquée qu'à Narbonne et à Nice, je l'ai recue des environs de Toulon par M. G. Robert, et de Cette par M. Bouchet.

\section{AIR A AGROSTIDEA.}

A. culmo basi geniculato radicante supernè erecto, foliis planis, ligulâ lanceolatâ, panicula ramis capillaribus patentibus, corollâ truncatâ valsulis calycinis multò breviori. A. minuta. Lois., Fl. Gall. 45 (exclus. synon.). Poa agrostidea. Decand. Ic. rar. fasc. I, pag. I, tab. I.

Celte espèce a été découverte par M. Delaroche, dans les lieux humides et herbenx, aux environs de Nantes; elle fleurit en juillet et août. $(\cdot)$.

\section{AIRA GLOBOSA. Thore, Journ. Bot. r, pag. 197 , tab. 7 , f. 3 et 4 .}

A. culmo erecto filiformi, foliis involutis subulatis, ligulâ truncato-laciniatâ, panicula subcoarctatá, valvulis calycinis glabris subhemisphoricis, corollis margine ciliatis. Milium tenellum. Cavan., ic. 3, 
n. 299 , tab. 274 , f. I. Airopsis globosa. Desv., Journ. Bot. I, pag. 200.

Ceite plante fleurit au mois de mai; elle a été trouvée par M. Thore, dans les Landes, aux environs de Dax. (.).

POA TRINERVATA. Willd. - Lois, F!. Gall. 50.

Cette espèce doit être retranchée de ma Flore, comme un double emploi; c'est la mème plante que la Festuca syluatica.

\section{POA PILOS A. Lin. - Lois., Fl. Gall. 5 r.}

Cette plante, que le premier j'ai indiquée en France, paroît y èire commune, je ne l'avois d'abord recue que de Toulon; depuis, elle m'a été envoyée de Genêve, de Turin, d'Arles, de Bayonne, de la Bretagne, eic.

POA DIVARICATA. Gouan. - Lois., FI. Gall. 52.

Cette plante n'étoit indiquée qu'aux environs de Montpelier; M. Artand l'a tronvée dans les pàturages de la Camargue, territoire d'Arles, ét M. G. Robert à Toulon: M. Savi dit qu'on la reucontre près de la mẹ en Toscane. 


\section{$(18)$}

DACTYLIS HISPANICA. Roth., Catalect., Bot. I, pag. 8 , ex Balb., Miscel. alt., pag. 7 .

D. paniculấ contractấ subspicatî́ secundâ. Roth.

J'ai reçu cette plante de plusieurs cantons de la Provence, et des environs de Nice, où elle fleurit en mai et juin: je donte fort qu'elle puisse former une espèce distincte; elle ne me paroît qu'une variété de la Dactylıs glomerata. $2 \%$.

FESTUCA PHANICOIDES. Lin.-Lois., FJ. Gall. 54.

Les synony mes d'Allioni et de Plukenet n'appartiennent pas à cette espèce, mais à celle qui va suivre.

FESTUCA C.APITOSA. Desf., Atl. I, pag. 9r, tab. 24 .

F. culmo basi ramosissimo, foliis involutis pungentibus, racemo spicato erecto, spiculis sessilibus 6-12-foris, aristis brevissimis. Bromus pinnatus, var. $\beta$. Lin., Sp. I 15 , (ex Smith et herb., Linn. ). Bromus ramosus. Lin., Mant. 34. Vahl, Symb. 2, pag. 22, (excl. synon. Gerardi, et synon. Linncei 


\section{( 19 )}

quoad Festucam phrenicoidem ). Lam., Dict. I, pag. 469. Vill., Dauph. 2 , pag. I 2 I. Bromus Plukenetii. All., Fl. Ped., n. 22.33. Gramen spicâbrizce mimus. Pluk., Alm. I73, tab. 33 , f. I. (fide herbarii Plukenetii, in Vahl, Symb., l.c.).

Cette plante fleurit en mai et juin; clle se trouve sur les rochers et dans les lieux pierreux du Piémont, du pays de Gènes, de la Provence, du Dauphiné. $2 f$.

Cette espèce a beaucoup de rapport avec le Bromus pinnatus, qui ayant l'arête terminale doit passer dans le genre Festuca, ainsi que les Bromus gracilis, pinnatus, et distachyos, qui ont le mème caractère.

FESTUCA PRATENSIS. Huds., Angl. ed. I, pag. 37. Curt., Lond. fasc. 66. Smith., Fl. Brit. I, pag. 63. Schrad., Fl. Germ. I, pag. 332.

F. paniculâ patente ramosâ, spiculis linearibus muticis multifloris, foliis linearibus, radice fibrosá. Schrad. F. elatior. Host., gram. 2 , pag. 57 , tab. 79 (exclus. synon. Smith.). Vill., Dauph. 2, pag. 107.

Cette plante est communé dans les prés et les bois, aux environs de Paris, et probablement dans toute la France: on la confond facilement avec la Festuca elatior, dont elle 
differe par ses fleurs plus nombreuses dans chaque épillet; elle fleuxit en été. 22.

FESTUCA CAPILI.ATA. Lam., FI. Fr., éd. I, vol. 3, pag. 597, (cxclus., var. $\beta$.). Hllust. I, pag. Ig2, (certe ex herb:ipso.).

F. folits capillaribus, culmis subtetragonis, patentis paniculce spiculis oblongis 4 5-floris muticis. F. temnifolia. Schrad., F!. Germ. I, p. 318. Gramen loliaceum, foliolis junceis Zrevibus, minuls. Moris., hist. 3, p. I82, s. 8 , t. 3, f. 13.

Celte espèce fleurit en mai et en juin; je l'ai tronvée dans les bois aux environs de Drenx; clie paroîl commune aux environs de Paris, car je l'ai recuelllie celle année à SaintGermain, à Romainville et au bois de Boulogne: clle se trouve probablement dans toute la France. $2 f$.

FESTUGA FLAVESCENS. Bell. - Lois., Fl. Gall. 55.

FESTUGA RHATICA. Sut. - Lois., Fl. Gall. 57 .

Ces deux plantes, indiquées sculement, la première dans les Alpes du Piémont, et la seconde dans celles du Valais, ont été retrouvées toutes deux par M. Rohde, au mont Canigou dans les Pyrenées orientales; elles fleurissent dans les mois de juillet et d'août. 


\section{FESTUCA STIPOIDES. Desf., All. I,}

p. 90.

F. paniculấ subcontractâ secundầ breviusculá, ramulis geminis, pedunculis apice d:laiatir, spiculis 3-5-floris aristatis, valsulá calycinâ alterâ minimâ. Bromus stipoides. Lin., Mant. 557. Bromus geniculatus. Willd., Sp. 4.34. (ex fide speciminis missi ad D. Desfontaines). Bromus ligusticus. All., Fl. Ped., n. 2222. Savi, Botan. Etrus. I, p. 77. Gramen bromoides, festuceá tenuique paniculä, minus. Barrel., Ic. 76 , f. 2. Scheuchz., Agrosi. 2y6, t. 6, f. 13 .

Cette espèce a le plus grand rapport avec la Festuca uniglumis, elle doit la suivre immédiatement; son arête terminale l'éligne d'ailleurs di genre Bromus. On la trouve sur le bord des champs en Toscane, en Ligurie, en Provence. Je l'ai recue de MM. Bertoloni, Rohde et G. Robert; elle fleurit en mai et juin. (.).

FESTUCA CILIATA. Decand. - Lois., Fl. Gall. 58.

Cette plante qui a été longtemps confondue avec les espèces yoisines, dont elle est d'ailleurs bien distincte, se trouve non-seulement en Languedoc et en Provence, où elle est: 


\section{(22)}

très-commune; mais elle a encore été trouvée a Nice par M. Rohde, et aux environs de Turin par M. Balbis.

BROMUS SQUARROSUS в. Lam., Dict. I, p. 466.

B. spiculis pubescentibus. Gramen festuceum majus, locustis crassis lanuginosis, aristis recurvis longissimis. Buxb., cent. 5, p. 19, t. 38 , f. I ?

Cette variété a été trouvée sur les montagnes aux environs de Beaucaire, par M. Léon Dufour.

BROMUS DIVARICATUS. Rohde, in herb.

B. paniculá erectâ subcontractâ, spiculis lineari-lanceolatis 10.15-floris pilbescentibus, gilumá corolliná exteriori bifidá acutâ, aristis basi contortis demum divaricatis. ß. Spiculis villosis sublanuginosis.

Cette plante fleurit en juin; elle habite dans les champs en Provence, où elle a élé trouvée par M. Rohde; je l'ai recue de Toulon, par M. G. Robert, et MM. Artaud et Requien me l'ont envoyée des environs d'Arles el d'Avignon. La variete $\beta$ que $j$ 'ai vue dans l'herbier de M. Desfontaines, et qui a été également trouvée par M. Rohde, à Hières près de Tou- 


\section{( 23 )}

lon, est caractérisée par ses épillets très-velus, presque lanugineux. ( $)$.

\section{AVENA ORIENTALIS. Willd., Sp. I, p. 446.}

Host., Gram. 3, p. 3r, t. 44. Schrad., Fl. Germ. I, p. 37r.

A. paniculâ secundâ, spiculis bifloris calyce minoribus, flosculo altero mutico, radice fibrosá annuáa. $A$. racemosa. Thuil., Fl. Paris. 5g.

3. Flosculis omnibus muticis.

Cetle plante se trouve dans les moissons aux environs de Paris; elle fleurit en juillet. ( $)$.

AVENA PANICEA. Lam., Illust., n. I I I7. Desf., Atl. I, p. 102.

A. paniculá contractâ, spiculis $3-5$-floris glabris nitidlis, glumis corollinis bifudis apice subbiaristatis, exteriori dorso aristatâ, aristâ rectâ corollis breviori. A. lceflingiana. Lam., Dict. I, p. 332. (non Lin.). A. neglecta. Savi, Fl. Pis. r, p. х3z, t. I, f. 4. Botan. Etrus. I, p. 84.

Cette espèce se trouve dans les champs en Toscane et dans le pays de Gênes, d'où elle m’a été envoyée par MM. Savi et Bertoloni. (.). 


\section{(24)}

AVENA PARVIFLORA. Desf., All. r, p. ro3, t. 32 .

A. foliis planis pubéscentitus, patentis paniculre ramis capillaribus, spiculis glabris nitidis 2-4-floris, aristis seliformibus glumâ sublongioribus infià apicem emergentibus. Festuca segetum Savi, Fl. Pis. I, p. I16, t. i, f. 3. Bolan. Eirtis, I, 1. 69 .

Cette plante a le port de l'Agrostis spicaventi; elle' est commune dans les moissons en Toscane, où elle fleuril en juin, et d'où $M$. Savi m'en a envoyé des échantillons. ( $)$.

ARUNidO FESTUCOIDES. Desf., Atl. r, p. 108, t. 34 .

A. foliis involutis, paniculấ secunctâ laxấ, calycibus 2-3-floris, pilis corollá dimidò brevioribus. A. tenax. Vahl., Symb. 2, p. 25. Willd., Sp. I, p. 455 . A. maunitiana. P.ir., Itin. 2, p. 104. A. ampelodesmon. Cyril., P!. rar. Neap. fasc. 2, t. 12, ex Bertol., Pl. gen. 23.

Cette plaste fleurit en mai et juin; elle habite dans le pays de Gênes et la Toscane, sur les collines du golfe de la Spezzia : je l'ai reçue de MM. Bertoloni et Savi. $2 \not$. 


\section{( 25$)$}

ARUNDO PSEUDOPHRAGMITES. Hall, fil. in Rom. Arch. I, B. 2, p. I , ex Schrad., Fl. Germ. I., p. 213 , t. 禾, f. 3.

A. paniculá diffusâ, calycibus acuminatis (unifloris), aristầ dorsali rectâ pilisque corollá pauló longioribus. Schrad.

Cette plante fleurit en juillet et août; elle habite dans les bois humides et sur le bord des ruisseaux : je n'ai pas d'indication certaine sur les contrées de la France où elle se trouve; il paroît qu'on la rencontre souvent dans les mèmes lieux que l'Arundo phragmites, et mêlée avec celte espèce, à laquelle elle ressemble un peri, et avec laquelle on la confond; mais on l'eu distingreera facilement eir faisant attention qu'elle est plus petite dans toutes ses parties, ct surtout que ses calices sont uniflores. $2 \%$.

ARUNDO SYLVATICA.Schrad.,Fl.Germ. I, pag. 218 , tab. 4 , f. 7 .

A. paniculá patente, calycibus acutis (unifloris), pilis brevissimis, aristâ dorsali geniculatâ calycem excedente. Schrad. Agrostis arundinacea. Willd., Sp. I, pag. 364 ( exclus. synon.).

Cette plante fleurit en juin, juillet et août; 


\section{( 26 )}

elle a éte trouvée dans les Pyrénées par $M$. Rohie. $2 \%$.

\section{SECALE CRETICUM. Lin., Sp. I 25.}

S. glumis extorsim ciliatis. Lin. Gramen creticum spicatum secalinum altissimum, tuberosâ raclice. Tour., Cor. 39.

Cetie plante a été trouvée dans l'ile de Corse yar M. Lasalle.

NORDEUM BULBOSUM. Lin., Sp. I25, Bertol, , Plant. Gen. 25.

H. Alosculis ternis, intermedio hermaphrod.to Iongissimie aristato, lateralibus masculis muticis involucro scabro brevioribus, radice tuberosâ. H. strictum. Desf., Atl. I, pag. 113, tab. 37. Gramen secalinum bulbosâ radice. Barr., Ic. II 2, f. 2.

Cette espèce habite dans les pàturages du pays de Gênes, où elle fleurit en mai, et I'uù M. Bertoloni m'en a envoyé des échantillons. 4 .

\section{HORDEUM JUBATUM. Lin., Sp. I 26 .}

I1. Alosculis geminis fertilibus aristatis cequalibus, flosculorum superiorum aristâ involucro 4-pluyllo multò longiori. Elymus crinitus. Schreb., Gram. 2, pag. 15, tab. 24 , f. 3. 


\section{(27)}

Cette espèce a été trouvée par M. Rhode, en Provence, sur les bords du chemin entre l'Esterelle et Frejus; elle fleurit au mois de mai. $(\cdot)$.

\section{TRITICUM TENUICULUM. N.}

T. culmis tenuiculis erectis, foliis involutis subulatis, spicâ simplici strictấ, spiculis subsessilibus alternis ovato-oblongis subseptemforis, corollis aristatis.

Cette espèce a la plus grande affinité avec le Triticum tenellum; elle en a tout le port, et elle est à celui-ci ce que le Triticum nardus est au Triticum unilaterale : comparée au Triticum teneluum, les différences essentielles qu'elle présente, sont d'avoir ses épillets moins nombreux, et plus alongés, mais surtout d'avoir les balles de chaque fleur terminées par une arête presque égale à la longueur de celles-ci. Ce petit Froment a été découvert dans les champs des environs de Nantes, au mois de mai, par M. Gochnat. ( $)$.

\section{TRITICUM UNILATERALE. Lin. - Lois. , Fl. Gall. 7 I.}

MIM. Requien et Gochnat m'ont commitniqué une variété de cette espèce, dont toutes les parties sont pubescentes : le premier l'a trouvée aux environs d'Avignon, et le second 


\section{( 28 )}

dans les champs à Montpollier; cette plante fleurit en avril el mai.

TRITICUM NARDUS. Decand. - Lois., Fl. Gall. 71.

M. Balbis a trouvé aux environs de Turin, ct m’a communiçné une variété de celte espèce, sons le nom de Triticum biunciale, remarquable par ses épillots pube cens. Cette plante a de grands rapports et pourroit se confondre avec la varieté pubescente du 'Triticum unilaterale que je viens d'indiquer; on la recounoîtra à ses tigges redressees, plus èlevées, an lieu d'ètre à demi-etalées; à ce que I'axe qui porte les épillets est presque droit ct non courbé en arc; cnfin à ses llenrs munies d'arêtes et non simplement aiguës.

TRITICUM JUNCEUAI. Lin., Sp. r $28,(e x-$ clus. synon.). Lois., Fl. Gall. 7I , (exclus. synon. Morisonii.).

T. racide repente, foliis involutis, spiculis alternis compressis distantibus 3.6-floris, corollis muticis subtrincatis striatis, rachi Icevi. T. farctum. Viv., El. Ital. frag. I, p. 28 , t. 26 , f. I.

Cette plante croit sur les bords de la mer, dans la Ligurie, en Provence, en Languedoc; je l'ai reçue de MH. Bertoloni et Artand, et 


\section{( 29 )}

je l'ai recueillic à Maguclone près de Montpellier, où je l'ai trouvée en fleurs au mois de juillet. 4 .

\section{TRITICUM RIGIDUM. Schrad., Fl. Germ. I, p. 392.}

T. radice repente, foliis involutis, spiculis alternis compressis subimbricatis, valvulis calycinis subseptemnervib: s obtusis 6-ro-floris, corollis muiticis, raclu lispidâ. T. elongatum. Host., Gram. 2, p. 18, t. 18. Gramèn angustifolium spicâ tritici multicre simili. Moris., Hist. 3, p. 178 , n. 10. s. 8 , t. I , f. 5.

Cetie plante fleurit en juillét : je l'ai trouvée sur les bords de la mer à Magnelone, et M. Artand me l'a envoyée des Saintes-Maries à l'embouchure du Rhône. $\Varangle$.

\section{TRITICUM (PUNGENS). Glancum, radice} repente, foliis demun subulato convoliteis pungentibus, glumis acuminatis muticis, carinâ mucronatâ. Pers., Synop. I, p. rog.

M. Persoon rapporte celte plante comme variété du Triticum junceum, mais elle me paroit avoir peu de rapports avec cetie espéce, et en avoir au contraire beacoup avec le 'I riticum repens. Aussi, c'sost sous certe dernière espèce que je crois qu'elle doit être 


\section{(30)}

rangée: elle m'a été envoyée de Provence, par MM. Artaud et G. Pobert. Je soupçonne que le Triticum junceum de la Flore de Paris, n'est autre chose que la variété dont il est ici question.

TRITICUM NigriCaNS. Pers., Syn. I,

$$
\text { p. IIO. }
$$

T. spicâ 4-gonâ subturgidâ, glumis margine villosis nigrescentibus, aristis longis.

Celte espèce, selon M. Persoon, a le port d'un Seigle ou d'un Orge; je n'ai pas eu occasion de l'observer : elle a été trouvée dans le voisinage de la mer, en Normandie, par M. Bory.

\section{T E T R A D R I E.}

GLOBULARIA INCANESCENS. Viv., Fl. Ita!, Frag. I, p. 2, 1. 3.

G. caule herbaceo, foliis subcanescentibus, radicalibus spathulatis, caulinis obnvatolanceolatis, paleis glaberrimis, dentibus calycinis subulatis basi pilosis.

Celie espèce croît en Toscane, sur les montagnes de marbre de Carrare; ses flemrs bleuâtres parnissent en mai et juin; elle m'a été communiquée par M. Bertoloni, 22 . 


\section{(3r)}

SCABIOSA COLUMBARIA. Lin. - Lois., Fl. Gall. 78.

M. G. Robert a trouvé dans les lieux stériles, aux environs de Toulon, une variété de cette espèce, dont les fleurs au lieu d'èrre sessiles sur le réceptacle commun, sont portées sur des pédicules de deux à huit lignes de longueur : cette plante paroît être celle indiquée dans Clusius, par une manvaise figure, sous le nom de Scabiosa prolifero flore. Clus., Hist. V.

SCABIOSA SUAVEOLENS. Desf. - Lois., Fl. Gall. $7^{8 .}$

C'est la même espèce quue la Scabiosa canescens. Waldst., Pl. Hung., p. 53, t. 53.

SCABIOSA URCEOLATA. Desf., Atl. I, p. 122.

S. corollis quinquefidis radiantibus, calyce multifido urceolato, folis subcarnosis pinnatifidis. Desf. S. maritima rutce canince foliis. Bocc., Sicul., t. 40, f. 3 , ct t. 52. Moris., Hist. 3 , p. 48. s. 6 , t. 13 , f. 24 .

Cette plante se trouve sur le bord de la mer en Toscane et dans le pays de Gênes; 


\section{(32)}

elle fleurit en juin et juillet; ses corolles sont blanchâtres: je l'ai reçue de M. Bertoloni. 26.

SCABIOSA MONSPELIENSIS. Jacq., Ic. rar. I, t. 24. Miscel. 2, p. 320. Lois., Fl. Gall. 79 .

Cette plante non-seulement doit être reIranchée de la Flore; mais encore elle ne doit pas faire unc espéce distincte, et la figure de Jacquin doit ètre rapportée comme synonyme à la Scabiosa stellata.

SCABIOSA SIMPLEX. Desf., At]. x, p. I25, t. 39 , f. r. Lois., Fl. Gall. $7^{8}$.

Je possède plusieurs échantillons de cette plante qui sont rameux; dans cet état ccite espèce est difficile à distinguer, et se confond avec la Scabiosa stellata, dont elle ne paroît être qu'une variété.

GALIUM DIVARICATUM. Lam. - Lois., F]. Gall. 82. Decand., Ic. rar. I, p. 8, t. 24 .

Il faut ajouter pour synony me à cette espèce, Galium terne. Vill. d'après un échantillon donné par M. Villars à M. Clarion, et que ce dernier ma communiqué.

Cette plante indiquée en Langnedoc par M. Pourret, paroît assez commune en France; 


\section{( 33 )}

elle n'a été longtemps oubliée, que parce qu'on la confondoit soit avec le Galium anglicum, soit même avec le Galium parisiense. M. Villars l'a recueillie en Dauphiné, M. Desfontaines dans le Berry; M. Perret me l'a envoyée des environs de Turin; M. G. Robert l'a recueillie dans les moissons des îles d'Hières, enfin, je l'ai trouvée à Fontainebleau sur le bord des bois : elle fleurit en mai et juin. ( $)$.

GALIUM SETACEUM. Lam. - Lois., Fl. Gall. 720 .

Cette espèce cst la même que le Galium microcarpum. Vahl., Symb. 2, p. 30.

GALIUM VERTICILLATUM.Tab. 2.Danth., in Lam., Dict. 2, p. 585. (Certè ex Desf. herb.).

G. caule basi ramoso, ramis subsimplicibus; foliis lanceolatis hispidis, inferioribus vervicillatis, superioribus oppositis, fructibus hispidis glomeratis subsessilibus verticillatis erectis.

Ce Caille-lait a la plus grande yessemblance avec la Scherardia muralis, et presque tous les Botanistes l'ont confondu avec celle-ci. Il s'en dislingue à ses tiges moins rameuses ou qui le sont seulement dans le bas de la plante, à ses feuilles simplement opposées dans la 


\section{(34)}

partie supérieure des rameanx, et non verticillées par trois ou quatre; mais surtout par la forme et la disposition de ses fruils. Cenxci sont ovales-arrondis, entièrement et également couverts de petits poils blancs, crochus à leur sommet; ils sont portés sur des pédoncules très-courts, réunis quatre à cinq en- semble en deux petits paquets axillaires, presque sessiles, ay ant l'apparence de former un verticille complet autour de la tige: les pédoñcules qui portent chaque fruit sont droits, jamais recourbés en dessous des feuilles, ce qui arrive au contraire toujours dans la Scherardia muralis. On pent encore ajonter que les fruits de celte dernière forment des verticilles beaucoup moins garnis; enfin qu'ils sont plus alongés et couronnés par une rangée particulière de poils. Le Caille-lait verticillé croît dans les champs en Provence; il a été trouvé, aux environs de Salon, par M. Suffren, et à Bédouin au pied du' mont Ventoux, par M. Requien. Ses fleurs sont bianchatres; elles paroissent en avrì et mai. ( () .

PLANTAGO PSYLLIUM. Lin., Sp. 167 . Lois., Fl. Gall. go.

P. caule è basi ramoso herbaceo, foliis linearibus, capitulis ovatis, bracteis longitudine calycis, foliolis calycinis lanceo- 
latis acutiusculis, seminibus oblongis cymbiformibus.

PLANTAGO ARENARIA. Waldst., Pl. Hung. 5 r, t. 5r. Poir., Dict. 5, p. 3̈g2. Dec., Fl. Fr., n. 23r5.

P. caule undiquè ramoso herbaceo, foliis linearibus, capitulis ovato-oblongis, bracteis calyce duplò triplòque longioribus, foliolis calycinis apice dilatatis obtusissimis membranaceis, seminibus oratis. P. psyllium. Bull., Herb., t. 363 (et omnium ferè alictoritm, non autem Linnceii).

Il fant faire beaucoup d'attention pour ne pas confondre ces deux plantes qui ont le plus grand rapport; mais qui different cependant assez pour constituer deux espèces dont les caractères ne paroissent pas équivoques. J'ai tàché de faire ressortir dans de nouvelles phrases, les différences les plus cssenlielles qui existent entre ces deux espèces, et qui n'avoient été qu'imparfaitement indiquées dans ma Flore. La dernière de ces plantes (Plantago arenaria) paroît très-commune dans toule la France; je l'ai recue du Piémont, de la Provence, de la Bretagne, elc.; je lai trouvée moi-nềne à Montpellier et aux environs de Paris. La première au contraire (Plantago psyllium) paroit plus rare; 


\section{( 36 )}

je la dois aux recherches de M. Requien, quai l'a recueillie dans les champs à Avignon, et à MM. Rohde et Gochnat, qui l'ont trouvée à Nice : elle fleurit en avril et mai, et elle est par conséquent plus précoce que la seconde espèce qui ne fleurit qu'en juillet et août. ( $)$.

PLANtago Genevensis. Poir., Dict. 5 ,

$$
\text { p. 3go. Lois., Fl. Gall. go. }
$$

Celte espèce doit être entièrement supprimée et rapportée au Plantago cynops. La plante qui m’a été communiquée par M. Castan, et qu'il avoit cueillie aux environs de Genève, dans le lieu même où elle est indiquée par MM. Poiret et Decandolle, non-seulement n'a offert à mon observation aucun caractère qui pût servir à la faire distinguer comme espèce, mais encore iĺ m'a paru que les trèslégères différences qu'elle présentoit, étoient trop peu remarquables, pour lui assigner un rang comme variété.

\section{PENT A N D R I E.}

MYOSOTIS PUSILLA. N., tab. $\mathrm{x}, \mathrm{f} .2$.

M. caule basi ramoso foliisque obovatooblongis pilosis, floribus axillaribus alter nis, seminibus loevibus. 


\section{( 37 )}

Cette plante n'a guères qu'un pouce de haut, et quelquefois que six à huit lignes; elle se distingue des individus nains de la Myasotis annua par ses fleurs peu nombreuses, alternes, la plupart axillaires, ne formant pas une grappe nue et unilatérale: ces fleurs, d'après les échantillons secs, m'ont paru avoir été blanches ou d'un bleu trèsclair. Cette nouvelle espèce a été découverte dans les champs en Corse, par M. G. Robert. ( $)$.

LITHOSPERMUM PROSTRATUM. Lois., Fl. Gall. I०5, tab. 4 .

MM. Deschamps et Bonnemaison ont retrouvé en Bretagne, aux environs de Brest et de Quimper, cette espèce que j’ai trouvée pour la première fois dans les landes près de Bayonne.

PULMONARIA SUFFRUTICOSA. Lin,, Sp. 1667 .

P. foliis linearibus scabriusculis, calycibus quinquepartitis subulatis corollâ dimidiò brevioribus, floribus terminalibus subcorymbosis. Lithospermum angustifolium umbellatum. Pluk., Phyt. 42, f. 7. Bocc., Sicul. 77 • 


\section{(38)}

Lithospermum graminifolium. Viv., FI. Ital., Frag. I, p. 3, tab. 5.

Cette plante croît dans les lieux pierreux du pays de Gênes; ses-fleurs blenes paroisscnt au mois de mai : elle m’a éée communiquée par M. Bertoloni. 2 .

ECHIUM CALYCINUM. Vir., Fl. Ital, Frag. I, p. 2, tab. 4 .

E. caule basi prostrato, foliis ovato oblongis, floribus sparsis, corollá subregulari calyce vix longiori, calycibus fructiferis prodluctioribus. E. parviflorum. Roth., Catal. I, p. I4?

Cette plante a été trouvée sur le bord des chemins près de Nice, par MM. Rohde et Gochnat; elle est indiquée aux environs de Gènes, par M. Viviani; ses fleurs sont bleues; elle fleurit on mars, avril et mai. 4 ?

\section{PRIMULA ALEIONII. N., tab. 3, f. I.}

$P$. foliis ovato-subrotundis pubescenti-glutinosis subintegerrimis, scapo $\mathrm{x}-2$-floro foliis ureviore, calycibus obtusis tubo triplò brevioribus. P. glutinosa. All., Auct. F1. Ped. 6 (excl. synon.).

Cette plantc est tout-à-fait différente de la 


\section{$(3 y)$}

Trimula glutinosa de Jacquin; l'espèce dont elle se rapproche le plus, est la primula villosa, mais elle en est encore bien distincte : elle croît en Piémont, au lieu dit la Madona delle finestre, dans les endroits ombragés, entre les fentes des rochers; elle fleurit au mois d'avril; je l'ai reçue de M. Balbis. 2 .

\section{LYSIMACHIA EPHEMERUM. Lin., Sp. 209•}

L. foliis oppositis lineari-lanceolatis sessilibus, racemis simplicibus terminalibus, petalis obovatis patulis. Ephemerum Matthioli. Dod. Pempt. 203.

M. Rhode a trouvé cette plarite sur le bord d'un fossé entre Olette et Mont-Louis, dans les Pyrénées orientales; elle fleurit en juillet. et août; ses fleurs sont gris-de-lin. 4 .

\section{LYSIMACHIA CILIATA. Lin., Sp. 2 го.}

L. foliis oppositis ovato-lanceolatis subcordatis, petiolis ciliatis, pedunculis subsolitariis axillaribus, floribus cernuis.

M. Lejeune a trouvé cette espèce, qu'on. croyoit particulière à l'Amérique, dans les ruisseaux entre Theux et Ensival, aux environs de Liége; elle fleurit eni été; ses tleurs sont jaunes. 4 . 


\section{( 40$)$}

ANAGALLIS VERTICILLATA. All., Fl. Ped., n. 318, t. 85, f. 4. Lois, , Fl. Gall. I 17.

D'après l'échantillon qui m'a été communiqué par M. Balbis, la plante d'Allioni ne paroît ĉtre qu'une variété de l'Anagallis ccerulea.

\section{CONVOLVULUS INTERMEDIUS. N.}

C. caulibus erectis simplicissimis, foliis lant ceolatis pubescentibus, pedunculis axillaribus terminalibusque I-2-floris folium subcequantibus, bracteis binis calyce longioribus.

Celte plante a beaucoup d'affinité avec le Convolvulus lineatus dont elle a presque tous les caractères, et dont on pourroit croire qu'elle n'est qu'une variété; mais dont elle me paroît cependant différer assez pour mériter d'en être séparée. Elle s'en distingue au duyet doßt ses feuilles sont courertes, et qui est court sans être serré et soyenx; à ses tiges droites qui s'élèvent à dix, douze pouces ou même davantage, tandis que celles du Convolvulus lineatus sont à demi-couchées, et n'ont souvent qu'un à deux pouces de haut. Elle a aussi des rapports avec le Convolvulus canabrica, mais ses tiges ne sont pas rameuses. 


\section{(4r)}

ct étalées comme dans ce dernier, ses pédoncules sont plus courts, et le duvet qui revêt ses feuilles est moins long. Le Liseron intermédiaire a été trouvé aux environs d'Avignon par M. Requien : ses fleurs sont d'une couleur purpurine claire; elles paroissent au mois de mai. 2 .

CONVOLVULUS SAXATILIS. Vahl., Symb. 3, p. 33. Willd., Sp. I, p. 868.

C. tomentosus, foliis linearibus, floribus subsessilibus capitatis terminalibus, calycibus lineari-subulatis. C. lanuginosus. Lam., Dict. 3, p. 55r. C. capitatus. Cavan., Ic. 2, p. $7^{2}$, tab. 8g. C. saxatilis erectus, etc. Barrel., Ic. 470.

Ce.Liseron croît sur les rochers aux environs de Perpignan, où il a été trouvé par M. Lamouroux qui me l'a communiqué. Il ileurit en juillet et août; ses fleurs sont purpurines très-olaires, tirant sur le blanc. $\not{f}$.

\section{CAMPANULA CERVICARIA. Lin. - Lois. , Fl. Gall. 122.}

Cette espèce a été trouvée par M. MeifrenLaugier, à Chartreltes près de Melun, à dix lieues de Paris: elle fleurit en juillet. 


\section{(42)}

IASIONE HUMILIS. Per's, Synop. 2, p. 215.

I. foliis obo"ato-oblongis integerrimis basiciliatis, caulibus basi suffruticosis ccespitosis, capitulis terminalit'rus subsessilibus, foliolis involucri subintegris. I. undulata ß. Lam., Dict. 3, p. 2r5. Plyyteuma crispa. Pourret, Chlor. Narb.

Cetic plante me paroît saffisamment disincte de la Iasione montana, et de la Iasione perennis, pour former une espèce particulière. Si d'ailleurs on vouloit ne la considérer que comme une variété, ce-seroit sous la Iasione perennis qu'elle devroit être placée, parce qu'elle n’a aucun rapport avec la première espèce qui est annnelle. Elle croît dans les Pyrénées; M. Robde l'a irouvée flenrie au mois d'août sur le sommet du mont Canigou: ses fleurs sont bleucs. 24.

\section{LONICERA E'TRUSCA. Santi, Viagg.}

I. Aloribus verticillatis terminalibus sessilibus, verticillis contiguis in capitulum congestis, foliis ovato-subrotundis pubescentibus, summis connato-perfoliatis.

Cetle espèce ressemble beaucoup au Lonicera caprifolium, mais celui-ci a ses feuil- 


\section{( 43 )}

les très-glabres des deux côtés et jamais pubescentes; ses fleurs forment des verticilles un peu écartés et non réunis en tête. Le chèvre-feuille d'Etrurie croít dans le pays de Gênes et la Toscane, d'où MI. Bertoloni et Savi me l'ont envoyé ; je l'ai aussi reçu du Valais par M. Schleicher : ses fleurs sont d'un blanc jaunâtre à l'intérieur, purpurines à l'extérieur; et paroissent en mai et juin. 古.

VERBASGUM MONSPESSULANUM, Pers., Synop. I, p. 215.

$V$. foliis ovato-lanceolatis petiolatis subtics pubescentibus suprà glabriusculis profundè dentatis quasi sinuatis, floribus spicatis, calycibus tomentosis.

Celte plante a été trouvée dans les environs de Montpellier, par M. Thibaud; je l'ai vue dans l'herbier de M. Richard. of'?

VERBASCUM MIXTUM. Decand. - Lois., Fl. Gall. I32.

Cette plante n'avoit été observée que par M. Ramond, dans le département des. HautesPyrénées; je l'ai trouvée cette année, au Bois de Boulogne près de Paris; elle fleurit en juillet et août. ठే? 


\section{(44) \\ DATURA TATUla. Lin., Sp. 256.}

D. pericarpiis ovatis crectis spinosissimis, foliis sinuato angulatis.

Cette plante exotique, dont le pays natal n'est pas bien conuu, paroît s'être naturalisée dans quelques parties des départemens méridionaux. M. Requien l'a trouvée trèsabondante au pont du Gard, mêlée avec le Datura stramonium, dont elle ne differe que parce qu'elle s'élève davantage et parce que les épines de ses capsules sont plus nombreuses, plus longues ct plus minces. Ses fleurs sont d'un violet bleuâtre; elles se succèdent les unes aux autres depuis le mois de juillet jusqu'en octobre. ( $($ ).

HERNIARIA GLABRA. Lin. - Lois., Fl. Gall. 143.

Cette plante n'est point annuelle comme tous les Botanistes l'ont cru jusqu'à présent; l'erreur vient de ce qu'elle croît fréquemment dans les champs cultivés, où ses racines périssent tous les ans lorsqu'on laboure les terres; mais lorsqu'elle se trouve abandonnée à la nature dans un terrain non cultivé, sa racine se conserve et pousse chaque année de nouvelles tiges; quelques-unes de celles- 


\section{( 45 )}

ci prennent même souvent dans leur partie inférieure une consistance dure et ligneuse. C'est ce que j'ai reconnu dans des échantillons recueillis par M. Artaud, dans la Crau près d'Arles : ces échantillons à racines ct tiges ligneuses m'ont d'ailleurs paru avoir absolument les mêmes caractères que ceux à tiges et racines annuelles que ¡avois des environs de Paris et d'autres pays, ce qui me porte à croire que les deux plantes ne forment qu'une seule et même espèce.

ERYNGIUM ALPINUM. Lin, - Lois., F! Gall. I53.

M. Requien m'a communiqué une variété de cette espèce, dont les fleurs et les involucres sont blanchâtres au lieu d'ètre d'un bleu améthyste; il l'a recueillie sur le col de Larche, dans les Alpes de la Haute-Provence.

BUPLEVRUM ROTUNDIFOLIUM. Lin. Lois., Fl. Gall. 155.

Cette plante offre une variété singulière, dont les feuilles sont trois fois plus longues que larges, dont les fleurs sont a'un jaune. foncé et même orangé, avec leur involucre plus ou moins coloré en jaune. Cette variété 


\section{( 46$)$}

a été trouvée dans les champs en Provence, par M. G. Robert, aux environs de Nice, par M. Perret, et près de Poitiers par M. Desvaux.

\section{LASERPITIUM AQUILEGIFOLIUM. Jacq.,} Fl. Aust. 2 , tab. 147 . Willd., Sp. I, p. 1415.

L. foliis supradecompositis, foliolis obtusis lobatis basi ovalis, fructibus orato-oblongis compressis.

Cette plante est indiquée par M. Decandolle, dans les Pyrénées, près de Gavernie, et dans les Cévennes: elle fleurit 'en juin; ses fleurs sont blanches. 2 .

SIUM SICULUM. Lin., Sp. 362. Jacq. , Hort. 2 , 'ab. r33. Desf., Fl. Ail. r, p. 256.

S. foliis radicalibus ternatis, caulinis bipinnatis. Lin.

M. Lasalle a trouvé cette plante à Bonifacio en Corse, et en a envoyé des échantillons à M. Desfontaines. 24.

SESELI VERTIGILlATUM. Desf., Atl. I,

$$
\text { p. } 260 .
$$

S. foliolis filiformibus, radicalibus subverticillatis brevioribus, umbelunlis distinctis, 


\section{( 47 )}

radiis centralibus brevissimis. Desf. Anmi Matthioli. Dalech., Hist. 6g5, cum icone.

Cette plante a été trouvée à Bonifacio, dans l'ile de Corse, par M. Lasalle, qui en a envoyé des échantillons à M. Desfontaines.

\section{PIMPINELLA CANESCENS. N. tab. 4.}

P. caule foliisque pinnatis pulescentibus, foliolis cuneiformibus lobatis apice dentatis, umbellá 4-7-fidá, fructibus hirsubie canescentibus. P. saxifiagai $\%$ Lois., H. Gall. 177. P. Lragium. Vill., Danph. 2, pag. 6u6. Tragium alterum Dioscoridis. Colum., Phyt. 75, (benè quoad descriptionem, male quoad iconem).

Toule cette plante est chargée de poils courts plus ou moins serrés, qui, lorsqu'ils sont abondans, lui donnent le même aspect que si elle étoit converie d'une poussière glauque et même blanchâtre; ces poils sont très-serrés sur les fruits et les rendent tout blancs. Je dois cetie nouvelle espece à M. Suffren qui l'a trouvée a Saint-Remi et at pied du Mont Venloux, oi elle fleurit au mois de juillet : ses fleurs sont bianches. Ello avoit doja été recueillie par M. Villars en Dauphiné, et par Commerson dans les en. virons de Montpellier, aux Capouladoux, 


\section{( 48 )}

an Vigan, à Meyrueis, d'après les échantillons que jai vus dans l'herbier de M. de Jussieu. $2 \%$.

\section{PIMPINELLA HISPIDA. N.}

P. caule foliisque pinnatis subpubescentibus, foliolis inferioribus subrotundis incisis dentatis, superioribus linearibus, umbellâ I520-fidâ, fructibus hispidis.

Cette plante est très-différente de la précédente; ses folioles sont plus arrondies, beaucoup moins cunéiformes; les poils courts dont elles sont couverles, ainsi que la tige, ne les rendent ni glauques ni blanchâtres; elles restent d'un vert foncé. La tige s'élève depuis un pied jusqu'à un pied et demi; elle est garnie de fenilles dont les inférieures ont leur's folioles arrondies, et les supérieures les ont linéaires. L'ombelle est à quinze ou vingt rayons, et les fruits sont hérissés de poils courts, roides, mais qui u'ont nullement l'aspect d'une poussière blanchâtre. M. G. Robert a découvert cette espèce daus les haies aux environs de Toulon, où elle fleurit en juillet; ses fleurs sont blanches. $\hat{\delta}$ ?

\section{STATIGE GLOBULARI EFOLIA. Desf., Atl. I, p. 274.}

S. foliis obovato-lanceolatis acuminatis 


\section{(49)}

margine membranaceis subundulatis, cusule erecto subdichotomo paniculato, racemis secundis terminalibus, floribus laxiusculis. Limonium medium, globularice folio, majus et minus. Barr., Ic. 7933, 794 .

Cette plante a été recueillie par. MMr. Artaud et Suffren, dans la Camargue aux environs d'Arles, et par M. Requien à Ceite. Ses fleurs sont bleues; elles paroissent en août et septembre. 24 .

\section{STATICE FERULACEA. Lin., Sp. 396.}

S. caule tereti paniculato, ramis ramosissimis, ramulis inferioribus sterilibus imbicatis squamis membranaceis apice piliferis, floribus secundis imbricatis. Limonium ferulaceo folio. Moris., Hist. 3, s. I5, t. r, f. 23.

Cette plante a été trouvée par M. Rohde, a l'île Sainte-Lucie, dans les environs de Narbonne: elle fleurit an mois d'août; ses fleurs sont jaunes selon Linné, elles me paroissent avoir été rougeàtres dans les échantillons que j’ai dans mon herbier. 2 .

LINUM VISCOSUM. Lin., Sp. 398. Bertol., Pl. Gen. 47.

L. caule recto, foliis lanceolatis tri-quinque nerviisve subpubescentibus calycibusque acu- 


\section{( 50$)$}

minatis maroine ciliato-glandulosis, ramis floriferis subdichotomis, floribus pedunculatis secundis. L. sylvestre. Scop., Carn. I, p. 229 , t. I r.

Cette plante m’a été envoyée des environs de Turin, par M. Balbis, sons le nom de Linum hirsutum; ce qui me donne lieu de soupconner que cette dernière espéce, indi.quéc aux environs de Nice par Allioni, n'est peut-être que la même plante que jai reçue de M. Balbis. Si cela étoit ainsi, il faudroit retrancher de la Flore le Linum hirsutum. Le Lin visqueux est aussi indiqué aux environs de Gènes, par M. Bertoloni; ses fleurs sont d'in violet tirant sur la couleur lie-devin. 4 .

Drosera ANGLiCa. Huds. - Lois., Fl. Gall. I87.

Celte plante, indiquée seulement dans le Palatinat et aux envirous de Mayence, a élé retrouvée par M. Castan dans les marais de Bonneville eu Savoie.

CR ASSUL A CESPITOSA. Cavan., Ic. I, p. 5o, t. 69 , f. 2 . Willd., Sp. x, p. 1560. Balb., Miscel. Alt. 13.

C. caule subdiviso, foliis globoso-ovatis in- 


\section{(5r)}

bricatis, cymá sübtrifloria , floribus sessilibus.

Cette plante a été trouvée par M. Risso entre Nice et Antibes. (.).

\section{HEX A NDR IE.}

NARCISSUS GOUANI. Roth., Catal. Bot. I, p. 32. Lois., Fl. Gall. 723. Red., Lil. tom. 4 , t. 220. $N$. incomparabilis. Curt., Mag. t. I2 1. Willd., Sp. 2, p. 35. N. odorus. Gouan, 11l. 23 , 11. 4. Lam., Dict. 4, p. 425.

Cette espèce, quoique très-distincte de toutes ses congénères, a été confondue par la plupart des Botanistes modernes, tantôt avec le Narcissus odorus, dont elle diffère beaucoup, et principalement par ses feuilles planes et glauques, tantôt avec le Narcissus pseudonarcissus avec lequel eile ne doit pas ètre confondue à cause de la longueur de son nectaire moitié plus court que les pétales. Elle est indiquée senlement aux environs de Montpellier; MM. Audibert et Requien l'ont trouvée à Tarascon et à Avignon, et M. Bertoloni me l'a envoyée dia pays de Gènes. 


\section{$(53)$}

NAPCISSUS BIFLORUS. Curt., Mag. t. 197. Engl. Bot. t. 276. Smith., Fl. Brit. 354 . Willd., Sp. 2, p. 3g.

2N. foliis planiusculis glaucescentibus acuté carinatis, scapo subcylindrico ancipiti bifloro, nectario rotato bresissimo membranaceo crenulato prorsis luteo.

Ce Narcisse a été trouvé aux environs de Genève, par M. Casıan, et aux îles d'Houat et d'Hedic sur les côtes de Bretagne, par M. Bonnemaison. Il fleurit au mois d'avril; ses pétales sont blancs et le nectaire est tout jaune. $2 \%$.

\section{NARGISSUS PATULUS. N.}

N. foliis glaucescentibus planiusculis subcanaliculatis patulis, scapo subcylindrico 2-4-floro (rariùs 5-6-floro), nectario cyathiforme subintegerrimo aureo petalis niveis alternè latioribus dimidiò breviore. N. orientalis. Lin., Mant. 62 ? N. latifolius simplex medio luteus tertius. Clus., Hist. 154 .

Ce Narcisse est une fois plus petit dans toutes ses parties que le Narcisstus tazetta, et il fleurit plus tard; ses fleurs ne paroissent 


\section{( 53 )}

qu'à la fin d'avril, les pétales sont d'un blanc de neige et le nectaire d'un jaune doré. Il a été trouvé aux îles d'Hières par M. G. Robert. 2 .

\section{NARCISSUS POLYANTHOS. N.}

N. foliis planiusculis viridibus, scapo subcylindrico ancipiti 8-20-floro, nectario cyathiforne subiniegerrimo petalis ovatis alternè latioribus triplò breviore. N. latifolius, simpiici flore prorsius albo, primus et securudus. Clus., Hist. 155.

Cette espèce, longtemps confondue avec le Narcissus tazetta en est très-distincte par ses feuilles larges, vertes et non glauques, par sa tige chargée d'une plus grande quantité de fleurs, et enfin par la couleur de cellesci. Les pétales sont blancs dans l'une et l'autre plante, mais le nectaire dans le Narcisse multiflore esî d'un jaune très-pâle, presque blanc, et il devient même tout-à-fait blanc quand. la floraison s'avance; dans le Narcisse tazette au contraire, le nectaire toujours jaune devient encore plus foncé à mesure que la fleur est plus éloignée du moment où elle s'est épanouie. Le Narcisse muitillore a été trouvé par M. G. Robert aux environs de Toulon, où il fleurit dans les premiers jours de mars, 


\section{( $\left.5 \frac{1}{4}\right)$}

quelquefois a la fin de février. Le Narcisse tazette fleurit près d'un mois plus tard. $2 \%$.

\section{NARCISSUS NIVEUS. $\mathrm{N}$.}

N. scapo depresso ancipiti 6-ro-floro, foliis planiusculis viridibus, nectario campanulato crenato petalis quadruplò bresiore. N. totus albus minor stellatus. Barr., Ic. 916 ?

Cette espèce est voisine de la précédente, mais elle s'en distingue à ses fleurs d'une blancheur parfaite, dont les" pétales sont plus alongés tandis que le nectaire est plus court : leur odeur est très-suave, elle ressemble beancoup à celle du jasmin. J'ai trouvé celte espèce en fleurs, au mois d'avril, dans le jardin d'un amateur qui m'a assuré l'avoir reçue du Midi de la France. $2 f$.

\section{ALLIUM CARNEUM. Bertol., PI. Gen. 5 I.}

Celte plante est une variété bulbifère de l'Allium roseum; elle est très-commune dans le pays de Gênes, à Nice et en Provence; je l'ai recue de MM. Bertoloni, Rohde et G. Robert. 


\section{ALLIUM ACUTIF́LORUM. N.}

1. caule planifolio umbellifero, umbellá subglobosâ, petalis lanceolatis acutis, staminibus tricuspidalis, filamentis margine ciliatis.

Tige cylindrique, d'un pied de haut ou un peu plus, engainée par les feuilles dans son quart inférieur, mue dans le reste de son étenduc. Feuilles linéaires, longues de six pouces, larges de deux lignes, très-glabres. Spathe d'une seule pièce, à peu près de la Jongueur des fleurs. Ombelle composée de quarante rayons et au-delà, formant une tête presque globuleuse; chaque rayon ou pédicelle de six à huit lignes de long. CoInlle de six pétales lancéolés, aigus, d’une couleur purpurine très-claire, avec une nerrure moyenne et longiudinale plus foncée. Etamines à trois pointes, égales à la longueur des pétales; filamens cilies en leurs bords. Cette plante fleurit au mois de juin; elle a été découverte par M. Perret 'dans le Piémont, à Tende et au Mont Gros. 24.

ALLIUM MAGICUM. Lin., Sp. 424. SaintAmans, Mém. Soc. d'Agric. d'Aggen I, p. 79 et suiv.

1. caule planifolio bulbifero, foliis lanceolatis canaliculatis, folio interiori fili- 


\section{( 56$)$}

formi basi caulem vaginante apice butbifero. A. speciosum. Cyril., Plant. rar. Neapol. fasc. 2 , p. 35 ?

Cette plante fruclifie dans les mois d'avrif et de mai; son ombelle est dépourvue de lleurs et ne porte que des bulbes: je l'indique d'après M. Saint-Amans qui l'a trouvée dans les environs d'Agen; je l'ai vue dans le jardin botanique de Bordeaux. 2 .

ALLUUM ALBUM. Santi, Viag. al mont. 35z, tav. 7. ex Bertol., Pl. Gen. 5 I.

A. scapo nudo obsolete triquetro, foliis radicalibus lineari-lanceolatis canaliculatis carinatis, umbellâ capsuliferấ, petalis ovatis, staminibus simplicibus.

Cetic espèce est bien distincte de l'Alliums triquetrum, dont la tige est plus décidemment triangulaire, dont les pétales sont lancéolés traversés par une nervure longitudinale roussâtre, et dont la spathe s'ouvre en deux pièces. L'Ail à fleur blanche est commun dans le pays de Gênes, d'où je l'ai reçu de M. Bertoloni; M. G. Robert m'en a aussi envoyé des bulbes des environs de Toulon: il fleurit au mois d'avil. 4 . 


\section{$(57)$}

\section{TULIPA CELSIANA. Red., Lil, I, t. 38.}

T. caule unifloro glabro, foliis lanceolatolinearibus canaliculatis, flore erecto luteo, petalis glabris.

Cette espèce diffère de la Tulipa sy. vestris avec laquelle elle a été confondue; sa tige est toujours unillore, pendant que celle de cette dernière porte ordinairement deux fleurs et quelquefois trois. M. Decandolle dit qu'elle est commune dans les prés du Languedoc; M. G. Robert me l'a envoyée des environs de Toulon. Sa fleur est jaune, elie paroît de très-bonne heure au printemps. 2 .

SCILLA CAMPANULATA. Ait., Kew. I, p. 144. Curt., Bot. Mag. 4. t. I 28. Willd., Sp. 2. p. I 28.

S. bulbo solido subdeformi, foliis lanceolatolinearibus, racemo multifloro oblongo cequali subconico recto, corollis campanulatis erectiusculis, bracteis bipartitis pedunculo longioribus.

Cette plante est indiquée dans les prés en Toscane, par M. Savi; ses fletirs bleues paroissent en mars et avril. 4.

L'Hyacinthus non scriptus Lin., et l'Hyacinthus patulus Dest., doivent être placés dans 


\section{$(58)$}

lo gemre Scilla, comme l'a fait M. Decandolle, ces deux plantes ayant plos grand rapport avec la Scalla campanulau, et ne pouvant mème s'en distinguer qu'avec peine. Voici les différences qui mont paru les plus sensibles entre ces trois espèces: la Scilla campanulata a sonvent sa bulbe alongée, un peu diforme; ses feuilles sont lancéolées-linéaires, redressées; ses fleurs, presque droites, également disposées de tous côtés, forment une grappe cosique, et leurs pétales sont évasés en cloche. L'Hyacinthus patulus a sa bulbe arrondie; ses fleurs forment une grappe disposée comme dans la première, mais les pétales sont droits, non évasés, et les feuilles un peu plus étroitcs sont étalées sur la terre. L'Hyacinthus non scriptus a ses lleurs panchées du même cồé; disposées en grappe unilatérale, léģèrement courbée en are; les pétales sont roulés en dehors à leur sommet, droits et rapprochés en tube dans le reste de leur étendue; entin les feuilles sont étroites, tont-à-fait linéaires.

\section{ORNITHOGALUM ARABICUM.Lin.- Lois., Fl. Gall. 20 I.}

HYACINTHUS ORIENTALIS. Lin. - Lois., Fl. Gall. $72\{$.

J'ai indiqué la première de ces deux plantes en Corse, où clle a été trouvée par 


\section{$(59)$}

M. G. Robert, et la seconde aux euvirons de Toulon, ou elle a été observée par le même: M. Suffren les a recueillies touttes les deux à Nice, il y a vingt ans.

HYACINTHUS SEROTINUS. Lin. - Lois., Fl. Gall. 206.

MM. Léon-Dufour et Audibert ont trouvé cette plante aux environs de Beaucaire.

\section{HYACINTHUS ROMANUS. Lin. Mant. 224.}

H. floribus racemosis, corollis campanulatis semisexfidis, staminibus monadelphlis. H. comosus albus cum cceruleis staminibus. J. B., Hist. 2, lib. 19, 1. 584. Bellevalia operculata. Lapeyr., Journ. Phys. 67. p. 425-427, cum icone.

Cette plante est commune, selon. M. de Lapeyrouse, dans les prairies humides des vallées des Pyrénées et aux environs de Toulouse; elle m’a été communiquée par M. Flugge qui l'a aussi trouvée près de cette ville : ses fleurs, qui sont d'un blanc sale, paroisseni au mois de mai. 2 . 


\section{(6o) \\ JUNCUS GERARDI. N.}

I. (setaceus) foliis linearibus canaliculatis, paniculi lerminuli, capsulis oblongis, folio terninali paniculam longè superante. Gerard, ined. Gramen junceum milii paniculâ. Barr., Ic. 747, f. 2.

Celte plante croît en Provence, dans les prés sur le bord des ruisseaux; elle diffère du .Juncus bulbosus, selon M. Gérard qui m'en a communiqué la description, par sa tige pius élevée, par sa panicule plus longue, par ses ombelles plus roides, par ses fleurs pius petites, par'ses capsules plus longues et plus étroites, et enfiu par la feuille florale-beaucoup pius longue que la panicule. $2 \dot{.}$

JUNGUS FLAVESGENS. Host., Gram. Aust. 3, p. 62 , t. 94 .

J. foliis angustissimis, corymbo subsimplici paucifloro, pedicellis unifloris, petalis sublanceolatis acutis capsulam élongato-acucam subarquantibus. Luzula Hostii. Desv., Jouru. Bot. I, p. 140, t. 6 , f. I.

Cette plante a été trouvée au Mont Canigou dans les Pyrénées orientales, par M. Rohde: elle fleurit en juillet. $\mathcal{F}$. 
JUNCUS GLABRATUS. Hopp., Herb. viv. cent. 3, Rostk., Monogr. Junc. 27 .

J. culmo foliis vaginisque glaberrimis, corymbo decomposito divaricato, pedicellis 2-4-floris breviter pedunculatis, capsulá fuscâ calycibus subcequali. $J$. intermedius. Host. Gram. 3, p. 65, t. 99. J. montanus $\%$. Lam., Dict. 3, p. 273. Luzula glabrata. Desv., Journ. Bot. I, p. r43, t. 5, f. 3.

J'ai recu ce Jonc des montagues de l'Auvergue. 26 .

JUNCUS PARVIFLORUS. Ehrh., Beitr. 6, p. I3g. Rostk. Monogr. Junc. 26, t. I, f. I.

J. culmo elato, foliis latis glabris, vaginis fauce pilosis, corymbo decomposito erecto, floribus solitariis breviter pedicellatis, capsulá oblongấ calycibus acutis breviori. $J$. pilosus \%. Lin., Sp. 468. Luzula parviflora. Desv., Journ. Bot. I, p. 144 .

Cette plante croît dans les montagnes aux environs de Genève; je l'ai reçue de M. Castain. 26. 


\section{$(62)$ \\ HEPTANDRIE.}

TRIENTALIS EUROPÆA. Lin.—Lois., Fl. Gall. 2 Ig.

Ce n'étoit que d'après Dalechamp qui avoit observé celie plante en Dauphiné, que je l'avois indiquée dans ma Flore; M. Lejeune me l'a enroyée de Spa et de Malmedy, département de l'Ourthe, où elle est très-commune.

\section{OCTANDRIE.}

CHLORA SESSILIFOLIA. Desv., Mém. Soc. Scien. Phys. 1807, p. 74 , Pl. 3, f. 2.

C. caule filiformi paucifloro, foliis sessilibus ovato-lanceolatis, caly'ce monophy-llo 6-7-fido, corollis calyce brevioribus. Desv. Centaurium luteum novum. Colum., Ecphras. 2, p. 78. C'entaurium pusillum lu-e Lezm. Bauh., Pin. 278. Tourn. Inst. 123.

Celte plante est indiquée par M. Desvaux, dans les lieux sablonneux, près de la Rochelle; je l'ai vue dans l'herbier de M. Merat, yenant des cnvirons de Narbonne. ( $)$. 


\section{(63)}

\section{ERICA UMBELLIFERA. N.}

E. antheris muticis exsertis, corollis ovatosubglobosis umbellatis, stylo exserto, foliis ternis calycibusque margine ciliatis. pedicellis pubescentiöus. Species nova? Erica umbellata. Lin., Sp. 5ог?

Celte plante a été trouvée par M. Lamouroux dans les environs de Perpignon; sez fleurs sont parpurines, elles paroissent en juillet et août. 5 .

ELATINE HEXANDR A. Decand, Ic. rar. fasc. $r$, pag. 14 , tab. $43, \mathrm{f} . \mathrm{r}$.

E. caule prostrato ramoso dichotomo, foliis ovato-oblongis oppositis, florcbus axullaribus.s alternis tripetalis hexandris. E. hydropiper $\beta$, Lois., Fl. Gall. 23r. E. triandra. Hoffm. Germ. I40? Alsinastrum serjullifolium, flore roseo tripetalo. Vaill., Bot. Par. 5, tab. 2, f. I. Birolia paludosa. Bellardi, Mém. acad. Tur., année 1808 , Descript. et icon.

Cette espèce se trouve dans les lieux inondés, et sur le bord des mares anx envirous de Paris; M. Decandolle l'indique aux cnvirons du Mans et de Nantes; M. Perret l'a 


\section{(64)}

trouvée dans les rizières du Piémont, et je l'ai recue de M. Bellardi qui me l'a envoyéc avec la figure qu'il vient d'en publier. L'Ela. tine hexandra a les fleurs blanches, roses en leur bord; elle fleurit en juillet et août. $(\cdot)$.

\section{E C A N D R I E.}

ANDROMEDA POLIFOLIA. Lin. - Lois., Fl. Gall. 237 .

Cette plante n'étoit indiquée qu'aux environs de Rouen; elle a été retrouvée au. mont Jura par M. Delaroche; dans les Vosges par M. Mougeot, et aux environs de Liége par M. Lejeune.

SAXIFrAGA CERNUA. Lin., Sp. 577. Fl. Dan. tab. 22.

S. foliis radicalibus et caulinis inferioribus glabris palmatis, superioribus ovato-lanceolatis, caule subsimplici bulbifero, flore terminali cernuo. S. foliis palmatis, caule simplici unifloro, Lin., Fl. Lapp. 172, tab.2, f. 4 .

- Cette Saxifrage se trouve au Grand-SaintBernard, et dans les Alpes du Valais; sa fleur est blanche. 2. 
SAPONARIA CÆSPITOSA. Decand., Voyag. Bot. 78 .

S. Calycibus cylindricis villosis, petalis apice emarginatis, foliis glabris lineari-lanceolatis subradicalibus, caulibus subnudis apice floriferis. Decand.

Cette plante croît dans les Pyrénées, sur les pelouses sèches, et sur les rochers des vallécs de Gavarnie et de Specieris; je ne l'ai pas vue, je l'indique d'après M. Decandolle qui l'a découverte.

\section{SAPONARIA ORIENTALIS. Lin., Sp. 585.}

S. caule dichotomo patulo, folius lanceolatolinearibus, calycibus cylindricis pilosis. Lychnis orientalis annua supina, flore minimo purpurascente. Tourn., Cor. 24. Dill. , Elth. 205 , tab. 167 , f. 204.

M. Gonan a trouvé cette espèce à Collioure près de Perpignan; ses fleurs sout rougeâtres. $($ )

\section{DIANTHUS NEGLECTUS. N.}

D. foliis linearibus, caulibus unifloris, squamis calycinis ovato-lanceolatis acutisimis tubum subaquantibus, petalis denticulatis pubescentibus. D. alpinus Démonst. Elém. de Bot. vol. 1, p. 55, tab. 161, (non Lin.). All. Fl. Ped. n. 1556. Balb., Misc. alt. 17. 


\section{(66)}

D. Glacialis. Haenke, in Jacq. Collet. 2, p. 84 , ex Willd., S.p. 2, pag. 683.

Cette espèce me paroît suffisamment distincte par la forme de ses feuilles étroites et linéaires, du Dianthus alpinus avec lequel elle a été confondue. Celui-ci a les feuilles ovalesoblongues, obtuses, une fois plus courtes et une fois plus larges que la plante dont il est ici question. Le Dianthus neglectus croit dans les Alpes, je l'ai reçu des environs de Seyne et de Barcelonette, par MM. Clarion et Requien; du Mont-Cenis par M. Perret; ses fleurs sont d'un rouge vineux; elles paroissent en juillet et août. $\mathcal{~}$.

DIANTHUS SUBACAULIS. Tab. 6 , fig. $I$. Vill. Dauph. 3, pag. 597 .

D. caulibus foliisque lineari-lanceolatis radicalibus margine scabris ccespitosis, scapis foliis vix longioribus unifloris, squamis calycinis quaternis ovatis mucronatis tubo dimidiò brevioribus, petalis integriusculis.

Les tiges et les feuilles de cette plante sont ramassées en gazon; ses fleurs s'élèvent rarement sur un pédoncule de plus d'un ponce, et sont quelquefois presque sessiles au centre d'une rosette de feuilles. Leur's pétales sont 


\section{(67)}

glabres, entiers et d'un rouge vineux. Ce petit oeillet se trouve au mont Ventoux, où il fleurit en juillet, et d'où M. Requien me l'a envoyé. M. Villars l'indique aussi en Dauphiné, aux environs de Buis. 2f.

\section{SILENE LUSITANICA. Lin., Sp. 594.}

S. Hirsuta, floribus erectis solitariis lateralibus, petalis crenatis indivisis, fructibus divaricato-reflexis alternis. Viscago hirsuta lusitanica stellato flore. Dill., Elth. 420 , tab. 3r r, f. $40 \mathrm{r}$.

Cette plante croît au bois de Gramont près de Montpellier, où elle a été observée par M. Gouan.

\section{SILENE RUBELLA. Lin., Sp. 600.}

S. caule loevi erecto gracili superné dichotomo, foliis radicalitus obovato-oblongis hispidiusculis, caulinis lineari-lanceolatis glabriusculis, floribus longè pedunculatis in dichotomá caulis, calycibus subglobosis glabris decemvenosis. S. annulata. Thore, Chlor. Land. 173. S. inaperta. Decand., Fl. Fr. n. ${ }^{\circ} 4335$, (exclus. Synon. Linnceíet Dillenii). Viscago lusitanica, flore rubello vix conspicuo. Dill., Elth. 423 , tab. 314, f. 406 .

Cette plante a été trouvée aux environs de 


\section{(68)}

Dax par M. Thore; elle a été observée aux environs de Tarbes et de Bagnères par $M$. Ramond, et M.de Lamarck l'a recue de Brives dans le Limosin, par M. Latreille. Elle se trouve communément dans les champs de Lin, ce qui lui a fait donner par les habitans des Landes, où elle est très-abondante, le nom de Mari-lin, May-dou lin : ses fleurs sont rougeâtres, et paroissent en juin et juillet. (.).

SILENE VELUTINA. Pourret, in Desf. herb.

S. foliis inferioribus obovato-lanceolatis petiolatis, superioribus lanceolato linearibus sessilibus, omnibus cauleque ramoso et calycibus pubescentissimis, floribus lateralibus breviter pedunculatis confertis, petalis semibifidis.

Cette plante croit dans les fentes des rochers aux environs de Bonifacio en Corse, où elle a été trouvée par M. Lasalle, qui en a envoyé des échantillons à $M$. Desfontaines; ses fleurs sont blanchâtres. 2 .

\section{ARENARIA VISCIDA. Hall. fil.}

A. foliis ovatis acutis sessilibus, caulibus basi prostratis ramosisque, supernè erectiusculis subsimplicibus, corollis calyce hispido nervoso brevioribus.

Je soupconue que cette plante n'est qu'une 


\section{(69)}

variéte de l'Arenaria serpyllifolia, dont elle ne se distingue que par les nervures plus prononcées de ses feuilles, de ses calices, et par son extrême petitesse, car elle n'a que dix à quinze lignes de haut: ses fleurs sont blanches, opposées, axillaires et terminales. Je l'ai trouvée dans les sables aux environs de Bordeaux, elle fleurit en avril et mai. ( $)$.

ARENARIA SAXATILIS. Lois., Fl. Gall. 26r. (exclus. synon.).

ARENARIA SETACEA. Thuil., Fl. Par. 220.

Decand., Fl.Fr., n. ${ }^{\circ} 4429$. Lois., FI. Gall. 26r. A. heteromalla. Pers,, Synop. I, pag. 504 .

J'ai fait un double emploi en rapportant ces deux plantes dans ma Flore; la première doit ètre supprimée. Mon erreur vient de ce que Linné a rapporté à son Arenaria saxatilis, le synonyme de Vaillant (Alsine saxatilis et mulifflora capillaceo folio. Vaill., Bot. Par. 7 , (ab. 2, f. 3); mais comme Linné assigne à sa plante d'a voir les folioles calycinales obtuses; et que la plante de Vaillant, qui est bien la même que celle de MM. Thuillier, Decandolle, Persoon, et la mienne, les a aiguës, il est évident que le synonyme de Vaillant ne peut lui conveuir. Je crois d'ailleurs que ce syuonyme appartient à l'Arenaria setacea. 


\section{$(70)$}

Thuil., et non à l'Arenaria verna. Lin., comme l'a pensé M. Decandolle. La première plante se trouve seule à Fontainebleau, dans les mêmes lieux où Vaillant l'a indiquée, tandis que la seconde ne se trouve pas même aux environs de Paris.

COTYLEDON SEDOIDES. Decand., Voyag. Bot. 79 .

C. Folïs ovato-ollongis obtusis convexis imbricatis, caule subsimplici apice paucifloro, floribus campanulatis subsessilibus ultrà medium quinquefidis. Decand.

J'indicque cette plante d'après M. Decandolle qui l'a découverte dans les Pyrénées, où elle croît auprès des neiges, aux ports de Venasque et d'Oo.

\section{SEDUUM BREVIFOLIUM. Decand., Voyag.} Bot. 79 .

S. foliis oppositis ovatis obtusis brevibus crassis, caulibus glabris basi ramosis diffusis fructiculosis, floribus subcorymbosis.

M. Decandolle a découvert cette plante sur les rochers des Hautes-Pyrénées, où il dit qu'elle est commune; je la liens de M. Rohde qui l'a trouvée au mont Canigou : ses fleurs. 


\section{(7I)}

sont rougeâtres, elles se développent en juillet ct aoụt.

SEDUM AMPLEXICAULE. Decand., Voyag. Bot. 80.

S. foliis gracilibus teretibus acutis basi solutis et in memibranam amplexicaulem acutis, flaribus cymosis $6-7-$ petalis. Decand.

Cetre plante a été trouvée dans les Cevennes aux environs de Montpellier, par M. Bouchet; je l'ai reçue du mont Ventoux, par M. Requien: ses fleurs sout jaunes. $\mathscr{L}$.

SEDUM ANOPETALUM Decand,, Voyag. Bot. 80.

S. Roribus sparsis teretibus glaucis acutis basi salutis, cymá subquadrifidà, petalis 6-7 lanceolato-linearibus acutis rectis.

M. Rohde a recueilli celle plante aux environs de Tonlon, et $M$. Decandolle l'a trouvée à Carcassone : elle fleurit en juin et juillet; ses flemrs sont d'un blanc tirant sur le jaune. 2\%.

\section{SEDUM BOLONIENSE. N.}

S. radice repente, foliis sparsis subteretibus glabris obtusis basi solutis, cymâ trifidá: 


\section{$(72)$}

ramulis 6-1o floris, calycinis foliolis sub. cylindricis obtusis.

Racine rampante donnant naissance à plusieurs liges simples ou rameuses et un peu couchées à leur base, ensuite redressées. Feuilles cylindriques, glabres, obtuses, prolongées à leur base, très-rapprochées et comme imbriquées sur les tiges qui ne portent point de fleurs, un peu plus écartées sur celles qui sont fleuries. Tiges se divisant le plus communément dans leur partie supérieure en trois rameaux étalés en cime, et portant chacun six à dix fleurs éparses, presque sessiles, composées d'un calice de cinq folioles cylindriques, obtuses; les pétales en même nombre que les folioles du calice, sont de moitié plus longs que celui-ci, lancéolés et d'un jaune clair. J'ai donné à celte espèce que je crois nouvelle, le nom de Sedum Boloniense, d'après celui que porte un bois très-riche en plantes et très-fréquenté des Botanistes de Paris, celui de Boulogne, dans lequel jai trouvé ma plante en fleurs, au commencement $d u$ mois de juillet dernier. 2 .

LYCHNIS PYRENAICA. Bergeret, Fl. Pyr. L. foliis glaucis, radicalibus obovato-lanceolatis, caulinis sessilibus ovatis acutis, floribus subpaniculatis terminalibus.

- Cette plante a été découverte par M. Ber- 


\section{( 73 )}

geret, sur les rochers de la Vallée d'Aspe près de Notre-Dame de Sarrance, dans les Pyrénées occidentales. 4.

\section{LYCHNIS CORSICA. N.}

L. Caule erectiusculo ramoso subdichotomo, foliis lineari-lanceolatis glabris, pedunculis elongatis unifloris, petalis oblongis subemarginatis.

Tiges un peu couchées à leur base, ensuite redressées, rameuses, presque dichotomes, s'élevant à huit ou douze pouces. Feuilles linéaires-lancéolées, glabres, très-aiguës. Fleurs portées sur des pédoncules beancoup plus long; que les feuilles, les unes disposées dans les bifurcations des tiges, les autres terminales. Calices relevés de dix nervures bien prononcées. Pétales rougeâtres, oblongs, entiers ou légèrement échancrés. Cette plante a été découverte par M. G. Robert, dans les champs aux environs d'Ajaccio en Corse. 4.

\section{DODÉ A NDR IE.}

\section{LYTHRUM VIRGATUM. Lin. , Sp. $6\{2$.}

L. folius suboppositis lanceolatis glaberrimis, caule supernè ramoso, floribus pedicellatis axillaribus subglomeratis, in racemum. virgatum dispositis. $L$, custriacum. Jacri., 


\section{(74)}

II. Aust., tab. 7. Lysimachia rubra secunda seu minor. Clus., Hist. LII.

Cette plante a été trouvée par M. Lejeune, à Theux anx environs de Liége : ses flcurs sont purpurines, elles paroissent eri juin et juillet. 22 .

\section{LYTHRUM NUMMULARIFFOLIUM. N.}

L. foliis obovato-subrotundis obtusis, caulinis oppositis, rameis nonnullis alternis, Alortbus axillaribus solitariis, calycibus 8 dentatis. Salicaria minima lusitanica nummularice folio. Tourn., Inst. 264, (certè ex herb.). an. Lythrum (nummularicefolia). foliis alternis subrotundis mucronatis, superioribus ovatis acutis, floribus axillaribus solitariis. Pers., Synop. 2, p. 8?

La plante que je rapporte ici a été trouvée dans les lieux humides en Corse, par M. Lasalle, qui en a envoyé des échantillons à $M$. Désfontaines. Ces échantillons comparés avec ceux de l'herbier de Tournefort leur sont bien semblables, ils sont seulement un peu plus grands, ayant huit à dix pouces, tandis que ceux de cet auteur n'en ont que trois à cinq. Quoique M. Persoon ait aussi rapporté le synonyme de Tourneforl à sa plante, je doute cependant qu'elle soit la mème que la mienne, à cause des feuilles toutes alternes, 


\section{$(75)$}

mucronées ou aiguës qu'il assigne à son espèce, qui a été recueillie dans les lieux humides à Lacray, dans les environs de Dijon, par M. Vallot, professeur de botanigue en cette dernière ville. Les fleurs de la plante de Corse sont rougeâtres, Jes pétales netits et très-caducs; la lige est garnic de rameaux opposés, et paroît avoir été couchée à la base. $(\cdot$.

\section{EUPHORBIA ROTUNDIFOLIA. N., tab. 5, f. I.}

E. caule basi ramoso patulo, foliis sparsis subsessilibus involucrisque subrotundis, involucellis cordato-reniformilus, umbellâ 2-4-fidà bifidâ, petalis lunatis, eapsulis. glabris.

Celte plante a de grands rapports avec l'Euphorbia peplus, mais elle me paroît mériter d'en être distinguée, soit comme variété remarquable, soit comme espèce. Elle en diffère en effet par sa taille deux fois plírs pe. tite, par ses feuilles arrondies, presque orbiculaires ei à peine pétinlées, par ses pétales rougeâtres, et parce qu'clle fleurit dès les mois de mars et d'arril, tandis que l'Euphorbia peplus ne fructifie pas avant le mois de juin ou de juillet; enfin elle croît sur le bord des chemins daus les lieux incultes, et l'autre 


\section{$\left(7^{6}\right)$}

espèce ne se rencontre que dans les jardius et les lienx cultivés. Cette plante a été trouvée aux environs de Toulon, par M. G. Robert. (C).

\section{EUPHORBIA OBSCURA. N., tab. 5, f. 2.}

E. foliis inferioribus retusis, superioribus involucrisque obovato-lanceolatis acutis, involucellis ovatis acuminatis, umbellâ 3-5-fidì bificlâ, petalis integriusculis obsolete lunatis, capsulis lcevibus glabris.

Cette plante a beancoup de rapport avec les Euphorbia peplus et falcata, même avec l'Euphorbia terracina: elle se distingue de la première par ses feuilles ot ses involucres aigus ou acuminés, et par ses pétales rougeàtres, entiers ou à peine lunulés; de la seconde parce que celle-ci a ses feuilles et ses involncres beaucoup plus aigus, ses pétales en forme de croisiant ou à deux cornes, et ses involucelles presque cordiformes; eufin elle se distingue de la troisième par ses capsules très-lisses et nou pas rudes sur les angles. Les graines sont sillonnées transversalement dans ces quatre espèces et ne peuvent servir à les faire distinguer. L'Eupborbe obseure a été trouvé par M. Suffren, dans les champs en Provence, aux cnvirons de Colignac et de Draguignan; M. Requien l'a 


\section{(77)}

aussi recueilli près d'Avignon : il lleurit en juin. $(\odot$.

EUPHORBIA BIUMBELLATA. Poir., Voy.2, pag. 174. Pers., Synop. 2, pag. 17.

E. foliis inferioribus linearibus obusiusculis mucronatis, superioribus involucrisque primariis lanceolatis, secundariis ovatis, involucellis subcordato-reniformilus, umbellâ duplici 8-12-fudâ, petalis lunatis, cap. sulis glabris.

Cet Euphorbe me paroît une espèce bien distincte et bien caractériste par ses deux ombelles disposées l'une au dessus de l'autre; car si l'ombelle inférieure manque quelque-fois, son involucre ne manque jamais et occupe toujours la mème place que s'il étoit accompagné des rayons de l'ombelle. M. G. Pobert a trouvé cette plante dans les champs aux environs de Toulon, où elle fleurit en mai; M. Persoon l'indique à Montpellier. ( $)$.

EUPHORBIA SAXATILiS. Jacr., FI. Aust., tab.345. Willd., Sp. 2 , pag. 912.

E. è basi ramosa, caulibus adscendentibus simplicibus, folies oblongis acuizs, involucris ovato-lanceolatis, involucellis subrotundis, umbellâa 6-8-fudâ subbifidâ, 


\section{$\left(7^{8}\right)$}

petalis integriusculis obsoletè lunatis, capsulis seminilusque lcevibus.

Cette plante n'a que deux à trois pouces de haut, et c'est surtout ce qui la distingue de l'Eupliorbia gerardiana avec laquelle elle a d'ailleurs de grands rapports; elle a été trouvée par MM. Suffren et Requien au sommet du mont Ventoux; elle fleurit en juin et juillet. 4 .

\section{EUPHORBIA GRACILIS. Lois.}

Celle espèce, que j’ai décrite page 728 de ma Flore, est un double emploi de l'Euphorbia leptophylla. Vill., Dauph. 3 pag. 825 , que j’ai d'ailleurs mentionné dans le même ouvrage, page 230 . J'ai commis cette erreur parce que n'ayant pas vu la plante de M. Villars, je n'ai pu la reconnoître sur la description trop incomplète qui a été donnée par cet anteur; il me semble surtont que l'expression (foliis lineari-gramineis) qu'il a employée pour caracteriser les feuilles, ne convient nullement à la plante dont il est ici question. Outre la figure de Matthiole qui la représente assez bien, mais uir peu trop rameuse, on peut lui rapporter le 'Tithymalus leptophyllos Riathioli. Dalech., Hist. 1645. Quant à celle de Fuchsius, page 8 r 2 , elle ne lui convient pas du tout. 


\section{(79) \\ ICOSANDRIE.}

PYRUS SALICIFOLIA. Pall., I, t. 3, pag. 73 , t. N. f. 3. Pall., Ross. r, pag. 20, t. 9. Lin., Supp. 255. Balb., Misc. alt. 18.

P. foliis lanceolato-linearibus integerrimis, suprà villoso-canescentibus, sibtiss albotomentosis, floribus pedunculatis subco. rymbosis, pedunculis axillaribus.

Cet arbre est indiqué en Provence, dans les haies et les vignes, entre Vidauban et le Luc, par M. Balbis, qui me l'a communiqué. Ses fleurs sont blanches; elles paroissent en mars et avril. 5 .

ROSA MAIALIS. Retz., Obs. 3, pag. 33. Reignier, Act. Soc. Laus. I, pag. 68, tab. 14 .

R. germinibus globosis pedunculisque glabris, calycinis laciniis integris, foliolis ovato-oblongis subtis glaucescentibus pubescentibusque, aculeis stipularibus subgeminis.

Celte espèce, très-différente de la Rosa cimamomea, avec laquelle plusicurs aiteurs l'ont confondue, est cultivée dans tous les jardins, sous le nom de Rose de mai; ses 


\section{( 80 )}

fleur's, d'un rouge vineux, paroissent à la fin de ce mois et en juin : elle croît spontanément dans les départemens méridionaux. $\hbar$.

\section{ROSA GLAUCA. Vill., ined.}

R. germinibus ovatis pedunculisque glabris, calycinis laciniis pinnatifidis, foliolis ovatis glaucis, aculeis sparsis.

CeRosier croît dans les montagnes des Vosges, il m’a été communiqué par M. Mougeot. $ち$.

ROSA STYLOSA. Desv., journal Botan. 2, pag. 317 .

R. germinibus ovatis pedunculisque glabris, calycinis laciniis pinnatifidis, foliolis ovatis acutis subtus pubescentibus, stylis connatis elongatis glabris. .

Cette Rose a été trouvée aux environs de Poitiers, par M. Desvaux, qui me l'a communiquée; ses fleurs blauches s'épanouissent au mois de juin. $\hbar$.

ROSA LEUCOCHROA. Desv., journ. Bot. 2, pag. $3 \mathbf{1} 6$.

R. germinibus ovatis pedunculisque glabris, calycinis laciniis ponnatifulis, foliolis ovatis glabris lucidis, stylis subsessilibus connaio-capitatis glabris. 
«. Rosa leucochroa, floribus albido-luteolis moschatis.

B. Rosa lactea, floribus candidis.

Je réunis ici deux Roses qui m'ont été communiquées par MM. Desvaux et Requien, parce que les différences, qui existent entre les deux plantes, sont si légères, qu'il ne me paroît pas qu'elles puissent servir à établir deux espèces. La première, qui a été trouvée par M. Desvaux aux environs de Poitiers, a ses pédoncules hérissés de quelques aiguillons, ses fleurs blanches, tirant un peu sur le jaune, et elles ont une odeur musquée bien prononcée. La seconde, cueillie par M. Requien, sur le mont Ventoux, a ses pédoncules dépourvus d'arguillons; ses fleurs sont d'un blanc de lait très-pur, j'ignore si elles sont odorantes. Ces deux Roses fleurissent en juin et juillet. 5 .

ROSA ANDEGAVENSIS. Batard, Fl. de Maine et Loire, pag. $18 \mathrm{~g}$.

R. germinibus ovatis pedunculisque hispidis, calycinis laciniis pinnatifidis, foliolis ovatis glaberrimis, stylis brevibus subpubescen. tibus.

Ce Rosier a été découvert par M. Batard, dans la ci-devant province' d'Anjou, aujour- 


\section{( 82$)$}

d'hui département de Maine et Loire; il a été retrouvé par M. Desvaux aux environs de Poitiers : ses fleurs d'un rose pâle, paroissent au mois de juin. $\hbar$.

\section{ROSA LEUCANTHA. N.}

R. germinibus ovatis pedunculisque glabris, calycinis laciniis pinnatifidis, petiolis aculeatis villosis, foliolis ovatis acutis subtics pubescentibus, floribus corymbosis terminalibus.

Cette Rose diffère de la Rosa dumetorum. Thuil., par ses fleurs blanches, réunies dix à quinze ensemble en une espèce de corymbe terminal. La suivante n'en diffère que par ses feuilles obtuses et par ses fleurs moins nombreuses ne formant jamais le corymbe. J'ai trouvé ce Rosier dans les haies aux en. virons de Dreux; il fleurit en juin. 5 .

ROSA OBTUSIFOLIA. Desv., Journ. Bot. 2 , pag. $3 \mathrm{r} 7$.

R. germinibus ovatis pedunculisque glabris, petiolis aculeatis villosis, foliolis ovatis obtusiusculis subtics pubescentibus, floribus subgeminatis.

Les fleurs sont blanches, elles paroissent en juin. Cette espèce a été trouvée dans les 


\section{(83)}

haies aux environs de Poitiers, par M. Desvaux. 5 .

Les Roses sont extrêmement difficiles à bien déterminer et à bien caractériser; beaucoup d'espèces sont très-voisines, et paroissent passèt de l'une à l'autre par des nuances imperceptibles. Ce n'est donc qu'avec doute que j'en rapporte ici quelques-unes comme nouvelles; et j'engage en même temps les Botanisteś à étudier ces plantes arec soin et exactitude, afin de reconnoître quels sont les caractères qui varient le moins, et qui pourroient être employés avec plus de certitude pour déterminer İes espèces.

POTENTILLA NORVEGICA. All., Fl. Ped. n. 1488. Lois., Fl. Gall. 3०4.

Cet article doit être rayé de ma Flore, la plante d'Allioni n'étant pas celle de Linné, mais bien la même que la Potentilla frigida de MM. Villars et Decandolle.

Il paroît qu'il faudra aussi supprimer la Potentilla Monspeliensis, rapportée sur l'autorité de Linné, et qui, selon M. Decandolle, ne se trouve pas aux environs de Montpellier. 


\section{(84) \\ P OLY A NDR I E.}

\section{PAPAVER AURANTIACUM. N.}

P. scapo foliisque pinnatis pilosis, pinnis aliis ovatis integerrimis, aliis dentatopinnatifidis, capsulis ovatis hispidis.

Cette plante a le port du Papaver alpinum, mais elle en diffère par ses feuilles toutes hérissées de poils, par la forme de ces mêmes feuilles, dont les folioles sont ordinairement ovales, entières ou dentées, mais toujours assez larges et jamais linéaires; enfin par ses fleurs qui sont d'un beau jaune orangé, au lieu d'ètre blanches avec une teinte de jaume très-pâle. Je dois ce pavot à M. Requien, qui l'a trouvé sur le mont Ventoux; il tleurit en juillet et août. $\mathcal{F}$.

\section{CISTUS LADANIFERUS. Lin. - Lois. , Fl. Gall. 3 I2.}

Cette espèce croît en Provence, entre le Mui et le Puget, où elle a été recueillie par par M. Bernard qui me l'a communiquée; elle ne se trouve pas au contraire, selon M. Lamothe, aux environs de Montpellier, où je l'avois indiquée d'après M. Gouan, qui avoit pris pour elle le Cistus ledon. Les fleurs paroissent dès la fin d'avril et au commencement de mai. 


\section{CISTUS VILLOSUS. Lin., Sp. 737 .}

C. fructicosus exstipulatus, foliis ovatis rugosis hirtis petiolatis, ramis pedunculis calycibusque villosis, pedunculis simplicibus bificlisve. Cistus mas. Matth. Valgr. I76.

Ce Cisle croît dans le pays de Gênes; il m’a été communiqué par M. Bertoloni; ses fleurs sont d'ùn rouge pâle, elles paroissent all mois de mai. $ち$.

CISTUS SERRATUS. Cavau., Ic. 2 , pag. 57 , t. 175 , f. r. Willd., Sp. 2 , p. I ig8.

C. herbaceus exstipulatus., foliis oppositis lanceolatis trinerviis hirtis viscosis, sadicalibus obovatis, racemis ebracteatis, petalis serratis. Willd.

Ce Ciste est indiqué par M. Decandolle, anx environs d'Angers, de Lorient et de Vaunes: je l'ai trouvé cette année dans le bois de Boulogne, pêle-mêle avec le Cistus guttatus, dont il ne paroît être qu'une légère variété caractérisée par ses pétales dentées en scie. Les fleurs sont d'ailleurs de la même couleur, avec une tache d'un violet noirâtre à la base de chaque pétale. ( $)$.

DELPHINIUM AMBIGUUM. Lin., Sp. 749 ?

D. nectariis monophyllis, corollis pentape-。 


\section{( 86 )}

talis, fructibus subunicapsularibus, foliis multipartitis cauleque ramosissimo pubescenti-canescentibus.

Si la plante que je rapporte ici avec doute, à une espèce de Linné, n'étoit pas celle de cet auteur, je crois que ses tiges à rameaux nombreux et étalés, toutes couvertes ainsi que les feuilles d'un duvet très-court, qui les rend presque blanchattres, suffiroient pour la faire distinguer du Delphinium ajacis, "dont elle diffère encore par ses fleurs plus petites, d'un bleu très-pâle ou même d'un gris cendré. Je l'ai trouvée dans les champs aux environs de Montpellier; elle fleurit en juin et juillet. $($ ).

DELPHINIUM INTERMEDIUM. Ait., Kew.2, pag. 243. Willd., Sp. 2 , pag. 1228.

D. nectariis diphyllis, labellis ovatis bifidis, laciniis ovatis, foliis tripartitis, laciniis trifidis incisis, fructibus tricapsilaribuis. Aco. nitum lycoctonum, flore delphinii, primum silesiacum. Clus. hist. XCIV.

Cette espèce a été trouvée par M. Rohde, à la vallée d'Eynes dans les Pyrénées orientales; elle fleurit en juillet et aout; ses fleurs sont bleues. 
ANEMONE PAVONINA. Lam. Dict. $\mathbf{r}$, pag. 166.

A. foliis radicalibus profundè 3-5-partitis, laciniis cuneatis trilobis dentatis incisopartitisve, caulinis ternis ovato-lanceolatis integris 3-5-fullisve, corolla ra-r5pelalâ, seminibus lanatis. A. hortensis. Thore, Chlor. Land. 238, (non Lin.).

Cette espèce est très-distincte de l'Anemone horterisis, dont elle differe par la graindeur de sa corolle qui a souvent plus de trois jouces de diamètre, et par la couleur de ses pétales qui sont d'un rouge éclatant. Elle crôit dans les vignes à $S$. Pandelon près de Dax, où elle a été trouvée par M. Thore qui me l'a communiquée; j’en ai aussi reçu des échantillons de M. Grateloup. Cette belle plante fleurit au mois d'avril; on en cultive dans les jardins une variété à fleurs doubles. 24 .

\section{ANEMONE PALMATA. Lin., Sp. 758.}

A. foliis radicalibus cordato-rotundatis trilobis crenatis, caulinis ternis trifudis, corollis subdecapetalis, seminibus lanatis. A. hortensis latifolia, simplo flavo flore. Clus., Hist. 248. A. latifolia flava prina. Clusii. Barr. Ic. $79^{2}$.

Cette plante a été trouvée par M. G. Ro- 


\section{( 88 )}

bert, dans les lieux secs et arides aux environs d'Hières en Provence : elle fleurit en avril et mai, ses fleurs sont jaunes. 24 .

THALICTRUM NIGRICANS. Jacq., Fl. Aust. 5, t. 421 . Willd., Sp. 2, p. I30o.

T. caile folioso sulcato, floribus paniculatis, foliolis radicalibus cuneiformibus trifidis, caulinis linearibus acutis.

MM. Rohde et G. Robert ont trouvé celte plante aux environs de Toulon; elle fleurit en juin et juillet. $\mathscr{\xi}$.

\section{RANUNCULUS ANGUSTIFOLIUS. Decand., Voyag. Bot. 78.}

P. Soliis lineari-lanceolatis nervosis acutis glabris, caule erecto apice subramoso glaberrimo multifloro. Decand.

Cette plante a été trouvée par M. Decandolle dans les lieux humides des Pyrénées orientales, près de Mont-Louis. «Elle diffère « du Ranunculus Pyrencus, parce que ses « pédoncules ne sont pas cotonneux, et du «R. amplexicaulis, par ses feuilles très" étroites, non embrassantes, et par ses fleurs « de moitié plus petites. "Celles - ci sont blanches et paroissent en juin et juillet. $\mathscr{F}$. 
RANUNCULUS NIVALIS. Lin., Sp. 778. Fl. Lapp. 232, tab. 3 , f. 2.

R. caule unifloro subunifolio, foliis glaberrimis, radicalibus tripartitis lobatis, caulino sessili digitato. R. minimus alpinus luteus, J. B. Hist. 3. A ppend. 86r , fig. super. s Ranunculus idem pygmceus. Lin., Fl. Lapp. 232 , tab. 3 , f. 3 .

Celte espèce a été trouvée par M. G. Robert, dans les Jieux humides sur les hautes montagnes de l'Ile de Corse. La variété $\beta$ liabite les sommités des mêmes montagnes. Elles fleurissent toutes deux en juillet et août; leurs fleurs sont jaunes et petites. $2 \%$.

\section{RANUNCULUS PARVULUS. Lin. - Lois., Fl. Gäll. 333.}

RANUNGULUS INTERMEDIUS. Poir., Dict. 6, pag. 1 ro. Lois., Fl. Gall. 332. R. pumilus. Thuil., Fl. Par. 227.

La plante de MM. Poiret et Thuillier que j’avois mentionnée comme espèce distincte, n'est nullement différente de la première; elle doit être supprimée et rapportée à l'espècc de Linné.

Le Ranunculus philonotis parôit aussi avoir les plus grands rapports avec ce même $R$. par: 


\section{$\left(9^{\circ}\right)$}

vulus; il ne s'en distingue que parce qu'il s'élève davantage et qu'il est plus rameux. Les fruits des deux plantes sont des capsules comprimées arrondies, marquées de petits points ún peu élevés au dessus de leur surface, et plus ou moins nombrenx. Ces tubercules seroient un bon caractère pour distinguer l'espèce ou les espèces, mais quelquefois les capsules en sont tout-à-fait dépourvues, d'autres fois leur disque en est tout couvert; jajouterai cependant que le premier cas étant plus rare, l'existence des capsules tuberculeuses mérite quelque considération pour la détermination des espèces, et c'est ce qui me fait croire, comme $\mathbf{M}$. Desfontaines l'a déja pensé, que l'espèce suivante est très-voisine, peut-être qu'elle n'est qu'une variété du $R$. parsulus,; mais qu'on est suffisamment aulorisé à séparer, d'après la manière dont on considère les espèces en général.

RANUNCULUS TRILOBUS. Desf., Fl. All. I, pag. 437 , t. 1 3 , Willd., Sp. 2, pag. 13 5 .

R. caule erecto glabro ramoso, foliis glaberrimis, inferioribus trilobis, lobis crenatis dentatis, superioribus laciniatis, seminibus compressis tuberculatis mucronatis.

Cette plante a été trouvée par M. Martin, 


\section{( $\left.9^{\mathrm{r}}\right)$}

dansles prés humides aux environs de Toulon, d'où M. G. Robert m'en a envoyé des échantillons. M. Decandolle l'a recueillie aux environs de Perpignan. Les fleurs sont jaunes, très-petites; elles paroissent en mai et juin. ()$^{\circ}$.

\section{RANUNCULUS SPICATUS. Desf. - Lois., Fl. Gall. 330.}

Cette espèce doit être rayée de la Flore de France; c'est à tort quie le Ranunculus saxatilis. Balb., lui a été rapporté par M. Decandolle et par moi. Nous nous sommes trompés tous les deux, si, comme je dois le croire, les échantillons, qu'il peut avoir reçus de $\mathbf{M}$. Balbis, sont semblables à ceux qui m'ont été envoyés par ce professeur; ceux-ci, qué jai comparés dans l'herbier de M. Desfontaines, ne peuvent en aucune manière appartenir à la Renoncule de la Flore Atlantique, mais ils convienvent parfaitement au Ranunculus Monspeliacus, que j'ai reçu de Montpellicr et de Provence, et dont M. Decandolle vient de donner une bonne figure dans ses Icones rar. plant. tab. 50.

RANUNCULUS TRIPARTITUS. Decand., Ic. rar. fasc. 1 , pag. 15, tab. 49 .

R. foliis submersis capillaceis, emersis tri- 
partitis, petalis oblongis acutis parulus, seminibus transversè striatis. Decand.

Cette plante n'est qu'imparfaitement distincte de la Renoncule aquatique, et je m'étonne que M. Decandolle, qui, dans sa Flore Française, a réuni, peut-être avec raison, plusieurs espèces comme de simples variétés du Ranunculus aquatilis, ait distingué cette plante comme espèce particulière; elle ne me paroît pas mériter celte préférence plus que les autres. D'après une suite d'échantillons de la Renoncule aquatique, que j'ai dans mon herbier, les fleurs de cetle espèce varient en grandeur depuis un pouce de diamètre, jusqu’a trois lignes; de sorte qu'il me paroît qu'on ne peut emprunter aucun caractère de la proportion variable des pétales. Quant aux semences sillonnées transversalement, toutes les renoncules qui croissent dans les eaux, les ont de même. Le Ranunculus titpartitıs, indiqué en Bretagne par M. Decandulle, se trouve dans les mares, les lieux inondés aux environs de Paris et probablement dans toute la France; il fleurit depuis le mois d'avril jusqu'en été. 


\section{$\left(9^{3}\right)$ \\ DIDYNAMIE.}

BETONICA INCANA Ait., Kew. 2 pag. 299. Willd., Sp. 3, p. 94.

B. spicâ interruptâ, corollarum galeâ bifidá, lacinia intermedia labii inferioris crenatâ, tubo tomentoso incurvo. Ait.

Cette plante est indiquée par M. Decandolle, dans les bois aux environs de Nantes. $\mathcal{F}$.

PRASIUM. Calyx turbinatus labiatus, suprì latior 3-fidus, infrà 2-fidus. Corolla longior labiata, superiils concava emarginata, inferiùs latior 3-fidâ, laciniấ mediấ majore. Semina 4-baccata.

\section{PRASIUM MAJUS. Lin., Sp. 838.}

$P$. foliis ovato-lanceolatis subcordatis dentatis, floribus axillaribus subsessilibus, caule suffruticoso. 'Teucrium fruticans, amplo et albo flore, italicum. Barr., Ic. 895.

Ce petit arbrisseau a été trouvé en Corse, où il fleurit en mars ct avril; ses fleurs sont blanchâtres. Il m'a été communiqué par M. Desfontaines, qui l'avoit reçu de M. Lasalle; il est aussi indiqué en Toscane, sur les bords de la mer, par M. Savi. 5 . 


\section{(94)}

BARTSIA BICOLOR. Decand., Ic. rar. fasc. I, pag. 4 , tab. Io.

B. pubescens, caule simplici aut subramoso, foliis oppositis lanceolato-linearibus hinc indè serratis, floribus densè spicatis, corollce labio superiore integro, inferiore trilobo, lobo medio lateralibus longiore. Dec.

Cette plante a été découverte par M. Decandolle, dans les champs secs et sablonneux de Belle-Isle en mer, près du village de Donnan; elle fleurit en juin et juillet, ses fleurs sont d'un violet pâle mêlé de blanc. ( $)_{\text {. }}$.

\section{ANTIRRHINUM ARENARIUM.}

Linaria (arenaria) foliis lanceolato - linearibus acutis sparsis pubescenti-viscosis, inferioribus verticillatis oblongis obtutis, caulibus erectis numerosissimis, floribus parvis longè subspicatis. Decand., Ic. rar. fac. I, pag. 5 , tab. 14. Linaria maritima minima viscosa, foliis hirsutis, floribus luteis. Moris. Hist. 2, pag. 499.

Cetle espèce a été trouvée par M. Decandolle, dans les sables du bord de la mer en Bretagne, entre l'embouchüre de la Loire et Lorient, et surtout dans la presqu'ille de Quiberon; elle fleurit en juillet et août. $(\cdot)$. 


\section{$\left(9^{5}\right)$}

\section{ANTIRRHINUM MAJUS. Lin. - Lois., Fl. Gall. 379 .}

Il y a dans cette espèce deux variétés remarquables; la première a les feuilles étroites, lancéolées ou mème linéaires et les fleurs rougeâtres; elle est commune dans les fentes des rochers et des vieux murs. La seconde variété, connue et indiquée par G. Bauhin, Boccone, etc., a les feuilles beaucoup plus larges, ovales ou ovales-lancéolées, et ses fleurs sont jaunes. Celle-ci est plus rare que la première; jusqu'à présent je ne l'ai reçue que des provinces méridionales. M. Rohde l'a trouvée à Nice, M. G. Robert à Toulon, et M. Requien à Vancluse. Si les différences qu'elle présente étoient constantes, on pourroit la regarder comme une espèce distincte.

\section{SCROPHULARIA SCOPOLII. Hoppe. - Pers., Synop. 2, pag. I6o.}

S. foliis cordatis crenato-dentatis, inferioribus ternatis, superioribus integris, floribus racemoso-paniculatis, bracteis lasceolatis linearibusque apice integerrimis. S. auriculata. Scop., Fl. Carn. 2, pag. 446, tab. 32. S. glandulosa. Waldst. Pl. Hung. 


\section{$\left(9^{6}\right)$}

Celte plante croît dans les lieux humides et ombragés des Pyrénées; elle m'a été communiquée par M. Rohde, qui l'a trouvée au mont Laurenti, et entre Luz et Barèges; elle fleurit en juin et juillet. $\not{F}$.

DIGITALIS FUCATA. Ehrh., Beytr. 7, pag. $15 \mathrm{I}$ ? ex Pers., Synop. 2, pag. I62 ?

$D$. caule erecto subramoso, foliis lanceolatis semi-amplexicaulibus glabriusculis, racemo oblongo, calycinis laciniis lanceolatis, corollae galeá obsoletè emarginatú obtusâ.

Cette plante ressemble à la Digitalis lutea, mais elle s'élève davantage, ses fleurs sont d'un pourpre clair et moitié plus grandes. Elle a été tronvée par M. de Saint-Hilaire dans un vallon au dessus de Combronde, dans la Limagne; elle fleurit au mois de juillet. $2 f$ ?

\section{TETR A D Y N A I E.}

ALYSSUM ARENARIUM. Lois., Fl. Gall. 401.

Cette plante, que j’avois donnée comme nouvelle, n'est pas une espèce distincte de 


\section{( 97 )}

l'Alyssum montanum. Lin.; ce n'en est qu'une simple variété à feuilles plus arrondies.

\section{SISYMBRIUM PANNONICUM. Jacq., Ic.} rar. I, tab. 123.

S. foliis inferioribus runcinatis dentatis, superioribus pinnatis, pinnis linearibus integerrimis, siliquis rectangulè patentibus. Willd., Sp. 3, pag. 502.

M. Thomas a trouvé cette espèce dans le Valais, sur les frontières de la Savoie. ( $(\cdot)$.

SISYMBRIUM COLUMN虚.Jacq., Fl. Aust. 4, tab. 323. Willd., Sp. 3, pag. 503.

S. folïs runcinatis dentatis cauleque villosis subincanis, siliquis erectis. Rapistrum montanum Irionis folio. Colum. Ecphr. I, pag. 266, tab. 268.

Cette plante a été trouvée en Alsace, par M. Nestler. ( )

BRASSICA CHEIRANTHOS. Vill. - Lois., Fl. Gall. 420.

Cette espèce, au lieu d'avoir toujonrs le pétiole de ses feuilles et le bas de ses tiges. garnis de poils qui rendent ces parties hispides, est quelquefois cntièrement glabre. Je l'ai trouvée ainsi dans les champs à Bayonne; 


\section{$\left(9^{8}\right)$}

je l'ai reçue de même de M. Suffren, qui l'a recueillie dans les montagnes de la Provence, aux environs de Colmar, et de M. Thore, qui l'a observée à Dax; ce dernier, dans sa Chloris des Landes, page 284, nomme cette plante Erysimum arvense.

SINAPIS NIGRA. Lin. - Lois., Fl. Gall.

B Sinapis torulosa, (Pers., Synop. 2, pag. 267) foliis latis hastato-lobatis glabriusculis, superioribus ovatis repandis, siliquis torosis caulibus appressis, rostro longo angusto.

\& Sinapis turgida, (Pers. J. c.) foliis lobatis repandis basi auriculatis, serraturis apice callosis, siliquis ovatis turgidis venosis divergenti-appressis, rostro conico striato.

Je mentionne ici ces deux plantes d'après M. Persoon, qui les indique dans les champs aux environs de Paris.

\section{O N A D E L P H I E.}

ERODIUM ROMANUM. Willd., Sp. 3 , pag. 630.

E. acaule, peduncults multifloris, foliis pinnatis, pinnis ovatis pinnatifidis, petalis calyce majoribus. Willd. Geranium romanum. Lin., Sp. 95 r. Cavan., Diss. 4, 


\section{( 99 )}

pag. 225, tab. 94 , f. 2. Geranium myrrhinum tenuifolium amplo flore purpureo. Barr. Ic. 1245.

Cette plante m’a été communiquée par M. Requien qui l'a trouvée près d'Avignon; elle est indiquée par M. Decandolle sur le bords des chemins aux environs de Nîmes et de Montpellier; elle fleurit presque toute l'année, ses fleurs sont purpurines. \& ?

\section{MALVA MiCROCARPA. Desf., Catal. 144. Pers., Synop. 2 , pag. $25 \mathrm{r}$.}

M. caule erecto ramoso, foliis cordatosubrotundis subquinquelobis crenatis glabris, pedunculis subgeminis petiolo brevioribus, foliolis calycis exterioris linearibus, fructibus supernè costato-rugosis. M. parviflora. All., Fl. Ped. n. I 415. Lois, Fl. Gall. (non Lin.). Decand., Fl. Fr., n. 4506? (exclus. Syrion.).

M. Balbis, en m'envoyant des échantillons de cette espèce, m'avertit qu'elle doit remplacer dans la Flore la Malva parviflora dont elle diffère, et pour laquelle elle avoit été prise. $(\cdot)$.

MALVA FASTIGIATA. Cavan., Diss. 2, pag. 75 , tab. 23 , f. 2. Willd, , Sp. 3 . pag. 780 . 


\section{( 100 )}

M. caule ramoso, foliis subcordatis quinquelobis incequaliter dentatis, floribus terminalibus subumbellatis.

* Foliis subtics tomentosis acutè dentatis, floribus plerisque terminalibus.

\& Foliis glabriusculis obtusè dentatis, floribus axillaribus solitaris et terminalibus subumbellatis.

La première variété de celte Mauve m'a été communiquée par M. Lamouroux, qui l'a trouvée aux environs d'Agen, et la seconde par M. G. Robert, qui l'a recueillie dans les montagnes aux environs de Toulon. Les fleurs de ces plantes sont roses; elles paroissent en juillet et août. $\mathscr{F}$.

HibISCUS PENTAGARPOS. Lin., Sp. 98\%. Jacq. , Ic. rar. I, tab. 143.

H. folius cordatis oblongis dentatis obtusus. culis angulatis leviter subtrilobis, pedunculis axillaribus, floribus cernuis, pistillis nutantibus. Willd., Sp. 3, pag. 83r.

M. Savi indique cette plante en Toscane, dans lés terrains marécageax'; elle fleurit at mois d'août, ses fleurs sont roses. $\mathfrak{z}$.

\section{DIADELPHIE.}

FUMARIA FABACEA Retz.,Prod. Fl. Scand, 


\section{( $\mathrm{ror}$ )}

ed. 2, n. 859 (excl. Syn. Fl. Danica). Willd., Sp. 3, p. 862.

F. Radice tuberosâ solidâ, caule simplici erectiusculo, foliis biternaits, floribus racemosis terminalibus, racemo paucifloro, bracteis subrotundis longitudine florum, calcare corollce recto.

Celte plante se trouve dans la forêt de Compiègne, ¿̀ i 5 lieues de Paris; ses fleurs sont blanchâtres, elles paroissent at mois de mars. $2 \%$.

\section{FUMARIA MEDIA. N.}

F. caule subramoso erecto, foliis bipinnatis, pinnis 2-5-laciniatis, laciniis oblongis planis, petiolis subcirrhoso-convolutis, racemis elongatis oppositifoliis, calycibus dentatis, pericarpiis subglobosis subtuberculatis depressiusculis monospermis. F. major floribus dilutè purpureis. Vaill., Bot. Par. 56, tab. 10, fig. 4 (exclusis pluribus Synonymis). F. capreolata. Thuil.?

Cette plante est intermédiaire entre la Fumaria officinalis et la $F$. capreolata; mais elle a un port particulier, qui la fait distinguer de l'une et de l'autre au premier coup-d'oeil : elle diffère en effet de la première, parce qu'elle s'élève davantage, qu'elle 


\section{(102)}

est moins rameuse et moins diffuse, que ses feuilles sont plus grandes et plus glauques, que ses pétioles cherchent souvent à s'entortiller autour des corps environnans; enfin, parce que ses fleurs sont plus grandes, un peu plus pâles, la corolle élant d'un blanc purpurin avec le sommet seulement d'un pourpre foncé. Elle se distingue de la secondc par ses fleurs plus petites, par ses calices dentés et non entiers, par les découpures de ses feuilles qui sont plus linéaires, par ses capsules presque échancrées au sommet et qui ne sont pas lisses, mais comme légèrement tuberculeuses; enfin, parce qu'elle s'élève moins, et que sa tige se soutient droite sans avoir besoin de sappuyer sur les corps qui sont dans son voisinage. Cette Fumeterre n'est pas rare dans les champs et dans les vignes aux environs de Paris; je l'ai trouvée à Marcoussis, à Saint-Cloud, à Romainville, etc.; elle fleurit en mai, juin et. juillet. ( $)$.

\section{FUMARIA VAILLANTII. N.}

F. caule ramoso erectiusculo, foliis bipinnatis, pinnis 2-5-laciniatis, laciniis linearibus planis, racemis brevibus oppositifoliis, pericarpiis glob̄osis sububerculatis vix mucronulatis monospermis. F. lo- 


\section{( 103 )}

7is longioribus et angustioribus sparsis. Vaill., Bot. Par. 56, tab. Io, fig. 6.

Cette plante a par ses caractères principaux beaucoup de rapports avec la Fumaria parviflora; mais ses rameaux redressés au lieu d'être étalés et presque couchés sur la terre, les découpures de ses feuilles plus alongées, planes et non canaliculées; enfin, ses, fleurs rougeâtres au lieu d'être blanches, la font facilement distinguer. Je l'ai trouvée cette année, en herborisant avec M. Merat, entre Chanteloup et Poissy, à sept lieues de Paris, où elle est très - commune dans les champs sablonneux; et après l'avoi r recueillie, examinée et comparée avec la $F$. parviflora, qui étoit aussi très-abondante dans ce canton, nous reconnoissions sans nous tromper, et rien qu'au port, les deux plantes à plus de vingt pas de distance. Cette espèce fleurit en mai et juin $(\cdot)$.

A l'article Fumaria officinalis, page 437 de ma Flore, les synonymes de Vaillant doivent être rayés, puisque je les ai rapportés aux deux nouvelles espèces que je viens de décrire.

\section{POLYGALA VULGARIS pubescens.}

M. Rohde a trouvé aux environs de Nice, dans un canton appelé valléc de la Crypto- 


\section{( 104 )}

gamie, par les Botanistes än pays, celte variété semarquable par les poils courts et assez abondans dont ses tiges et ses feuilles sont couvertes.

\section{POLYGALA PARVIFLORA. N.}

P. Roribus cristatis racemosis, alis calycinis zuninerviis obtusis corollâ longioribus, caule erecto ramoso glaberrimo, foliis radicalibus ovatis, caulinis lineariuus crassiusculis canceliculatis obtusis.

Cette plante a été découverte par M. Requien, sur les bords de la Durance, dans les environs d'A vignon. Elle fleurit en juillet et août; la corolle est blanchâtre, marquée de rouge au sommet. ( $)$.

GENISTA SCARIOSA. Viv., Fl. Ital., frag. I, pag. 5 , tab. 7 .

G. ramis triquetris, foliis simplicilus margine scariosis, rameij lineari-lanceolatis acutis, caulinis obovatis obtusis, fioribus axillaribus racematim dispositis, leguminibus mudis subfalcatis. G. Januensis. Bertol., Pl. Gen. 85. Savi, Bot. Eu. I, pag. $17^{30}$

Cet arbrisseau croît dans le pays de Gênes, sur les collines; il m'a été cornmuniqué par M. Bertoloni; ses fleurs jaunes paroissent en mai et juin. 5 . 


\section{( 105$)$}

ULEX PROVINCIALIS. N. tab. 6, f. 2.

$U$. dentibus calycinis lanceolatis distanibibus, bracteis mimitis adpressis, ramulis gla briusculis erectis, caiycibus subpulescentibus corollam vix superantibus.

Cet arbrisseau s'élève à environ trois pieds; i) est par conséquent plus grand que l'Ulex namus, et plus pelit que l'U. europious; il paroît être intermédiaire entre les deux; car, pour en donner une idée assez juste, ou peut dire qu'il a les fleurs du premier, et les rameaux du second. Il a été découvert dans Jes champs, et sur les hords de la mer en Provence, aux environs de Toulon, par M. G. Robert; il lleurit en avril. $\frac{5}{5}$

ONONIS MOLLIS. Savi, Mem. della Soc. Ital., tom. 9, pag. 35r r, tab. 8, ex Savi, Cent., pag. 137. Lois., Journ. Bot., 2, pag. 36r.

D'après les échantillons qui m’ont été communiqués par M. Savi, cette plante ne diffère pas de l'Ononis reclinata. Lin.

\section{ONONIS ORNITHOPODIOIDES. Lin.,}

Sp. Ioog. Cavan., Ic. 2, pag. 74, Lab. $9^{2}$.

O. pertunculis subbifloris aristatis folio brevioribus, foliolis te"natis oboratis antice 


\section{(106)}

denialis, leguminibus cermis linearibus compresso-nodosis. Savi, Bot. Etrus. I, pag. 17 t.

M. Savi indique celte espèce cu Toscane; les fleurs sont d'un jaune pâle; elles parois: sent en mai $(\cdot)$.

\section{LATHYRUS MICRANTHUS. Gérard, ined.}

'z. foliis conjugatis, leguminibus strictis subsessilibus patentibus folio longioribus, cirrhis simplicibus brevissimis. Gér.

Les tiges de celte plante sont redressées, menues, anguleuses; elles s'élèvent à un demipied. Les feuilles, accompagnées de stipules plus longues que le pétiole qui est très-court, sont composées de deux folioles lancéolées, linéaires, chargées de nervures en dessous, et munies d'une vrille simple, de la longueur du pétiole. Les fleurs axillaires, solitaires, sont portées sur des pédoncules fort courts; les dents de leur calice sont sétacées, presque égales à la corolle dont l'étendarl est rouge. Le Jégume est cylindrique, un pen velu, plus étroit que les folioles; il renferme Luit à dix semences. D'après la description de celte espèce, qui m’a été communiquée par M. Gérard, la planie de cet auteur paroit avoir beaucoup de rappont arec le Lathyrus 
sphœricus; mais le légume de ce dernier n’est pas du tout velu, et il est plus large quie lés feuilles. Le Lathyrus micranthus a ététrouvé dans les moissons en Provence, par M: Gérard. (.) ?

VICIA SORDID 4. Waldst. Pl. Hung. Willd., Sp. 3, pag. I İo8.

$V$. Roribus axillaribus subgeminatis subsessilibus, vexillo glaberrimo, leguminibus pilosis reflexis, foliolis ovatis retusis mucronatis, stipulis subdentatis maculâ notatis V. grandiflora. Scop. Fl. Carn, 2, pag. 65, tab. 42 .

Cette espèce m'a été communiquée par $\mathbf{M}$. Bertoloni, qui l'a recueillie dans le pays de Gênes. Ses fleurs sont d'un jaune pâle; elles paroissent en mai et juin. ( $)$.

ORNITHOPUS EBRACIEATUS. Brot.--Lois., Fl. Gall. 467 .

Cette plante, connue depuis quelques années seulement, paroît être assez commune en France; je l'avois trouvéc aux environs de Dax et de Bayonne; M. G. Robert me l'a voit enroyée de Toulon; M. Bertoloui vient de la retrouver dans la Ligurie; M. Balbis, à Canues et à Autibes, et M. Saint-Hilaire, dans la Sologne, à quelques lieues d'Orléans, 


\section{( 108$)$}

L'Ornithopus durus, Balb., Miscel. ait. 23, n'en difiere pas.

\section{ASTRAGALUS BAIONENSIS. Lois., FI. Gall. 474 .}

M. Bonnemaison a reirouvé sur les côtes du département du Finistère, dans la cidevant Bretagne, cette espèce que jai trouvée le premier, dans les sables du bord de la mer, aux environs de Bayonne.

TRIFOLUUM ELEGANS. Savi., Fl. Pis. 2, pag. 61 , tav. I, fig. 2 . Lett. Bot. in Giornale Pisano, tom. 5 , pag. 240.

T. capitulis umbellarious pedunculatis, legtzminibus oblongis subdispermis, caule fistuloso adscendente, foliolis obovatis tenuissimè serratis, calycinis dentilus subulatis subcequalibus. T. "hybridum. Des"., Fl. Ati. 2, pag. 195, et omnium feré Auct: Gall. T: Vaillantii. Poir., Dict. 8, pag. 4 (exclus. synon. Trichelii). Nelitolus $P$ ariensis, humifusus, foliis serralis, glabris. Vaill." Bot. V'ar., tab. 22, fig. I. Trifolicistrim pratense, corymbiferun, non repens humi stratum. Michel., Nov. Gen., pag. 27 .

J'avois pris celle plante pour le Trifolium hybridum de Linne, et je crois que la plupart 


\section{( 109$)$}

des Botanistes français en ont fait autant; mais M. Savi, dans la critique judicieuse qu'il a faitesur cette espèce d'un diagnostic dilficile, a très-bien observé que Linne et ceux qui l'avoient suivi, a voient confondu deux plantes sous le mème nom; l'ùne dont les légumes ne contiennent qu'une ou deux semences, trèsrarement trois, c'est celle dont il est ici question; et l'autre ayant des légunies renfermant quatre semences. On perit ajouter que cette dernière (Trifolizm hylridum) diffère encore par ses feuilles plus cunéiformes, sourent échancrées a leur sommet, par les dents du calice plus élargies, et par ses fleurs blanches. Le T. elegans, dont j'ai reçu des échantillons de M. Savi, se trouve aux environs de Paris; je l'ai recueilli sur le bord des hois à Armanvilliers, et il m'a été communiqué par M. Thuillier; il fleurit en juin, juillet, août, ef lès le mois de mai dans la Toscane; ses fleurs sont rougeàtres. $($ ).

TREOLIUM MICHELIANUM. Savi, Fl.

Pis. 2, pag. 159 . Lett. Bot., in Giornale Pisano, tom. 5, pag. 236.

T. Caule fistuloso assurgente, foliolis ovatocuneatis dentatis, capitulis pedunculatis numbellaribus, calycinis dentibus setaceis incequalibus, vexillo oblongo, leguminibus 


\section{( IIO)}

ovatis compressis subaispermis. T. hybridum $\beta$. Lin., Sp. 1080. T. V aillantii. Lois., Journ. Bot. 2, pag. 365. T. orientule altissinum, caule fistuloso, flore albo. Vaill., Bot. Par. Ig5, tab. 22, f. 5. Trifoliastrum pratense corymbiferum erectum annuum et pracaltum, caule crassiore fistuloso, folio longiore cordiformi, flore albo, siliquâ incurvá latâ compressâ ac clispermá. Mich. Gen., pag. 28 , tab. 25 , f. 2.

Ce Tréfle a beaucoup de rapports avec le. précédent; mais on l'en distingue au premier coup-d'oeil, à ses feuilles plutôl cunéiformes qu'ovales, à ses capitules qui ne sont formés que de vingt à trente fleurs, au lieu de l'être de quarante à cinquante et plus, à ce que ses fleurs sont moitié plus grandes; enfin, à ce qu'elles sont bianches, et non pas d'un rouge clair. Il m'a été communiqué par $\mathrm{M}$. Savi, qui l'a trouvé dans les.prés humides en Toscane, et par M. Gochnat qui l'a recueilli aux environs de la Rochelle. Il se trouve, selon Vaillant, à Fontainebleau et à Palaiseau, et probablement dans une grande partie de la France. Il fléurit en mai et juin. (.).

\section{TRIFOLIUM MICROPHYLLUM. Desv. ,} Journ. Bot. 2, pag. 3氵6.

I. caule glabro ramoso suberecto, foliolis 
ovatis denticulatis margine villosis, spicis subglobosis, calycinis dentibus villosis incequalibus.

Cette espèce a des rapports avec le Trifolium rubens et le 'T. alpestre; mais elle diffère du premier par ses feuilles petites, ovales, par la forme de son épis de fleurs, et par sa pubescence; du second, par ses feuilles très-pelites et sa tige glabre. Elle a été découverte, dans les bois sces, aux environs de Poitiers, par M. Desvaux.

\section{TRIFOLIUM SYLVATICUM. Gérar.}

T. caule suluramoso erccto pubescente, foliolis ovatis obtusis, stipulis dilatatis, spicis oblongis villosis, dentibus calycinis setaceis ciliatis corollá brevioribus, unico longiore patente. Planta semipalmaris, sericeâ lamunine vestita; stipula suprema spicam nondum florigeram fovens; spica uncialis sericea, constans floribus ultrà 40 ; corollae purpurece.

Cette plante a été trouvée dans les bois des Maures, en Provence, par M. Gérard, qui la croit nouvelle, et qui m’en a communiqué la description.

TRIFOLIUM BOCGONE. Savi, Memor. sopra 


\section{( II 2$)$}

i Trifogli, in Gionuale Pis., tom. 1o, n. ${ }^{\circ} 28$; fig. $r$.

T. caule basi ramoso adscendente, foliolis oblongo-cuneatis apice subdentatis, capitulis ouato-oblongis geminatis, calycinis dentibus lineari-subulatis subaqualibus corolla vix longioribus. T. noxiflorum, etc., Boc. Mus., pag. 142, lab. rof.

Celte plante a été découverte par M. Savi, au mont Castellare, dans les environs de Pise en Toscane, elle fleurit en juin ; l'élentard des lleurs est d'un rouge pâle, les ailes et la carene sont blanches. $\delta$.

TRIFOLIUM MONTANUM. Lin. - Lois., Fl. Gall. 483.

I. Perret a trouvé, aux environs de Fréjus, une variété de cette espèce, dont les fleurs sont purpurines.

'TRIFOLIUM PALLIDUM. Waldst. Pl.Hung., tom. I, pag. 35, tab. 36. Willd., Sp. 3, pag. I 3 r.

'T. capitulis subglobosis solitariis foliis Aluobus superioribus obvallatis, dentibus calyciruis subrequalibus ciliatis patentibus corollá monopetalá dimidiò brevioribus, stipulis et foliis cauleque diffuso villosizusculis.

Culte espèce a élé trouvée par Mr. Savi, 


\section{( 113$)$}

dans les pâturages aux environs de Fise, en Toscane, où elle flenrit en mai; ses fleurs sont blanches. Elle a de grands rapports avec le Trifolium pratense, et surtoul avec sa variéte $\beta$; mais elle en diffère évidemment, jarce qu'elle est annuelle. ( )

TRIFOLIUM LIGUSTICUM. Balb., in Lois, Fl. Gall. 73 I.

Cetie espèce est la mème que le Trifolium genzellum. Pourret, in Willd., Sp.3, p. 1376, dont M. Savi fait aussi mention dans le Memoire cité à l'article précédent, et dont il donne une figure sous le $n .^{\circ} 2$. Elle se trouve aux cnvirons de Pise, selon ce dernier auteur; je l'ai recae de MM. Requien et G. Robert, qui l'ont recueillie dans les champs aux lles d'Hières et à Toulon; elle fleurit en mai ę̃ juin. ( () .

TRIFOLIUM UNIRLORUM. Lin., Sp. Io85. T. pedunculis trifidis triflorisque stipulà breviorikus. Lin. Amoen. acad. 4, pag. 285. T. acaule, pedunculis unifloris, floribus foliisque commixtis. Lin. Sp., 1 , pag. $77 \mathrm{I}$. $T$. vernum repens purpureun. Buxb. Cent. 3, p. I7, t. 3r, f. I. T. vernum repens, flore albo exiguo. Duxb. Cent. 3 , p. 17, t. 3r, f. 2.

Je n'ai pas, vu cette plinte; M. Requieu 


\section{( 1 I 4 )}

m'écrit quil l'a trouvée aux environs de Marseille.

\section{TRIFOLIUM BADIUM. Schreb. in Sturm. Ic.}

T. caule erecto subvilloso, foliolis ovatooblongis seiratis, intermedio sessili, capiculis rotundis imbricatis, vexillis deflexis persistentibus, calycinis dentibus glabris, binis superioribus brevissimis. Lotus montanus aureus amplo Lipuli capite, annuus. Barr. Ic. 1024 , fig. inter?

Celle espèce a beaucoup d'affinité avec le Trifolium spadiceum; ses lleurs prennent de même en vieillissant une couleur de café brûlé; mais elle en diffère par ces mêmes fleurs dont l'étendard est plus gुrand, et parce que celles-ci forment des tètes moins alongées et presque sphériques; enfin, parce que les dents du calice sont glabres. On trouve cette plante dans les montagnes de la Provence et de la Savoie; je l'ai recue de MM. Clarion, Castan, Deiaroche et Thomas : elle fleurit en juin et juillet. ( $)$.

\section{TRIFOLIUM CAMPESTRE. Schreb. in Sturm. Ic.}

11. caiule diffuso, ramis decumbentibus, foliolis ovato-oblongis cuneato-obcordatisve, intermedio peciolato, vexillis de- 


\section{( 115$)$}

Rexis persistentibus, caijoinis dentibus linearibus glabris, binis superioribus multò brevioribus. T. procumbens (1). Smith.,

(1) Les Trèfles de celle section sont très-difficiles à bien distinguer, tant ils sont voisins les uns des autres, et tant les caractères qui les sjparent sont peu prononcés: c'est ce qui a été cause que j’ai fait, dans la Flora Gallica, plusieurs erreurs touchant les Trifolium agrarium et procumbens; erreurs que je vais tâcher de rectifier ici. J'observerai d'abord, quant à la première espèce ['Trifolium agrarium], que la foliole impaire est toujoưrs sessile, et que c'est même là, le principal caracière qui puisse la distinguer des individus à tige droile et simple du $T$. campestre; ensuite le synonyme de Vaillant [ Melilotus pratensis, capitulis longissimis pediculis insidentibus. Bot. Par., tab. 22, f. 4$]$, rapporté à cetle espèce, ne lui convient pas, et il doit, au contraire, être rapporté au T. procumbens; enfin cette plante, au lieu de venir dans les prés humides, croît dans les bois ou dans les champs, et elle est assez rare aux environs de Paris.

Quant au T. procumbens, le synonyme de Smili et la figure de la Flora Danica ne lui appartiennent pas, et doivent être reportés au $T$. campestre. Le synonyme de Vaillant [Melilotus qui Trifolium pratense luteum, capitulo lupuli, vel agrarium. Bot. Par., tab. 22, f. 3], doit également en être distrait, pour être transporlé au 7 . agrarium. Je crois aussi que la variété $\beta$ [T. spediceum, Thuil. ] n'est pas du tout différente du vrai T. agrarium. Pour ce qui est de l'habilation du T. procumbens, il crô̂t dans les prés humides; c'est lui qu'on trouve dans les préz à $S$. Gratien et ailleurs, aux environs de Paris. 


\section{$(x+6)$}

F1. Brit. 792. (synon. confusis). Fl. Dan., tab. 796. T'. agrarium. Curt. Lond. Fasc. 3, tab. 45 .

Cefite plante est commune dans les champs et sur le bord des'bois; ses fleurs sont d'un jame ordinairement peu foncé; elles paroissent dépuis le mois de mai, jusqu'au mois de septembre. (O).

\section{LOTUS IIRSUTUS incanus.}

Cetle variété se fait remarquer par les poils nombreux et soyeux qui reconvent tonte la planie el la rendent blanchâtre; elle ne présente d'ailleurs ancun antre caractere; et des ęchántillons, dans lesquels les poils sont un peu plus rares, la rapprochent et ne permettent pas de la séparer de l'espèce principale. IM. G. Robert l'a trouvée aux îles d'Hières; M. Requien l'a recueillie au mème lieu, et Mr. Rohde à Nice. 5 .

LOTUS PARVIFLORUS. 'Desf., Fl. All. 2 , pag. 206 , tab. 2 Ir. Decand., Ic. I'ar. fasc. I, pag. 9 , tab. 30.

L. pilosus, caule ramoso, capitulis axillaribus dimidiatis 4-6-floris, bracteis monophyllis, calycilus corollam subcequanvibus, leguminibus oblongis compressis bresibus 3-5-spermis. 
"Caulibus erectis. Desí. 1. c.

\& C'aulilus prostratis. Desf.1. c.

Celte espèce est très-voisine du Lotus hiispidus et da $I$. diffusus; la briéveté de ses légumes est le meilleur caractère qui puisse servir à la faire distinguer. Je l'ai recue de M. Noiscite qui l'a recueillie dans l'île de Corse; ses lleurs sont jaunes, l'étendard est plas foncé que le reste de la corolle.

LOTUS DIFEUSUS. Soland, in Merb. Bapks. ex Smith, Fl. Brit. 794. Engl. Bot., tab. 925 .

L. pilosus, caule ramosissimo decumbente, pedunculis axillaribus 1-2-floris, bracteis subtriphyllis, calycibus corolla paulò brevioribus, leguminibus teretibus strictis gracilibus poly'spentnis.

MM. G. Robert et Reguien ont trouvé cette espèce aux îles d'Hières; M. Desvaux l'a recueillie aux environs de Poitiers, et M. Decandolle l'inciique auprès de Nantes : elle fleurit en mai, -juin, juillet; la corolle est jaune avec l'étendard plus foncé.

\section{IOTUS COMMBRESIS. Willd. - Lois., N.}

Gall. 488. Balb., Miscel. alt. 24.

II. Balbis avoit trouvé cette espèce à Fréjus; M. Lejeune vient de la retronver à l'antre 


\section{( I18)}

extrémité de la France et dans la partie la plus septentrionale, aux envirous-d'Ensival, dans le ci-devant pays de Liége, aujourd'hni département de l'Ourbe. Les échantillons du Tord offrent une particularité qu'on n'observe pas dans ceux du Midi, les dents du calice et l'extrémité des feuilles sont terminées par un ou plusieurs poils.

MEDICAGO PROSTRATA. Jacq. Hort. Vind. I, pag. 3g, tab. 8g. Lin., Suppl. 3 fo. Willd., sp. 3 , pag. 1405.

M. pedunculis racemosis, leguminibus cochleato-contortis lrevibus, stipulis subulatis basi dentatis, foliolis lineari-cuneiformibus apice dentatis.

Celte plantc croît dans les lieux secs en Toscane; elle má été communiquée par $\mathbf{M}$. Savi : ses fleurs sont jaunes. $\psi$.

\section{MEDICAGO LITTORALIS. Rohde, Herb.}

M. pedunculis 2-4-floris, leguminibus cochleatis cylinaricis glabris, aculeis subulatis rectiusculis patentibus raris subbrevibus, stipulis dentatis, foliolis cuneatis subtriargularibus pubescentibus apice dentatis, caule prostrato. M. polymorpha rigidula. Bertol., P]. Gen. 97 [ exclus. sgren.]. 


\section{( IIg)}

Cette espèce croît dans les sables du bord de la mer, dans le pays de Gênes, à Nice. et sur toutes les côtes de Provence; elle ma été communiquée par MM. Rohde, Bertoloni, Suffren et Requien; elle leurit en mai et juin; ses fleurs sont jaunes. 2f ?

MEDICAGO OBSCURA. Retz, Obs. r, p. 24, t. r., Willd., Sp. 3, p. 1406.

M. pedunculis racenosis, leguminibus reniformibus dispermis, stipulis dentatis, foliolis rhombeo-ovaris. Willd.

Cette espèce croît dans les départemens méridionaux. $(\cdot)$.

\section{MEDICAGO ELEGANS. Jacq. - Willd. Sp. 3, p. 1408.}

M. pedunculis subbifloris, leguminibus inermibus cochleatis orbiculatis planis margine transversim rugosis, stipulis dentatis, foliolis rhombeo-obovatis cientatis. Willd. M. rugosa. Lam., Dict. 3 , p. 632. Medica cochleata major dicarpos, capsula compressâ orbiculatâ rugosâ albâ. Moris., Hist. 2 , p. 152 , s. 2 , t. 15, f. 4 .

On trouve celte plaute dans les parties méridionales de la France. (). 


\section{( 120$)$ \\ SYNGENESIE.}

SONCHUS PECTINATUS. Decand., Voyag. Bot., pag. 78 .

S. caule angulato glabro, pedunculis ramosis pilos glandulosos hinc indè gerentibus, involucris glabris, foliis pectinato-multifulis, acutis subintegris. Dec.

Je ne commois pas celte plante, je la rapporte d'après M. Decandolle, qui l'indique comme nouvelle espece, croissant sur les rochers maritimes, aupres de Collioure en Roussillon.

\section{TARAXACUM OBOVATUM.}

T. foliis obovato-oblongis obtusiusculis plis minisve dentatis, quandòque integerrimis, scapo unifloro, squamis calycinis cxterioribus ovatis patulis. $\pi$. officinale d. Lois., Fl. Gall. 5 × 2. Leontodon obovatus. Willd., Sp. 3, pag. 1546 .

N. Reguien a trouvé celle espèce sur les coleanx arides à Avignon; M. Guckenberger l'a observée à Iflontpelier, et M. Clarion l'a recueillie sur les montagnes aux environs de Ceyne, daus la Haute-Provence. Les fleurs sont jaunes, elles paroissent en avril, mai ct juin. 36 . 
HIERACIUM PROSTRATUM. Decand., Voyag. Bot., pags. $7^{8}$

H. caule basi prostrato foliisque inferioribus lanatis, superiorlubs pedunculisque nudiusculis, floribus subcorymbosis, calycibus pilosis.

Cette plante paroît différer assez de l'Hieracium eriophorum pour en être séparée. On l'en distingue facilement, parce que sa lige est ionjour's couchée, surtout à sa base, parce que les longs poils, qui recouvrent sa tige et les fenilles inférieures, sont moins nombremx, et qu'ils disparoissent pre que toutà-fait sur les feuilles supérieures et sur les pédoneules; enfin, parce que les flenrs ne forment qu'un corymbe peu fourni et irrégulier. J'ai trouvé, le premier, cette espèce dans les dunes aux environs de Bayonne, entre Biarits et l'Adour, au mois de juin : 803; mais ne l'ayant pas alors observée en lleurs, je ne pus determiner à quel genre elie appartenoir. M. Decandolle l'a retronvée depuis dans les̀ memes lieux, et elle m'a été communique par le Docieur Thore, qui l'y a anssi remillie en fructification dans les premiers jours de septembre: ses fleurs sont jaunes. $2 \%$. 
CREPIS STRICTA. Scop., FI. Carn. 2, p.99, tab. 47 .

C. foliis inferioribus pinnatifidis, canle erecto ramusque patulis strictis, floribus terminalibus subcorymbosis, corymbis pauci/loris, calycibus subvillosis, pappis sessilibus. C. virerss. Santi, Viag. al mont., p. I22, tav. 2.

M. Bertoloni a trouvé cette espèce anx environs de Sarzane, dans la Ligurie : elle a un port tout particulier qui peut servir à la faire reconnoître; ses fleurs sont pelites, d'un beau jaune, elles paroissent en avril et mai. $(\odot$.

CREPIS BELLIDIFOLIA. Lois., Fl.Gall. 527•

Cette espèce, découverte en Corse par M. G. Robert, a été retrouvée, par M. Suffien, dans les lieux arides aux environs de Salon, en Provence: elle fleurit en mai. Les feuilles varient dians les échantillons que M. Suffren m'a communiqué; d dans les uns elles sont entières; dans les autres, elles sont roncinées.

CREPIS VESICARIA. Lin., Sp. I I32.

C. foliis ovato-oblongis runcinato-dentatis hirtis, caule basi sulcato, floribus corymbosis, bracteis calycinisque squamis exte- 


\section{( 123 )}

rioribus membranaceis scariosis. Willd., Sp. 3., pag. 159 f́.

Cetle plante a berucoup de rapports avec la Crepis iantinensis; elle a comme celle-ci ses semences amincics au sommet et formant une espèce de pédicule sous l’aigrette : elle m’a été commaniquée par M. Bertoloni, qui l'a recueilie dans le pays de Gênes; elle fleurit en mai; ses fleurs sont jaunes. 24?

CREPIS TARAXACOIDES. Desf., AH. 2 ,

$$
\text { pag. } 23 \text { s. }
$$

C. foliis runcinato-pinnatifidis dentatis hispidis plerisque radicalibus, scapis adscendenutibis subnudis foliolisve linearithus instructi: I 3-floris (rarò multifloris), calycibu, tomentosis, pappis stiputatis. C. taraxucifulia. Willd., Sp. 3, pag. 1593.

Cette espèce a aussi beaucoup de rapports avec la Crewis iaurinensis; mais elle en differe évidenment, parce que ses flenrs ne sont pas disposées er corymbe, mais portées sur des hampes simples, bifurquees ou trifides.

MM. Iratad et Sufren ont trouvé cette plante dans les exidroits stériles et pierreux aux enviruns d'Arles et de Salon, en Pro. vence : elic lleurit en juin et juillet; ses fleurs sout jaunes. ô. 
HYPOCHARIS MACULATA. Lin.-Lois., F. Gall. 53 r.

Cette plante rarie beancoup: on la trouve le plus souvent à fenilles marquécs de tacnes violettes, et graelquefo is à feuilles dépnurvues de taches; ou la rencontre uniflore, d'antres fois sa tige se ramifie et porte jusqu'à cing à six fleurs; cufn, ses feuilles sont simplement dentées ou elles sont pinnalifides. M. Perret m’a communiqué cente dernière varieté, qu'il a recucille aux cnvirons de Tuin.

\section{HYPOCHTRIS BALBISII. N.}

II. foliis obovato-oblongis dentatis hispidis, scapis subunifloris, calycibus glabriusculis, pappis omnibus stipitatis cequalibres. $\boldsymbol{H}$. minma. Balls. Misc., Alt. 29 (non Def. nec IVilld.).

Celte espèce m’a été communiquée par $\mathbb{M}$. Balbis qui l'a tronvée dans les lieux stériles, aux environs de Frejus, en lrovence. Elle diffère évidemment de l'E. minima par ses aigreties tontes pédiculées; quant à celte dernière plante, je crois qu'elle n'est qu'une v u icle de l'H. glabra. $($.

SERRATULA TNCTORIA. Lin. - Lois., F1. Gall. 534.

\& S. integrifolia, foliis indivisis serratis. 
* S. pygnncea, caule unifloro unciali, foizis pinnarifids.

La prenière de ces deux variélés a été trouvée aux environs de Turin par M. Perret; jen ai recueilli un seul excmplaire dans la forêt de Montmorency, à quatre licues de Paris. La seconde varieté es fort singulière; elle est unillore, et ra gueres plus d'vin pouce de haut. Je l'ai reçue de M. Grateloup, gui l’a trouvée daus les Landes, anx environs de Dax.

\section{SERRATULA HUMILLS. Dest., Fl. All. 2,} P. 244, t. 220. Pers., Synop. 2, p. 3̧go.

S. foliis pinnatifulis, laciniis integerrimis lanceolatis subtis niveo-tomentosis, caule unifloro subunciali, calycibus tomentosis. S. mollis. Cavan, Ic. 1, p. 62, t. 90 , t. I. Pers., Synop. 2, p. 3̈go. S. suluacaulis. Pers., Synop. 2, p. 3yo. Cardunis mollis. Gouan., 111. Bot. 03. (non Lin.).

Cette plante croit aux environs de Mont. pollice; ses fleurs sont rougeatres et paroissent en été. 2 .

\section{CNICUS APVENSIS $\beta$}

C. arvensis, pedunculis foliisque subtis tomencosis.

Dans cette variété, les pédoncules et le 


\section{( 126$)$}

dessous des feulllés sont recouverts d'un duvet blanc et cotonneux. L'échantillon m'a éié communiqué par M. Mougent, et a été trouvé anx environs de Sedan, département des Ardennes.

SANTOLINA PINNATA. Viv., Fl. Ital., Frag. $x$, pag. I, tab. I.

'S. foliis quadrifariam dentato-pinnatis glaberrimis, pinnis linearibus acutiusculis, pedunculis uniforis calycibusque glabris.

Cette espèce croît sur les montagnes des Apennins, dans le pays de Gênes. Elle fleurit en juillet; ses fleurs sont d'un jaune trèsclair. M. Berloloni m'en a communiqué des échantillons. $\hbar$.

\section{ARTEMISIA PEDEMONTANA. Balb, ined.}

A. cespitosa, foliis tomentoso-incanis, inferioribus palmato - multifidis petiolatis, superioribus pinnatifidis sessilibus, floribus axillaribus globosis subsessilibus nutantibus, calycinis squamis linearibus acutis tomentosis, corollulis lanatis. Balb.

Cette espéce a été découveric en Piémont, dans la vallée de Macros, aux environs de Prass, par mon ami, le Docleur Balbis, qui a bien roulu me la communiguer avant de 
l'avoir publiée lui-même : elle fleurit à la fin de l'été. 4.

\section{ARTEMISIA FRAGRANS. Willd., Sp. 3 , pag. 1835.}

A. foliis incanis, radicalibus bipinnatis, pinnis confertis linearibus obtusis, rameis pinnatis sessilibus, floralibus:s simplicibus linecaribus flore brevioribus, floribus oblongis erectis sessilibus in racemulis dispositis.

Cette espèce m'a été communiquée par MM. Balbis et Savi; elle croît au bord de la mer, dans le pays de Gênes et la Toscane : elle fleurit en août et septembre. 4.

SOLIDAGO CAMBRICA. Ait., Hort. Kew. 3, pag. 218. Willd., Sp. 3 , p. 2066.

S. foliis ovato-lanceolatis serratis pilosiusculis, caule simplicissimo pubescente, racemo terminali erecto conferto, pedunculis 1-3-Mloris. S. littoralis. Savi, Cent. 182. Virga aurea cambrica, floribus, conglobatis. Dill., Elth. 2, pag. $413 \overline{3}$, t. З3०6, f. 393 .

Cette plante n'est qu'imparfailement distincte du Solidago Virga aurea. Lin., et n'en est probablement qu'une variété causée par la 


\section{( 228 )}

différence d'habitation: elle n'en diffère effectivement que par sa lige simple, et qui ne s'élève guères au delà de trois à dix pouce; et parce qu'elle est plus pubescente dans tonies ses parties. Elle croît au bord de la mer, ea Toscane et dans le pays de Gênes, d'où elle m’a été envoyée, par MM. Savi et Bertoloni; seo fleurs sont jaunes, et viennent en septembre et octobre. 2 .

BELLIS SYLVESTRIS. Cyrill, Pl, rar. fasc. 2 , pag. 12 , tab. 4. Willd., Sp. 3 , pag. $\angle \mathrm{I} 22$.

$B$. foliis lanceolatis obtusis trinerwits subcrenatis, scapo nudo uniflora, calycinis squamis oblongis.

Cette espèce est très-voisine du Bellis perennis; elle est seulcment plus grande dans toutes ses parties; ses feuilles et les folioles du calice sont plus alongées. Elle fleurit en antomne; les demi-fleurons sont blancs en dedans, rouges en dehors. On la trouve dans les bois, en Provence et dans le pays de Gènes. MM. G. Robert et Berwoni m'en ont communiqué des échantillons. 4.

\section{CHRYSANTHENUM PERPUSILLUA. N. tab. 6 , fig. 3.}

C. caule pusillo subramoso stolonifero, foliis 


\section{(129)}

pinnatifidis, pinnis rotundatis integerrimis, floribus axillaribus perdunculatis, pedunculis caule longioribus, seminibus nuclis.

Cette espèce a été découverte dans les petites îles Sanguinaires, voisines d'A jaccio en Cor'se, par M. Lasalle, qui en a envoyé des échantillous a M. Desfontaines, lequel a bien voulu me les communiquer; c'est une petile miniature, sa fleur n'a gueres que deux lignes de diamètre, et la plante entiere n'a pas plus d'un pouce de hant. Le disque des fleurs est jaune, et les rayons sont blancs. $(\cdot)$.

\section{ANTHEMIS INGRASSATA. N.}

A. caule ramoso patulo foliisque bipinnatifidis pubescentibus, lacinulis integris acutis, pedunculis incrassatis, seminibus tetraquetris sulcatis apice umbilicatis, receptaculis conicis.

Cette espèce a le port de l'Anthemis mixta; mais elle en diffère par ses fenilles plus incisées, abondamment couvertes de poils blanchâtres, et par la forme de ses semences qui sont à quatre angles, élargies à leur sommet et ombiliquées. Elle croît anx environs d'Arles et à l'embouchure du Rhône, dans les endroits stériles et pierreux, où elle a été découverte par MM. Artaud et Requien : ses fleurs sont 


\section{( 130$)$}

blanches; elles paroissent en juin et juillet. (.) ?

\section{CENTAUREA VARUFOLIA. N.}

C. caule erecto ramoso, foliis scabrizusculis, aliis linear-lanceolatis integerrimis, aliis basi dentatis, coteris pinnatifidis, pinnulis oblongolanceolatis integris, squamis calycinis ovato-lanceolatis ciliatis.

Celte plante a beaucoup de rapport pour Ja forme de ses calices, et la couleur purpurine de ses fleurs, avec la centaurea scabio$s a$; mais clle en differe beancoup par le port. Elle est plus rameuse; ses feuilles sont souvent très-entières, linéaires-lancéolées; quelquefois pinnatifides; d'autres fois munies seulement d'une ou deux dents à leur base. M. G. Robert a trouvé celte espèce dans les champs, en Provénce, du côlé de la znontagne de l'Achen; elle flemrit en juillet. 2 ?

\section{CENTAUREA RUPESTRIS. Lin., Sp. I 2 y8.}

C. pubescens subtomentosa, caule crecto subramoso, foliis inferioribus bipinnatis, superioribus simpliciter pinnatis, foliolis omnibus linearibus sulcatis, calycinis squamis ciliatis subspinosis. C. arachnoidea. Viv., Annal. Dot. I, Par. 2, pag. 183. Jacea montancs 


\section{( $\mathbf{I} 3 \mathbf{I})$}

lutea minima tenuifolia. Col., Ecphr. I, p. 36 , t. 35 , f. 2 .

Cette plante s'élève depuis un pied jusqu'à trois pieds de hauteur; ses fleurs jaunes paroissent en juillet. Elle croît dans les lieux pierreux du pays de Gêues, d'où M. Bertoloni m’en a envoyé des échantillons. 2f.

\section{G Y N A N D R I E.}

ORCHIS BREVICORNU. Viv., Fl. Ital. Frag. fasc. I, p. II, tab. 12, f. 2.

O. bulbis subrotundis, foliis lanceolatolinearibus, spica laxâ, labello trilobo denticulato, petalis exterioribus patentibus, cornu obtuso conico germine criplò breviore.

Cetle plante croît sur les collines aux environs de Gênes; ses fleurs sont purpurines. Elle se rapproche de l'Orchis mascula et de l'O. laxiflora; mais elle paroît en différer assez pour faire une espèce distincte. $\mathcal{F}$.

ORCHIS SECUNDIFLORA. Bertol., Rar.Ital. PI. Dec. 2, pag. 42.

O. bulbis subrotundis, foliis lanceolatis, spicí densâ, floribus secundis deorsumb inibricatis, pelalis coadunato cucullatis, 


\section{( 132 )}

labello tripartito, laciniis lateralibus lineasibus, medià duplò latiori subtridentatî,, cornu brevissimo. Ophrys densiflora. Desf., An. du Mus. vol. 10, pag. 228, tab. 16. Desf., Choix de Pl., pag. in, tab. 6.

Celte plante a été trouvée par M. BertoJoni sur les collines aux environs de Sarzane, daus le pays de Gênes; ses fleurs sont couleur de chair ou d'un ronge pâle; elles pa. roissoient en avril et mai. L'espèce, dont elle approche le plus, paroit être l'Orchis zustulata. 2f.

ORCHIS ROBERTIANA. Lois., Fl. Gall. 6o6, tab. $2 \mathrm{I}$.

Il fatut ajouter pour synonyme à celte es.pèce: Orchis longibracteata. Bernardi, Sicul. Pl. Cent. I, pag. 57 , t. 4.

\section{OPHRYS PALUDOSA. Lin., Sp. r34r.}

O. bulbis ovatis, caule pentagono subnudo, foliis oratis ovato-oblongisve, labello ovatolanceolato integerrimo, petalis duobus interioribus lateralibus reflexis. O. bifolia palustris nostras. Pluk., Phyt, t. 247, f. 2. Malaxis paludosa. Swartz, Act. Holm. Ann. 1789, 127, t. 6 , f. 2. Willd., Sp. 4, pag. $9 \mathrm{I}$.

Celte espèce croit dans les marais, an milieu 
des Sphagnum; elle a été trouvée aux environs de Malmédi, dans le département de l'Ourthe, par N. Lejeune; elle tleurit en juillet; ses fleurs sont d'un jaune verdâtre. z6.

OPHRYS SPECULUM. Bert., Pl. Gen. I24.

O. bulbis subrotundis, caule folioso; labello convexo elongato villoso subintegerrimo, sursim incurvo, apice breviter appendiculato, anticè maculấ glabrấ nitidấ insignito.

Cette plante a été trouvée sur les collines aux environs de Gênes, par M. Bertoloni; aux environs de Turin, par M. Perret; et dans le pays de Nice, par M. Rohde. Ses fleurs qui paroissent au mois de mai, sont conleur de rose, leur division inférieure [le nectaire ou labcl] est velue, d'un pourpre noirâtre, remarquable par une tache plus pâle, glabre et luisante. $2 \%$.

OPHRYS LUTEA. Cav., Ic. 2 , pag. 46 , tab. 160 .

O. bulbis subrotundis, caule folioso; labello pubescente obovato ajice trilobo, lobis subrequalibus, medio majore emarginato, petalis obtusizusculis, tribus exterioribus 


\section{( 134$)$}

ellipticis, binis interioribus lanceolatis duplò brevioribus. Villd., Sp. 4, p. 70.

Celte espèce a été trouvée aux environs de Nice, par M. Risso; aux Martigues dans le territoire d'Arles, par MM. Requien et Audibert; M. Rohde m'a aussi assuré qu'elle avoit été recueillie aux environs de Montpellier; elle fleurit au mois de mai. $\mathcal{H}$.

SERAPIAS TRILOBA. Viv., Fu. Ital. Frag fasc. I, pag. II, t. I 2, f. I.

S. bulbis subrotundis, foliis lanceolatis, labello trilobato, lobis omnibus exsertis suboequalibus rotundatis crenato - undulatis.

Cette espèce croît dans la Ligurie, aux environs de Gênes; ses fleurs sont purpurines. $\mathcal{H}$.

ARISTOLOCHIA LUTEA. Desf., Ann. du Mus. vol. Io, tab. I9, pag. 295. Desf., Choix de Pl. I3, tab. 8 .

A. caule erecto non scandente, foliis cordatis pedunculatis, floribus solitariis luteis folio longioribus, corollce labio incurvo fornicato, capsulis cernuis. Radix luberosa subrotunda. A. orientalis subrotunda, folio oblongo cordiformi, flore tubulato luteo. Tournef., Coroll. Inst. 9 . 


\section{( 135$)$}

Cette plante a été trouvée dans les mon. tagnes du pays de Gènes, par M. Bertoloni; et anx environs de Turin, par M. Perret. Ello fletrit en mai et juin. $2 \xi$.

\section{O N OE G I E.}

ChARA TRANSLUCENS. Pers., Synop. 2, pag. 53r.

C. Latè virens pellucida flexilis, caulibus prcelongis subsimplicibus, verticillis inferioribus distantissimis, superioribus sub. approximatis, ramulis fructiferis brevissimis verticillato-glomeratis, fructibus bracteolatis.

Les tiges de celte espèce ont la consistance et la grosseur d'une corde à bnyeau ordinaire; elles sont d'un vert gai, très-glabres et luisantes. Je les ai trou vées en fructification, dans les mares et les étangs des forèts de SaintLéger et d'Armanvilliers, pendant les mois de juin et juillet. ( $)$ ?

\section{CHARA GLOMERATA, Desv., ined. (I).}

C. coespitosa pellucida Rexilis, caulibus brevissimis filiformibus, ramulis numerosis

(x) M. Desvaux ayant reconnu plusieurs espèces nouvelles dans le genre Chara, a bien voulu me les communiquer, avant de publier un travail plus con. 


\section{$(136)$}

inverticillum conferim dispositis ; verticillis approximatis.

Cette espèce a guelques rapports avec le Chara fexilis; mais elle est peu élevée, à peine ramerse, et ses liges forment des espèces de gazons. Elle se trouve dans les rinisseaux dont le comrant est peu rapide. MM. Desvaux et Thuillier l'ont recueillie aur environ de Paris.

CharA TENUISSIMA. Desv., Jomrm. Bot., vol. 2 , pag. 3 เ 3.

C. caulibus setaceis pellucidis, ramis glomerato verticillatis brewsimis tenuissimis pelluciais, ramulis subllabellatis.

M. Desvanx a ironvé celie espèce en fructification, pendant le mois de juin, daus les ruisseaux d'me fontaine aux environs de Poitiers. M. G. Robert me l'a aussi envoyée des environs de Toulon.

\section{CHARA OBTUSA. Desv., ined.}

C. caulibus subflexilibus subopacis fumicularibus, verticillis distantibus ramulis lineca-

sidérable qu'il a commencé sur le genre eritier, ot dans lequel il se propose d'examiner tontes les espèces comparativement. 


\section{( 137 )}

ribus apice obtuso-acuminatis. Planta desiccata glaucescens.

Ce Črara a été recueilli par M. Thuillier, daus les canx stagnautes, aux environs de Paris; et par M. Desvanx, dans lé Poitou.

\section{CHARA FRAGILTS. Desv., ined.}

C. caulibus opacis rigidissimis fragilibus, ramulis articulatis, articulis approximatis, bracteis fructu brevioribus. C. vulgaris, Thuil.

ß. C. fragilis minor:

Cette espèce se trouve dans les eaux stagnantes, aux environs de Paris. La variété est plus petite dans toutes ses pariies, excepté dans ses globales fructifères qui sont égaux à ceux de l'espèce.

\section{CHARA DELICATULA. Desv., ined.}

C. caulibus opacis rigidis minutissimis fragilibus, ramulis brevibus capillaribuis articulato-torulosis.

Cette espèce a beaucoup de rapports avec la précédente; mais sa tenurté est si grande qu'elle ne peut en être considérée comme une simple variété. Le Chara capillacea en est encore plus voisin; mais les rameau de ce 


\section{( 138 )}

dernier sont un peu moins grêles, et surtout beauco:np plus alongés. Le Chara delicatuia a elé tronvé daus les ruisseáux aux environs de Paris, par M. Desvaux.

\section{CHARA INTERTEXTA. Desv., ined.}

C. caulibus opacis rigidis capillaribus, ramulis vericillorum superiorum subaculeatis.

M. Desvaux soupconne que cctle espèce, mieux examinée, pourra rentrer dans quelqu'autre; cependant les rameaux supérieurs étant garnis de très-petites pointes, il est possible que, si on la voyoit dans un meilleur. état qu'elle n'a eté observée dans son herbier et dans celui de M. Thuillier, ellé présentât des caractères plus prononcés. Elle se trouve davs les eaux stagnantes, aux envirous de Paris.

\section{CHARA DECIPIENS. Desv., ined.}

C. caulibus viridibus apice aculeatis, aculeis retroflexis caducis, ramulis subpellucidis articulatis simplicibus.

Cette espèce perd très-facilement les appendires aigus qui couvrent ses tiges lorsqu'elles sont encore jeures, ce qui fait qu'elle finit par parnître presque toute glabre. M. Des. vaux l'a trouvée dans les étangs, aux environs de Poitiers. 


\section{( 139 )}

\section{CHARA CANESCENS. N.}

C. caulibus tenuissimis canescentibus copiosè hispidis, spinulis subulatis subverticillatis, ramis dichotomis nitidis, internodiis approximatis, ranulis fructiferis brevissimis verticillatis, bracteis fructu duplò lon. gionilus.

Cette espèce diffère du Chara hispida, nou-senlement parce qu'elle est trois à quatre fois plins petite dans toutes ses parties; mais encore par la couleur blanche et brillante de ses tiges et de ses rameaux. M. G. Robert l'a trouvée dans les eaux stagnantes, aux environs de Toulon.

\section{BETULA CORDATA. N.}

B. foliis subrotundo cordatis obtuśis, axillis venarum subtics villosis, seminibus compressis alâ membranaceá brevissimá cincbis.

Cet arbre a été trouvé dans l'île de Corse, par A. G. Robert. 5 .

URTICA MEMBRANACEA. Poir. - Lois., F]. Gall. 653.

Cette espèce, que M. Artaud a trouvée, le premier, en France, aux environs d'Arles, 


\section{( 140 )}

a été retrouvée depuis en plusieurs endroits de la Provence, par MM. G. Robert et Requien; et en Bretagne, par M. Bonnemaison: elle fleurit, pendant le printemps et l'été. Je ne crois pas qu'elle soit vivace; clle me paroit plutôt annuelle.

\section{AMARANTHUS ALBUS. Lin. - Lois., Fl. Gall. 655.}

Celte plante, regardée par Linné comme indigène de l'Amerique Septentrionale, est aujourd'hui comme spontanée dans plusieurs parties du Midi de la France. Je l'avois d'abord trouvée anx environs de Montpellier; M. Perret vient de la retrouver très-abondante aux environs de Turin; et M. Bertoloni me l'a'envoyée du pays de Gêneśs

\section{AMARANTHUS SYLVESTRIS. Desf., Catal. Hort. Par. 44.}

A. caule ramoso erecliusculo, foliis ovatis petiolatis, floribus triandris glomeratis axillaribus, calycilus triphyllis mucronatis. A. sylvestris et vulgar is. Tournef., Pl. de Par. 2, p. 248, et Herb.sic. (exclus. synon). Vail., Bot. Par. 2 I.

Ceitte plante est très-dislincte de l'Amaranthus Blitum avec 1:quelle la plupart des Botanistes modernes paroissenl l'avoir confondue; 


\section{( 1 f 1 )}

s'ils ne l'ont pas entièrement oubliée. Elle en diffëre, parce que cette dernière espèce a ses tiges toujours conchees, et jamais redressees, ses fenilies échancrées au sommet, et ses tiges terminées par des grappes de fleurs qui forment l'épi, ce qui n'a jamais lieu dans l'Amaranthe sauvage. Celle-ci croît aux environs de Paris, dans les lieux cultivés et sur le bord des chemins. Il paroît qu'elle n'est pas rare en France, car je l'ai recueillie aux environs de Dreux; M. Flugge l'a trouvée sur les remparts de Grenoble; et M. La. mouroux, en m'en communiquant des échantillous, m'a assuré qu'elie étoit très-commune à Agen. Elle fleurit pendant tout l'éte; ses fleurs sont verdâtres, un peu rongeâtres. ( $)$.

\section{AMARANTHUS ASCENDENS. N.}

A. caule ramoso ascendente, foliis ovatis emarginatis, floribus triandris glomeratis et subspicatis, glomerulis axillaribus, spicis terminalibus axillaribusque, calveibus triphyllis acutiusculis. Blium pulchrum magnum album. J. Bauh., Hist. 2, p. 967 . Blitum album majus. Tournf., Inst. 507 , et Herb. sic.

Cette espèce diffère de l'Amarantluzs Blitum, par ses ligges redressées, ct parce qu'elle est trois fois plus grande daus toutes ses 


\section{(142)}

parties. La figure du Blitum pulchrum rec. tum magnum rubrum, J. Bauh., Hist. 966, la représente assez bien. M. Requien a trouvé cetie plante dans les lienx cultivés auy environs d'A vignon; et M. Lamouroux l'a recueillie à Agen. Ses' leurs sont verdàtres et se snccèdent depuis le mois d'août jusqu'en octobre. $(\cdot)$.

AMARANTHUS SPICATUS. Lam., Fl. Fr.2, pag. 192. Dict. Enc. I, pag. I17. Lois., FI. Gall. 655.

Il fant retrancher cette espèce de la Flore de France; car elle ne differe pas de la suivante, d'après la comparaison des échantillons, faite dans l'herbier de M. de Lamarck. Le calice est certainement à cinq folioles, et il contient cinq étamines.

\section{AMARANTHUS RETROFLEXUS. Willd.--}

Lois., Fs. Gall. 556.

Il faut ajouter à cet article les synonymes de l'Amarantlus spicatus. Lam., qui n'en differe pas. Si cette plante est originaire de la Pensylvanie, comme le dit M. Willdenow, clle est aujourd'hui si bien naturalisée en France, qu'elle y croît comme dans son pays natal. MM. Balbis et Perret me l'ont envoyée du Piémont; M. Requieu l'a trouvée 


\section{(143)}

à Avignon; M. Rohde à Perpignan; M. Lámóuroux à Agen, et je l'ai recueillie plusienrs fois aux environs de Paris.

QUERCUS PSEUDO-SUBER. Desf., FI. Atl. 2, pag. 3.48. Savi, Cent. PJ. Etrus. 201.

Q. foliis perennantibus lanceolatis sinuatis subrius pubescentibils, lobulis mucronatis, cortice rimoso fungoso. Q. Hispanica \&. Lam., Dict. I, p. 723 .

Cet arbre croît en Toscane; M. Savi m'en a communiqué un échantillou. $ち$.

\section{OSTRYA.}

Niasculi. Amentum imbricatum. Caly x squama. Corolla milla. Filamenta ramosa.

Fominei. Amentum nudum. Calyx nullus Corolla nulla. Capsulce inflatre, imbricatce basi monosperma.

OSTRYA VULGARIS. Willd., Sp. 4,

$$
\text { pag. } 469 \text {. }
$$

O. foliis ovatis acutis serratis, strobilis ovatis pendulis gernmis obtusis. O. Italica, carpini folio. Mich., Gen. 223, tab. 104, f. I, ct. 2. Carpinus Ostrya. Lin., Sp. 1417.

Cet arbre croît dạns le pays de Gênes, aux environs de Sarzane; il fleurit au mois de mai. M. Bertoloni m'en a commúniqué des échantillons. 5 . 


\section{$(144)$ \\ D I OE C I E.}

SALIX RUFINERVIS. Dec, Voyag. Bot. II.

S. subarborea, foliis ovato-oblongis acutis subcrenatis reticulato-nervosis, nervis subtuis villis rufis onustis, capsulis villosis. Dec.

M. Decandolle indique cet arbuste comme très-commun dans le Maine, l'Anjou et la Bretagne, où on le plante dans les haics. Il porte à Angers le nom de Saule brun. 5 .

\section{P O L Y G A M I E.}

PARIETARIA LUSITANICA. Lin., Sp. $149^{2}$.

P. caule ramoso procumbente, foliis ovatosubrotundis obtusiusculispetiololongioribus, glomerulis subsolitariüs axillaribus trifloris, calycibuis ovatis subconformibus, bracteis subquinquefidis flores cequantibus. $P$. alsinés folio, sicula. Bnc., Ic. rar. p. 47 , t. 24 , f. B. P. Lusitanica annua minima. Tournef., Inst. 5og.

Après avoir examiné les nouveaux écliantillons de cette espèce, qui m'ont été envoyés par M. G. Robert; après les a voir comparés à la figure de Boccone, et à l'herbier de Tournefort, $j$ e me suis assuré qu'ils ne pouvoient 


\section{( $\left.\mathrm{I}_{45} 5_{-}\right)$}

appartenir à la Parietaria Cretica. Lin., et qu'il falloit rayer de la Flore, cette dernière espèce, pour lui substituer la Pariétaire de Portugal. $(\cdot)$.

\section{R I P T O G A I E.}

\section{PTERTS CRISPA. Lin.-Lois., Fl. Gal. 704.}

Cette plante, déja indiquée dans les Alpes, Jes Pyrénées et les montagnes de Corse, a été retrouvée au Ballon, dans les Vosges, par $\mathbb{M}$. Mougeot.

\section{ASPLENIUM GLANDULOSUM. N.}

A. petiolo cylindrico foliisque confertis subpiubescenti - glandulosis pmnatis, pinnis ovato-subcordatis lobatis crenatis obtusissimis, lineis fructificantibus ovatis, primium distinctis, demiim confluentilus totum discum occupantibus.

MM. Suffren et Requien ont découvert cette fongère, qui paroît nouvelle, dans les fentes des rochers aux environs de Salon et a la fontaine de Vacicluse; ce dernier l'a communiquée à M. Guérin, qui l’a publiée sois le nom de Pulypodium Petrarchice, dans Sa description de Tancluse. La plante est en fructification, pendant une grande partie du printemps el de l'été. 2 \%. 


\section{( 146$)$}

\section{POLYPODIUM PLUKENETII. N.}

P. periolo paleaceo, foliis pinnatis, pinnis oblongo-lanceolatis pirnatifidis subtics piloso-paleaceis, lobulis acuminato-spinulosis, infinis anticis majoribus, fructificationibus vix rotundalis sub parvis tegumentis umbilicatis, punctis demim subconfluentibus. Aspidium lobatum. Smith, Fl. Brit. 3, pag. I123? Filix aculeata, Lonchitidis cemula nostras. Pluk., Phyt., tab. 180 , f. 3. (icon bona).

Celte espèce est intermédiaire entre le $P_{O}-$ lypodium Lonchitis, et le $P$. aculeatum; elle a ses folioles plus incisées que le premier, et moins profondément que le second : dans ce dernier les Inbes sont enx-mèmes de petites folioles distinctes. Je dois celle Fougère à M. Degland qui l'a trouvée en Bretagne. 24.

POLYPODIUM CRISTATUM. Lin., Sp. I55 I, (excluso synonymo Plukenetii).

P. petiolo paleaceo, foluis pinnatis, foliolis pinnatifidis, lobulis oblongis obtusis apice acute dentatis, punclis fructificationum rotunndis, tegumine umbilicato obtectis, longitudinaliter digèstis approximatis, demuim confluentibus. Polysticluum callipteris. Dec., Fl. Fr., n. ${ }^{\circ}$ 1426. Filix mas pin- 


\section{$(147)$}

nulis cristatis. Moris., Hist. 3, s. $14, \mathrm{t} .3$, f. II ?

L'arlicle de celte espèce, tel qu'il est dans ma Flore, pag. 707 , doit être corrigé ainsi que je viens de le faire ici. J'avois decrit, par erreur, une anire plante à la place du Polypodium cristatum de Liuné. Celle que je possèle aujourd'hui paroît être réellement l'espèce de cet auteur; ellc m'a été communiquée par M. Delaroche, qui l'a reçe des environs d'Abbeville, et je l'ai trouvée trèsaboudamment dans les licux bumides et maré. cageux de la forèt de Saint-Léger, à dix lieues de Paris. Elle fructifie dans les mois de juillet et ack̂t. Allioni indique le $P$. cristatum en Piémont; et M. Gouan, aux environs de Misontpellier; mais ¡ignore si leur plante est la même que la mienne. $2 \mathcal{L}$.

\section{NOUVELES ADDITIONS.}

VERBENA REPENS. Bertol, Pl. rar. Ital. Dec. 2, pag. 27.

$V$. glaberrina, caule repenie, folis carnosis cuneiformibus apice dentatis, spicis capitato-conicis longè pedunculatis, uracreis obuusissimis. IV. nodiflora. Thah., Pin. 26g. Prod. 125., clan icone boná. TV. no. 


\section{( 148 )}

diflora capite oblongo, etc. Bar., Ic. 855, figura mediocris. Verbenaca nodiflora. Imper., Hist. Nat., ed. Ven. 673, cum icone.

M. Bertoloni, dans sa seconde Décade des Plantes rares de l'Italie, a trèi-bien établi les différences qui existent entre cette plante, et l'espèce d'Amérique, à laquelle Linné a fort malà-propos consacré le nom de Verbena nodiflora, en la confondant avec celle d'Enrope, qui avoit recu ce nom des auteurs anciens. Les fleurs de la Verveine rampante sont blanches ou d'un rouge clair; elles paroissent en août et septembre. La plante croît dans les prés marécageux aux environs de Sarzane, dans le pays de Gênes; je l'ai ręue de M. Bertoloni. $(\cdot)$.

\section{VALERIANELLA DISCOIDEA.}

$V$. caule erecto dichotomo hispidiusculo, foliis oblongis subpilosis grossè dentatis, superioribus pinnatifidis, floribuscorymboso. capitatis congestis terminalibus, fructibus hirsutis subduodecimdentatis. Valerianella scabiosa semine, major Liusitanica. Moris., Hist. 3, p. 104, s. 7, t. 16, f. 29. Valeriana discoidea. Willd., Sp. I, p. I84.

Celte plante a été trouvée dans le Pays d'Àvignon, par M. Requien, el aux environs de Toulon, par M. G. Robert : ses fleurs 


\section{( 149$)$}

sont rougeâtres; elles paroissent en mars et. avril. ()$^{\circ}$.

VALERIANELLA ERIOCARPA. Desv., Jour. Bot.2, p. 3r 4. Ic. N., tab.3, fig 2.

$V$. caule erecto dichotomo, foliis oblongis integriusculis, floribus corymbosis subfastigiatis, bracteis lanceolatis glabris, fructibus lispidis subsexdentatis. Valerianella major semine umbilicato hirsuto. Moris., Hist. 3, p. 104, s. 7 , t. 16, f. 33 ?

M. Desvaux a découvent cette espèce dans les moissons, aux environs de Poitiers; elle fleurit au printemps. ( $)$.

\section{VALERIANELLA CARINATA. N.}

$V$. caule dichotomo divaricato, foliis oblongis integiniusculis, floribus corymbosis congestis, bracteis lanceolatis glabris, fructibus oblongis nudis umbilicatis dorso carinatis. An? Valerianella semine umbilicato nuclo oblongo. Moris., Hist. 3, p. rof, s. 7 , t. 16 , f. 3 I.

Celle espèce peut se confondre, quand elle est en fleurs, avec la I'alerianella olitoria; elle en diffère par ses bractées non cilices, et par ses semences oblongues, au lieu d'ètre arrondies et comprimées. Ce n'est qu'avec doute que jai rapporté le synonyme de Morison, 


\section{( 150$)$}

parce que la plante de cet anteur est représentén avec les feuilles pinnatitides, et que la ryienne les a entières. J'ai recueilli celle VaJérianelle; dans les champs aux environs de Paris; elle fleurit au printemps. (•).

\section{VALERIANELLA MEMBRANACEA. N.}

7 . caule erecio dicliotomo, foliis lanceolato. linearibus, inferioribus subintegerrimis basivedentatis, superioribus trifidis vel quinquefidis, floribrus corymbosis congestis, bracteis ovato - lanceolatis membranaceis ciliatis, fructibus semi-globosis tricostatis sut dentulis. Valerianella pumia. Dec., il. Fr. n. ${ }^{\circ} 3335$. Talerianella semine umbilicato nudo rotundo. Moris., Hist. 3, p. 04 , s. 7 , t. 16, f. 32. Valeriana pumila. Villd., Sp. I, p. I84.

«. fructibus subnudis edentulis. B. fructibus subtriclentatis.

Celte plante croît dans les champs des départemens méridionaux; je l'ai recue des cnvirons de Toulon et d'Avignon, par MM. G. Robert et Requien; Morison et M. Decandolle l'indiquent aux environs de Montpellier : se's fleurs sont rongeâtres, elles paroissent en matrs, avril et mai. Le non spécifique ( $V$. purvila). qu'on lui avoit donné, ne lui couvient nullcment, car elle n'est pas plus pelite quo 


\section{( 151 )}

toutes les autres espèces congénères; c'est ce qui m'a engagé à lui en donner un aulre tiré de la nature de ses bractées. $(\cdot)$.

\section{VALERLANELLA MICROCARPA. N.}

$V$. caule dichotomo, foliits oblongis integriusculis obtusis, floribus corymboso subfastigiatis, bracteis lineari-lanceolatis glabris, fiuctilus subconoüdibus hispidiusculis nudis latere umbilicatis. Valerianella minor se. mine umbilicato hirsulo. oris., Hist. 3 , p. 104, s. 7 , t. 16 , f. 35, (si folia integra subjiciantur).

M. G. Robert a découvert cette nouvelle espèce dans les champs aux environs de Toulon, où elle fleurit au printemps. $(\cdot)$.

\section{POLYCNEMUM REGURVUM. N.}

P. caule prostrato ramoso, foliis subulatis sparsis palulis distinctis subrecurvis, calycibus axillaribus sessilibus capsulam subcequantibus.

Le Polycnemon à feuilles recourbées se distingue de l'espèce vulgaire, èn ce qu'il est plus petit dans toutes ses parties; mais surtout parce que ses feuilles, un peu rècourbées, sont ou vertes, plus distantes, et qu'elles laissent les capsules à déconvert; tandis gine, dans 


\section{( 152 )}

le $P$. Arvense, les feuilles sont roides, trèsrapprochées les unes des autres, presque embriquées, appliquées contre les tiges, entip leur base cuveloppe et cache presque en entier les calysules. Cette espèce a été découverte à Vartigny en Valais, par M. Thomas; clle fiemrit en août et septembre. $(\cdot)$.

CYPERUS DIFFORMIS. Lin., Sp. 67. Rotlb., Gram. 24 , tab. 9 , f. 2.

C. culno triquetro nudo, umbellâ diphyllâ subquadrifidà , ümbellulá intermedíá sessili, spicis lanceolato-linearibus sessilibus confertis, squamis ovatis concavis obtusis. Gramen cyperoides elegans, paniculâ spicis mollibus compositâ, maderaspatanum. Pluk, Phyt., táb. ig2, f. 3.

Cette espèce, regardée comme indigène de l'Inde, a été trouvée à Verceil, en Piémont, par M. Perret; M. Balbis me l'a communiquée venant des environs de Novarre, dans lo royaume d'Italie; et M. Delaroche l'a récueillie à Valence, en Espagne. Il est probable que celte plante n'est pas spontanée dans ces différens pays, où elle croît idans'les rízières; mais qưlle a été apportée en Errope avec le Riz. Elle fleurit en août et septembre. $(\cdot)$ 
PHALARIS ERUCAEFORMIS. Lin, Sp. 80. Savi, Bot. Etrus. I, pag. 37 .

$P$. paniculấ unilaterali coarctatá, spiculis erectis subsessilibus secundifloris, ghumis calycinis obtusis navicularibus $\mathbf{1}-\mathbf{2}-$ floris, corollis acuminatis. Cynosurus ernucceformis. Ait., Hort. Kew. I, p. 105. Willd., Sp. I, pag. 412. Gramen palustre locustis erucceformibus. Barr., Ic. 2 , observ. i 58.

Cette plante croît dans les fossés et les lieux humides aux environs de Pise, en Toscane; elle fleurit an mois de mai. $\not{f}$.

ROTTBOELLIA SUBULATA. Savi, Cent. 35 , Giorn. Pis., t. 4, p. 230, fig. 4, 8. Bot. Etrus. I, pag. 27

R. spicấ tereti subulatâ erectâ, glumấ calycinâ univalvi ensiformi acuminatá adpressâ. Gramen loliaceum junceum majus. Barr., Ic. 5.

Je dois cette espèce à M. Savi qui l'a trouvée dans les lieux maritimes et argilleux de la Toscane, aux environs de Pise et de Sienne. Elle fleurit en juin. $(\odot$ ).

SCABIOSA UCRANICA. Lin. - Lois., Fl. Gall. 79 .

M. de Saint-Hilaire vient de tronver, parmi 


\section{$(\div 54)$}

Jes rochers de Roncevaux, à quelques lienes de Fontainebleat, cette plante qui n'ctoit indiquée qu'en Piémont. Ses lleurs sont blenatres, tirant un peu sur le jaune; elles paroissent à la fin de l'été.

\section{PLANTAGO MINIMA. Decand. - Lois., Fl. Gall. 88.}

Cette plante n'est qu'une variété du Prantago major, et même cette variété n'est pas constante. Je l'ai trouvée, au milieu de l'éé dernier, dans les moissons, auprès de la forêt d'Armanvilliers, du côté de celle de Crécy; c'étoit dans des terres qui avoient été inondées pendant l'hiver, et qui étoient alors entièrement desséchées. Ce Plantaía m'a paru être évidemment la jeune plante venue des graines de l'année précédente; jai jugé que lorsqu'il se trouvoit dans un terrein quion ne labouroit pas, et qu'il survivoit plusieurs années, il devenoit beaucoup plus grand. Effectivement, ¡’ai trouvé en même temps, sur le bord des bois et dans le mème lieu, des individus qui ne differoient pas du tont du Plantago major; et dans les terres cultivées où étoient les plus petits échantillons de la même espèce, dont quelques-uns n'avoient que huit à dix lignes. de haut, avec un épis de deux à quatre fleur's, j’en ai recueilli d'autres qu'on pouvoit regarder comme 


\section{( 155$)$}

intermédiaires; leurs épis s'élevoient à quatre ou six pouces, et étoient composés de vingt à cinquante fleurs.

VIOLA LUTEA. With. 263, ex Smith., H1. Brit. 249 .

$V$. caule triquetro simplici ascendente, foliis ovatis oblongisque crenatis ciliatis, stipulis painnato-incisis, corollis calyce duplò longioribus, calcare petalis dimidiò breviore.

a. floribus luteis.

B. Rloribus crerulescentibus.

MM. Nestler et Mougeot ont recueilli celle plante dans les pâturages des Vosges; M. Lejeune me l'a envoyée du pays de Liége, aujourd'hui département de l'Ourthe, ou elle croit communément partout où existe la Cálamine. Elle var ì à fleurs jaunes et à lleurs bleuâtres, et fleurit depuis le mois de juin jusqu'en automne. $2 f$.

\section{CHIRONIA LINARIFOLIA.}

C. caule herbaceo tereti erecto dichotomo, foliis linearibus crasciusculis obbusis, calyce ad. basin usquè quinquefido, laciniis incequalibus abo subbrerioribus. Gentiana Linarifolia. Lam., Dict. 2, pag. 64r. Eryttirca-Linarifolia, Pers., Synop. I, 


\section{( 156 )}

pag. 283. Centaurium minus purpureum angustifolium. Barr., Ic. 423.

Cette nouvelle espèce pour la Flore, a été trouvée par M. Requien, sur les bords de la Durance, à quelques lieues d'A vignon. Elle fleurit en août et septembre; ses fleurs sont d'une couleur rose un peu foncée. ( $)$.

SELINUM RIGIDULUM. Viv., Fl. Ital., Frag. fasc. I, pag. 14, tab. 15.

S. caule tereti striato, foliis inferioribus bipinnatis, superioribus simpliciter pinnatis, pinnulis angustissimis mucronatis, vaginis foliorum arctè caulem amplexantibus, involucro universali monophyllo. S. appianum. Pers., Synop. I, pag. 3og.

Cette espèce m’a été communiquée par M. Bertoloni, qui l'a recueillie dans les montagnes de la Ligurie : elle fleurit en juin et juillet; ses fleurs sont blanches. $\not{f}$.

NARCISSUS (I) MAJOR. Curt., Bot. Mag., t. $5 \mathrm{I}$.

N. foliis planiusculis glaucescentibus, scapo subcylindrico depresso ancipiti unifloro,

(I) Ayant ajouté à difiérentes reprises plusieurs espèces nouvelles à la Flore de France, j’ai jugé convenable, avant de publier la monographie du 


\section{( 157 )}

nectario campanulato erecto sexlobato crenato superante petala oblonga.

Il y a plusieurs annees que je trouvai cette espèce dans les montagnes entre Guéret et Limoges; mais les échantillons, que je recueillis alors, s'étant gâtés, et ne les ayant pas mis

genre entier, à laquelle je travaille, de présenter ici l'essai d'un tableau méthodique des espèces qui croissent en France ou qui peuvent s'y trouver. M. Haworth, dans le cinquième volume des Transactions de la Société Limnéenne de Londres, p. 242 et suivantes, a proposé un nouvel arrangement du genre Narcisse; mais l'ordre d'après lequel il distribue ses espèces ne me paroît pas du tout naturel. Des plantes, qui sont très-voisines par le port et les caractères, se trouvent éloignées les unes des autres : par exemple; entre le Narcissus odorus et le $N$. jonquilla sont interposés le $N$. poeticus et le $N$. tazetta. M. Haworth ne donne d'ailleurs aucune description complète de ses espèces nouvelles; il se borne à une phrase très-courte, qui ne sufint nullement pour les faire reconnoître.

\$. I. Narcissi porrifolil. Folia planiuscula vel canaliculata dorso carinata et subcarinata plerùmque glaucescentia.

\section{* Scapo unifloro et subuniforo.}

I. Narcissus major. Curt., Bot. Mag., t. 5 r. N. foliis planiusculis glancescentibus, seapo subcylindrico depresso ancipiti unifloro, nectario 


\section{( 158 )}

dans mon herbier, joubliai cette plante que je n'avois d'ailleurs considérée que comme une variété du Narcissus pseudo-narcissus. Ayant eu depuis l'occasion de l'observer dans

campanulato erecto sexlobato crenato superante petala oblonga.

2. Narglssus pseudo-nárcissus. Lin. Sp. 4ra. Bull. Lerb., 1. 389. Red., Lil. vol. 3, 1. 158.

Ir. foliis planiusculis glaucescentibus, scapo subcylindrico compresso ancipiri unilloro, nectario campanulato erecto crenato crispo aquante petala:

3. Narcissus bicolor. Lin., Sp. 4.5.

IV. foliis planiusculis glaucescentibus, scapo subcylindrico compresso ancipiti unifloro, nectario campanulato margine patulo undulato crenato aquante petala. Vix species distincta; fortè mera varietas procedentis.

4. Narcissus Gouani. Roth., Cat. Bot. I, p. 32. Red., Lil. vol. 4 , t. 220.

IT. foliis planiusculis glaucescentibus, scapo subcylindrico ancipiti unifforo, nectario campanulato margine sexlobo undulato crenulato petalis dimidio breviore. N. incomparabilis. Curt., Mag. Bot., t. I2r.

3. Narcissus ponticus. Lin., Sp. 4I4. Bull. Herb., t. 3o6. Thed., Lil. vol. 3 , 1. 160.

N. foliis planiusculis glaucescentibus obtusè carinatis, scapo subcylindrico striato ancipili unifloro 


\section{( 159 )}

les jardins, j’ai reconnu qu'elle étoit une espèce distincte. La fleur est toute entière d'un

[rarissimè bifloro], nectario rotato brevissimo membranaceo crenulato, margine croceo.

6. Narcissus angustrfolius. Curt, Bot. Mag. t. 193.

$\mathrm{N}$. foliis gracilibus glaucescentibus dorso acutè carinatis, scapo subcylindrico leviusculo subancipiti unifforo, nectario rotato brevissimo meml) ranaceo crenulato margine croceo.

7. Narcissus biflurus. Curt., Mag. Bot., t. 197.

N. foliis planiusculis glancescentibus acutè carinatis, scapo subcylindrico ancipiti bifloro [interdum unifloro], nectario rolato brevissimo membranaceo crenulato prorsùs luteo.

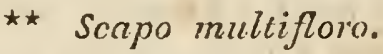

8. Narcissus calathinus. Lin., Sp. 415 . Red. Lil. vol. 3, t. 177 .

N. foliis planiusculis [glaucescentibus?], scapo 3-4-floro, nectario campanulato subintegerrimo equante petala.

9. Nareissus nubius. Gollan., Ill. 22.

I. Foliis planiusculis glaucescentibus, scapo 24-floro, nectario cyathiforme subintegerrimo pclalis ovatis æqualibus dimidiò breviore, floribus prorsùs albis. N. palididus. Lam., Dict. 4, p. 424, [ $x$ fide herbarii] .

10. Narcissus patulus. Lois., Not, 52.

N. Coliis glaucescentibus suhcanaliculatis patulis, 


\section{( 160$)$}

bẹa jaune; elle paroît en avril dans les jardins, et en mai dans les montagnes. 4.

NARCISSUS ANGUSTIFOLIUS. Curt. Bot. Mag., t. I93.

N. foliis gracilibus glaucescentibus dorso acutè carinatis, scapo subcylindrico lic-

scapo subcylindrico 2-4-floro [ rarius 5-6floro ], nectario cyatliforme subintegerrimo aureo pelalis niveis alternè latioribus duplò breviore.

II. Narcissus tazerta. Lin., Sp. 416, [exclus. synon. Clusii et Bauhini].

N. foliis planiusculis glaucescentibus, scapo subcylindrico 4-8-floro [rarius 9-12-fioro], nec-. tario cyathiforme vix crenato aureo pelalis albis ovatis æqualibus duplò breviore.

12. Nancissus polyanthos. Lois., Nol. 53.

N. foliis planiusculis virescentibus, scapo subcylindrico ancipiti 8-20-floro, nectario cyathiforme subintegerrimo petalis ovatis alternè latioribus subtriplò breviore.

I3. Narcissus niveus. Lois., Not. 54.

N. foliis planiusculis subglaucescertibus, scapo depresso ancipiti 6-ro-floro, nectario cyahifurme crenato pelalis ovato-oblongis quadruplo breviore. Nectarium et petala candidissima.

14. Nargissus subalbidus. Lois., Not. 163.

N. foliis planiussculis virescentibus, scapo depresso 


\section{( $16 \mathrm{I})$}

viusculo subancipiti unifloro, nectario rotato brevissimo membranaceo crenulato margine croceo.

Les caractères qui distinguent cette plante sont si peu prononcés, que je regarde comme très-douteux qu'elle puisse faire une espèce distincte; sa fleur est de la même couleur et a la même odeur que celle dı́ Narcisse des

ancipiti 3-6-floro, neclario cyathiforme subsexlobato petalis lanceolatis quadruplò breviore. A'ectarium saturatè luteum; petala spurcè alb .

\$. II. Narcissi JUverforin. Fulic subsemicyïndracen et subsylindraced plics miniesve satirate virentia. 15. Nancissus ecnoleucus. Lois., Not. i63.

N. foliis virentibus canaliculatis dorso semicylindraceis, scapo subcylindrico lavi 4-8-Horo, nectario cyathifone subintegerrimo petalis ovatosubrotundis alternè latioribus dimidiò breviore

16. Narcissus odorus. Lin., Sp. 4i6. Red., Lil. vol. 3, t. 157 [excius. synon. Gouan., Illust. et Flor.].

$\mathrm{N}$. foliis viridibus subsemicylindraceis canaliculatis scapo cylindrico 2-4-floro [quandòque unifloro], nectario campanulato sexlobato lavi petalis dimidiò breviore.

17. Narcissus infundibuen. Lam., Dic. 4, p. 427.

N. foliis [viribus subscmicylindraceis?] canalicu- 


\section{( 162$)$}

pocies; les pélales sont senlement un peu plus étroits. Cette plante croît dans les prés en Provence; je l'ai reçue de M. G. Robert. Dans Je nidi, clle fleurit en mars; a Paris, en avril,

latis, scapo [cylindrico lrvi?] 2-3-floro, nectario campanulato integro subrquante petala.

18. Narcissus intermedits. Lois, Fl. Gall. igi, t. 6.

N. foliis viridibus canaliculalis dorso subsemicylindraceis, scapo 2-5-floro, neclario cyathiforme margine crenato petalis subtriplò breviore.

19. ANarcissus Jonquilea. Lin., Sp. 417 . Bull., Herb., 1. 334. Red., Lil. vol. 3, 1. 359 .

N. Foliis semicylindraceis subulatis subcanaliculatis, scapo I-4-floro, nectario cyathiforme ore dilatatissimo integro petalis multotiès breviore.

20. Narcissus Bulbocodiun. Lin., Sp. 417. Curt., But. IJag., t. 88. Red., Lil. vol. I, t. 24.

N. foliis angusto-linearibus virentibus planiusculis dorso subsemicylindraceis sulcatis, scapo cylindrico levi $\mathrm{r}$-floro, nectario turbinato integro petalis lineari.lanceolatis longiore.

21. Narcissus reflexus. Lois., Not, rg't.

N. foliis angusto-linearibus virentibus planinsculis dorso subconvexis binerviisque, scapo cylindrico levi I-2-floro, nectario campanulato mar. gine sexcrenato petalis reflexis alternè latioribus subæequali, floribus cernuis. Stamina sex, trin iongiora, tria breviora. 


\section{( 163$)$}

environ quinze jours avant le Narcisse des poètes. 4 .

\section{NARGISSUS SUBALBIDUS. N.}

N. foliis planiusculis virescentilus, scapo depresso ancipiti 3-6-floro, nectario cyathiforme subsexlobato petalis lanceolatis quadruplò breviore. Nectarium saturatè Iurcum; petala spurcè alba.

Quoique cette espèce ait beancoup de rapports avec le Narcissus nivens, elle paroit cependant devoir en être distinguéc. Son lieu natal m'est inconnu, je ne l'ai trouvée que dans les jardins. Les Botanistes la prennent pour une varicié du Narcissus tazetta; mais elle en diffère beaucoup. Je l'ai sue en fleurs dans le mois d'avril. 2 .

\section{NARCISSUS OCHROLEUCUS. N.}

$N$. foliis virentibus canaliculatis dorso semicy-lindraceis, scapo subcylindrico levi 48 floro, nectario cyathiforne subintegerrimo petailis osato-subrotundis alternè latioribus dimidiò breviore.

Cette espèce est intermédiaire entre les Narcisses à feuilles porriformes et les Narcisses à fenilles jonciformes. Ses fleurs ressemblent beaucoup à ceiles du N. tazetta, ct ses feuilles different à peine, pour la forme et la couleur, 


\section{( 164 )}

de celles du $N$. odorus. J'ignore le lieu natal de cette plante; je l'ai vue culitivée dans les jardins. Il est possible qu'elle se trouve en France; mais on la confond probablement avec le $N$. tazetta. Elle fleurit en avril; les pélales sont blanchâtres tirant un peu sur le jaune, et le nectaire est d'un jaune trèspâle. 4 .

NARCISSUS INFUNDIBULUM. Lam., Dict. , pag. 427 .

N. foliis (viridibus subsemicylindraceis?) $c a^{-}$ naliculatis, scapo (cylindrico loevi?) 23-floro, nectario campanulato integro subcequante petala.

Je n'ai pu retrouver, vivante, cette espèce que M. de Lamarck a observée autrefois dans le jardin de M. de Saint-Germain, et dont il conserve un échantillon dans son herbier. Les fleurs sont d'un jaune uniforme, elles ont le port de celles du $N$. odlorus; mais elles diffèrent jar les caractères indiqués. Quoique je ne connoisse pas le lieu natal de cette plante, je l'indique ici, parce qu'elle me paroît une espèce très-distincte, sur laquelle je crois devoir appeler l'attention des Botanistes, et que peutêtre on la trouvera en France, lorsqu'on saura la distiugier. 2 . 


\section{$(165)$}

\section{NARCISSUS REELEXUS. N.}

$N$. foliis angusto-linearibus virentibus planiusculis dorso subconvexis binerviisque, scapo cylindrico lcevi $\mathrm{I}-2$-floro, nectario campanulato margine sexcrenato petalis reflexis alternè latioribus subaquali, floribus cernuis.

D’après les caractères assignés par Linné à son Narcissus triandrus, ma plante en diffère par son nectaire presque aussi long que les pétales, et non moitié plus court; par les étamines, au nombre de six, et le style tout au plus égaux au neclaire, et non sailJants, plus longs que lui. Le $N$. triandrus. Curt., Bot. Magg., tab. 48, qui n'est peut-être pas celui de Linné, paroît aussi différer de mon espèce par son nectaire moitié plus court que les pétales, par les fleurs qui sont près de moitié plus grandes, et par la couleur de ces mêmes fleurs, qui est d'un jaune pâle, tandis qn'elle est toute blanche dans le $N$. reflexus. Cette nouvelle espèce a éié trouvée par M. Bonnemaison, dans les îles Glênan, voisines des côtes de Brelagñe; elle fleurit au mois d'avril. $\mathscr{F}$. 


\section{(166)}

VACCINIUM MYRTILLUS. Lin.-Lois., I1. Gall. 223.

\&. Vaccinum folius oblongris crenatis, fructu albo. Gmel., Sib. 3, p. 136, 11.0 9.

Cette variété a été trouvée par M. Lejeune, aux environs de Maimedy, dans l'ancien Pays de Liége.

PASSERINA HIRSUTA. Lin. - Lois., FI. Gall. 228.

ß. P. Hirsuta, foliis utrinqué tomentosis.

M. Requien a trouvé, aux cnvirons de Marseille, cette variété remarquable par ses fenilles presque anssi tomenteuses en dessons qua'en dessus. Il n'a pas en occasion de l'observer fleurie; si elle offroit dans ses fleurs quelque caractère particulier, elle pourroit former une espèce distincte.

\section{CUCUBALUS MOLLISSIMUS. Lin., Sp. 59 ?}

C. caule foliisque tomeniosis subincaris, inferioribus spathulatis mucronatis, superioribus lineari-lanceolatis, ramulis floriferis oppositis trifidis, unguibus petalorum calyce longioribus. Lyclunis maritima pulverulenta, folio carnoso. Tournef., Inst. 338 ?

Cette plante fleurit en mai et juin; ses flérrs 


\section{$(167)$}

sont blanches. Elle a été trouvée par M. Requien, aux environs d'isignon. $2 \%$.

\section{ANTIRRHINUM ANGUSTISSMUU. N.}

A. caule erecto ramoso, foliis sparsis linearibus angustissimis subuninerviis acutis, floribus caudatis spicalis imbricatis terminalibus, pedunculis capsulâ sublongrionribus.

Cette plante a beancoup de rapports avee I'Antirrhinum linaria et l'A. genisiifolium; mais elle me paroit différer assez de l'un et de l'autre, pour former une espèce distincte. Elle a été trouvée sur les bords de la Stura et à Superga, en Piémont, par M. Perret. Elle flenrit en juin et juillet; ses fteurs sont jaunes, avec le palais plus foncé. $2 f$ ?

\section{BISCUTELLA CICHORIFOLIA. $\mathrm{N}$.}

B. caule erecto piloso, foliis ob̈longis sinuato-subruncinatis pilosis, calycibus bicalcaratis, siliculis. scabriusculis enarginatis.

Celte espèce a été trouvée par M. Berger, de Breslaw, cians les fentes des rociers, au pied des Pyrénées, daus les environs de Bagnèré. Ses fleurs, d'un jaune pâle, paroisseat ea juin, juillet et aoùt. $z$ ? 


\section{$(168)$}

BISCUTELLA APULA. Lin., Mant. 254. Desf., E]. All. 2, pag. 75 .

$B$. caule recto foliisque lanceolatis sessilibus remotè denlatis hirtis, calycibus basi ecaledatis subgilibosis, siliculis scabriusculis. Siliculce ex toto, vel margine tantum scabriusculae. Thlaspi clypeatum. Clus., Hist. CXXXIII.

Cette plante croit dans les champs, en Provence, où elle a été trouvée par MM. Suffren et G. Robert. Ses fleurs sont d'un jaune clair; elles paroissent en mai et juin. (.).

\section{BISCUTELLA MOLLIS. N.}

B. caule recto foliisque pilosis, inferiorilus lyratis sinuatisve, superioribus linearibus basi subcordatis sessilibus, calycilus basi ecaudatis subgibbosis, siliculis junioribus scabriusculis.

M. Savi m'a cuvoyé celle plante sous le nom de Biscuiella coronopifolia; mais les fruits n'étant pas ciliés en leur bord, elle ne peut appartenir à cetle espèce. Elle croît en Toscane, sur les collines du bord de la mer. Ses fleurs sont de la même couleur et de la même grandeur que celles de la B. Lce vigata; sont port est aussi à peu près le même; mais 


\section{$(\mathrm{I} 6 \mathrm{~g})$}

les poils, qui couvrent sa tige et ses feuilies, sont plus nombreux, plus courts et plus doux au toucher. $($ ).

\section{GENISTA TENUIFOLIA. N.}

G. caulibus debilibus, ramis teretibus striatis erectiusculis, folizs linearibus uninerviis glar bris, floribus racemosis terminalibus, leguminibus glabris.

Celte espèce est très-voisine du Genista tinctoria; mais elle est beaucoup plus petite dans toutes ses parties. Je la dois à M. Perret qui l'a découverte en Piémont, près de Casaglia. Elle fleurit en èté; ses flẹrs sont jaunes. 5 . 


\section{TABLE DES GENRES.}

Agrostis.

Aira.

Allium.

Alyssum:

Amaranthus.

Anagallis.

Andromeda.

Anemone.

Anthemis.

Anthoxanthum.

Antirrhinum

Arenaria.

Aristolochia.

Artemisia.

Arundo.

Asplenium

Astragalus.

Avena.

13 Cinicus.

I6 Convolvulus.

54 Cotyledon.

96 Crassula.

I40 Crepis.

40 Cucubalus.

64 Cyperus.

87

129 Dactylis.

18

7 Datura.

94, I67 Delphinium.

68 Dianthus.

125

40

70

50

122

166

34 Digitalis.

I. 26 Diosera.

IO, 152

$2 / 4$

145 Echium.

Io8 Elatine.

23 Erica.

Erodium.

Bartsia.

Bellis.

Betonica.

Betula.

Biscutella.

Brassica.

Bromus.

Buplevrum.

Campanula.

Centaurea.

Claara.

Clironia.

Chlora.

94. Eryngium.

I28 Euphorbia.

93

139 Festuca.

167 Fumaria.

44

85

65

$9^{6}$

50

97

22 Galium.

38

63

Ibid.

98

45

75

45 Genista.

Globularia.

18

100

41

13 Herniaria.

135 Hibiscus.

44

r.55 Fieracium.

I0O

I $2 I$

62 Hordeum.

26

I28 Hyacinthus.

148

I 24

Circóa.

Cistus.

84 
Table des genres.

Iris:

9 Potentilla.

$17^{1}$

Jasione.

Juncus.

Laserpitium.

Lauhu us.

Prasium.

Linum.

Liihospermum.

Loellıngia.

Lonicera.

Lulus.

Iyc nis.

Iysimachia.

Lyırum.

Malva.

Medicago.

Myosulis.

Narcissus.

Ononis.

Op res.

Orchis.

Onithogalum.

Ot nit opus.

Ostrya.

Panicum.

Papaver.

Parielaria.

Passerina.

Phalaris.

Pimpinella.

Pinguicula.

Plantago.

Poa.

Pol cnemum.

Pol gila

Polypodium.

5I, 156 Scirpus.

Scrop ularia.

I0.5 Secale.

I32 Sedum.

I3, Selinum.

58 Serapias.

I07 Seseli.

I43 Serratula.

Silene.

I1 Sinapis.

84 Sisymbrium.

I44 Sium.

I66 Solinago.

I53 Sonchus.

47 S alice.

5 Syutherisma.

34,154

I7 Taravacum.

$15 \mathrm{r}$ Thalictrum.

Io3 Trientalis.

$35, \times 53$

143

88

79
$I 53$

14

126

65

6 ?

57

10

95

26

66

I 56

134

46

124

I46 Tritolium.

120

88

62

108 
172

Triticum.

Tulipa.

Vaccinium.

Valeriana.

Valerianella.

Verbascum.

Table des genres.

\section{Verbena.}

57 Veronica. Vicia.

166 Viola.

8

148 Ulex.

43 Urtica.
147

I

107

$\times 55$

I0 5

I39

Fin de la Table. 
$P L . I$.

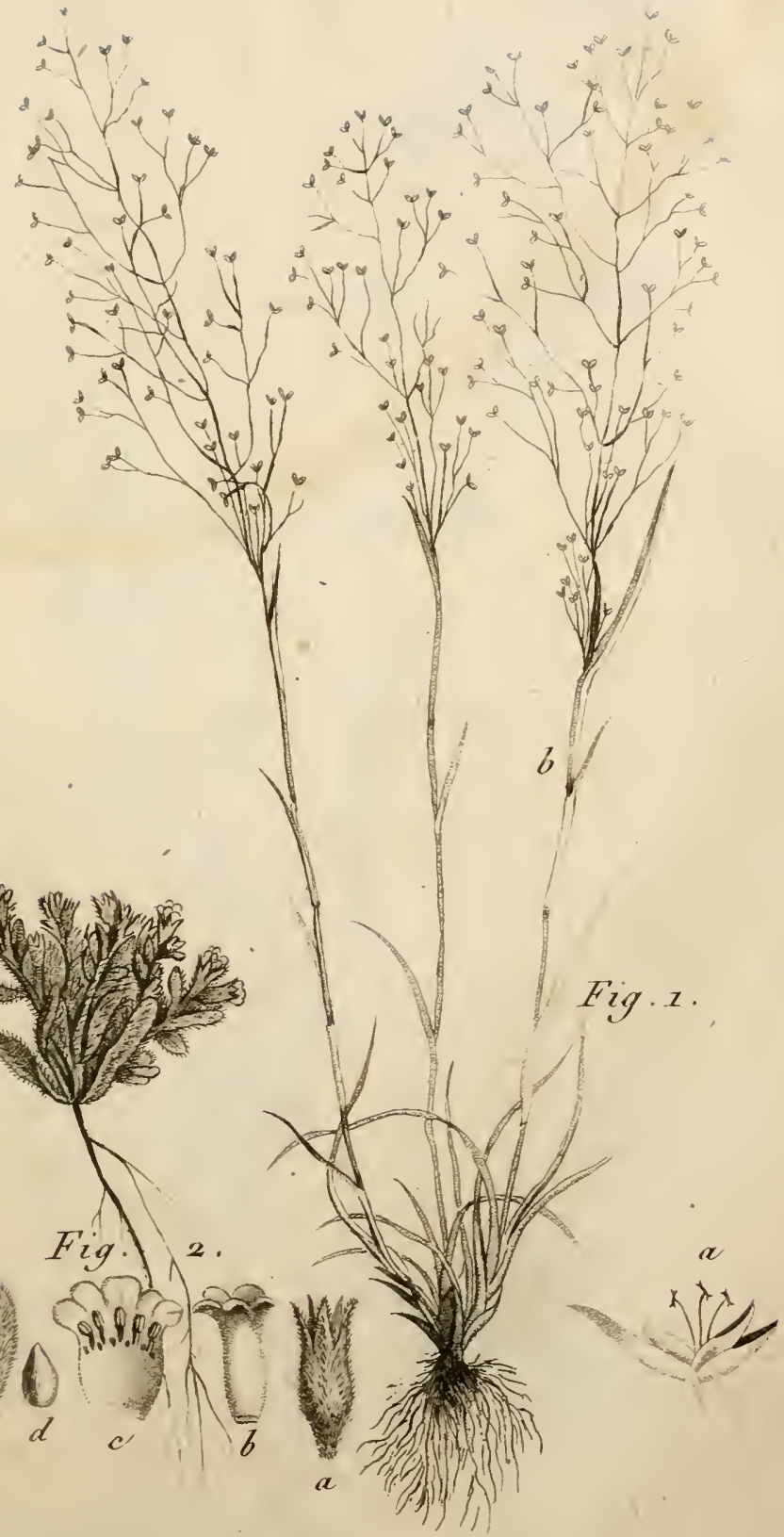

Fig.1.AGROSTIS Elegans. Fig. 2.MYOSOTIS Pusilla. 

PL.II.

1

को

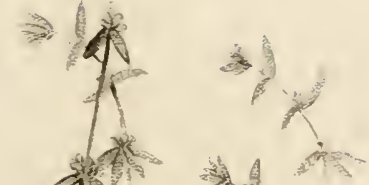

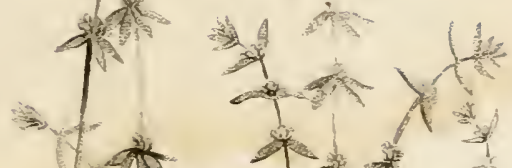
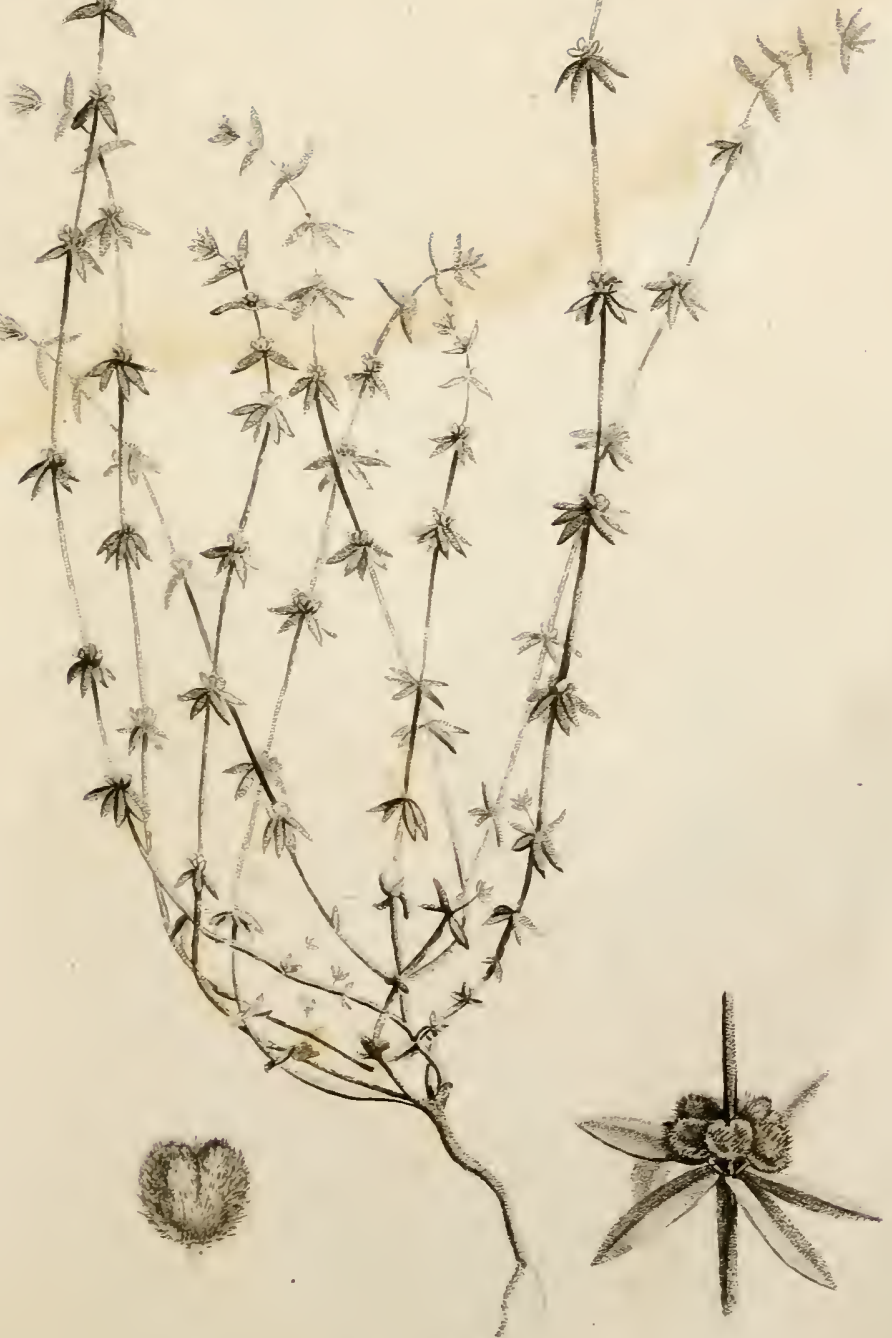

G.1LIITM Terficiliatum. 



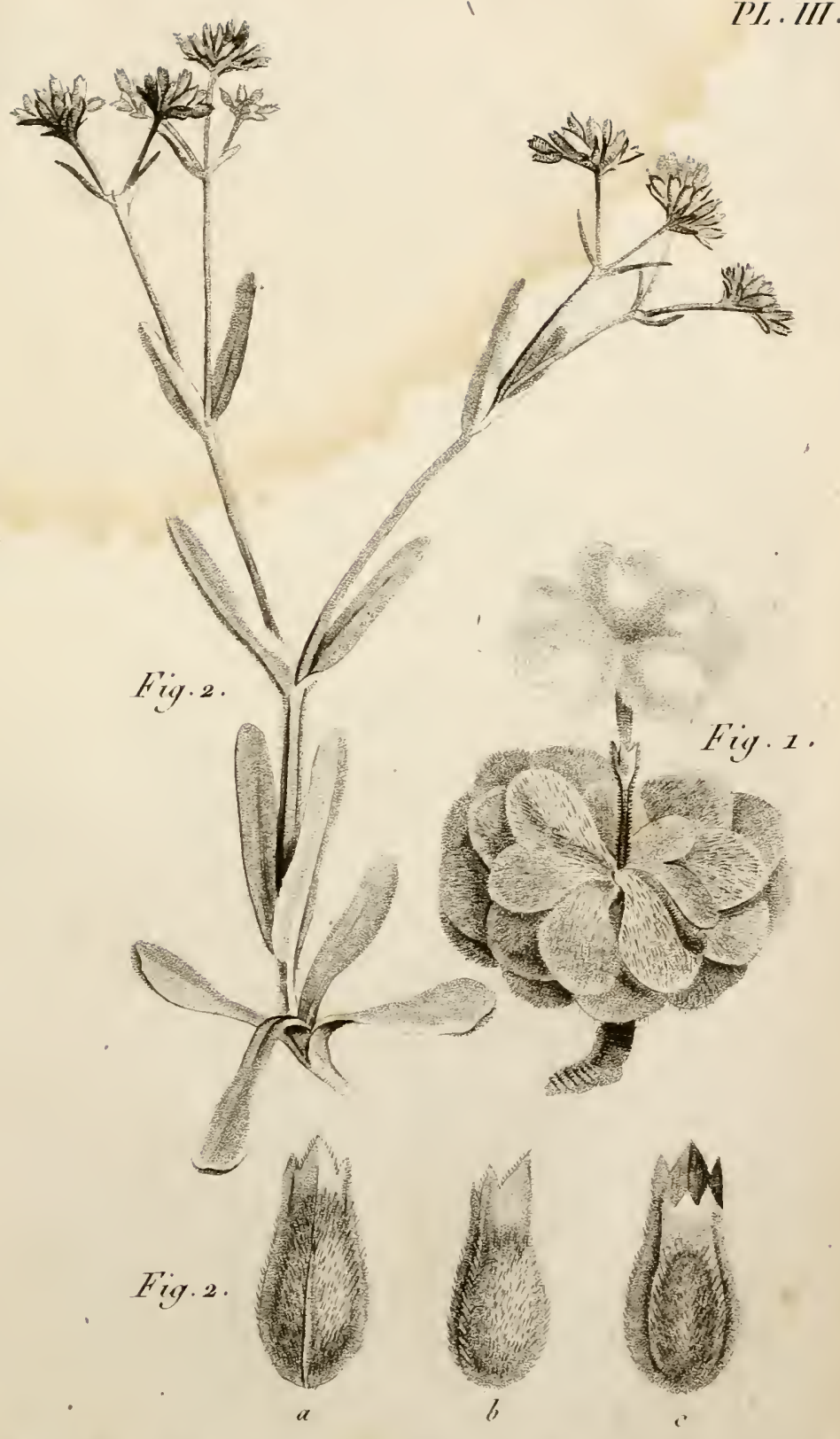

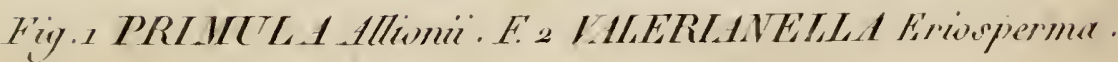



7I.IV.

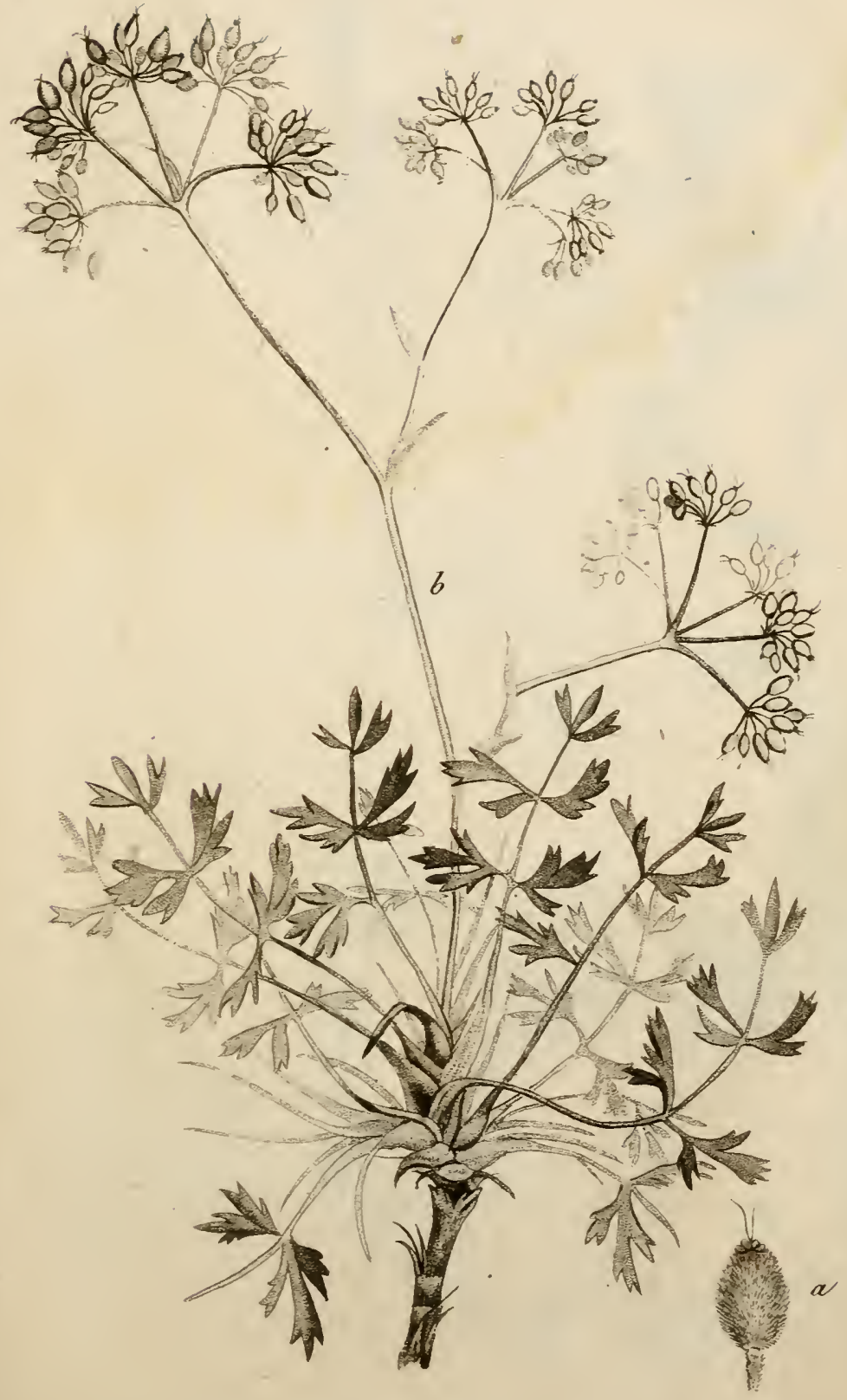

PIMIINELLA Canescens. 

I'L. $Y$.

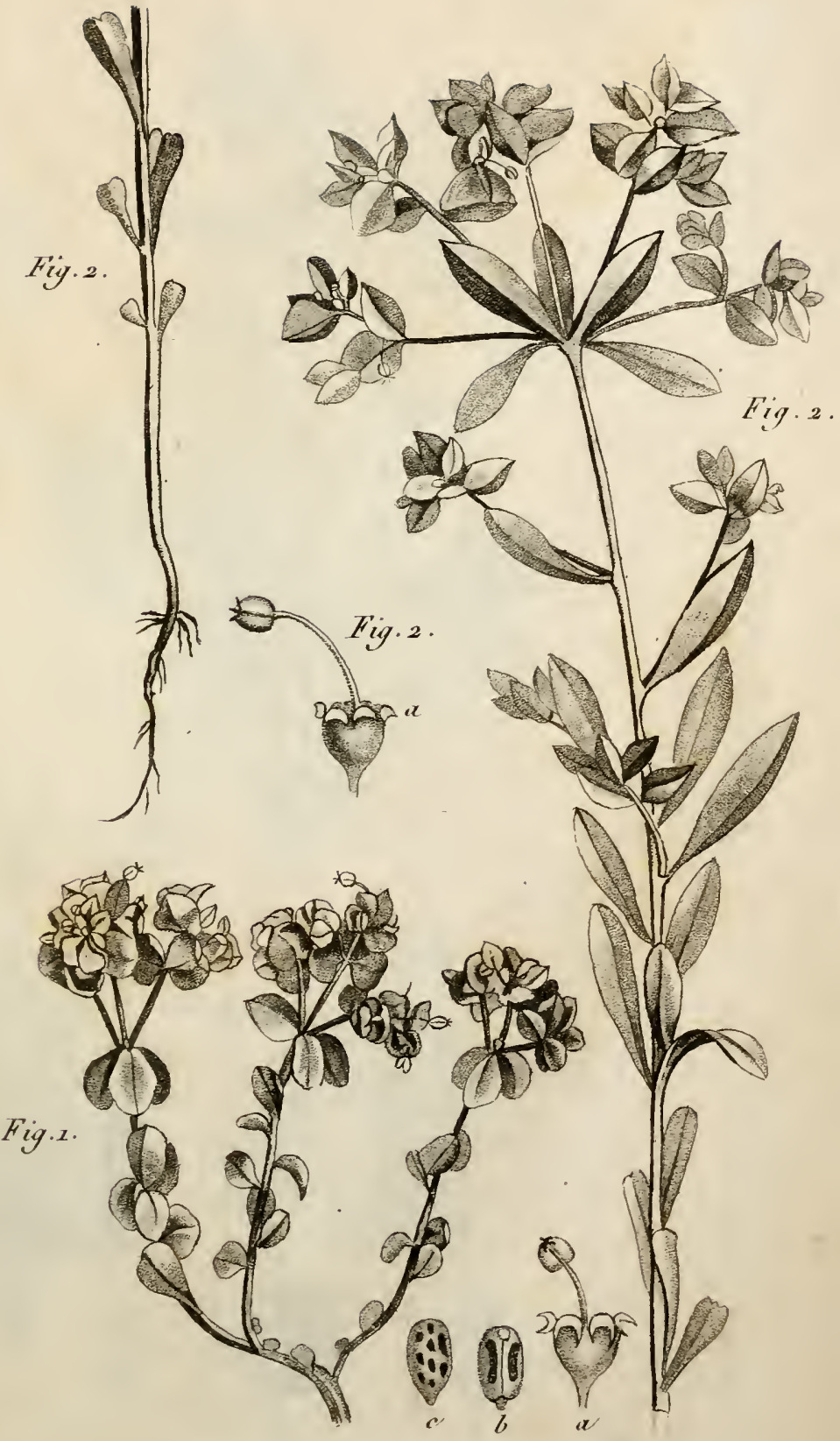

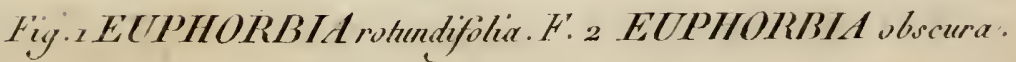









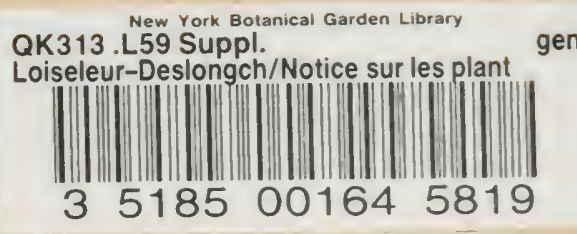


